Check for updates

Cite this: RSC Adv., 2019, 9, 28961

\title{
Discovery of novel 1,4-disubstituted 1,2,3-triazole phenylalanine derivatives as HIV-1 capsid inhibitors
}

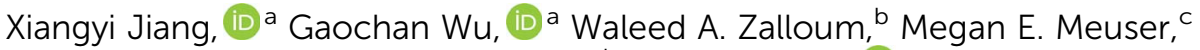 \\ Alexej Dick, ${ }^{\mathrm{C}}$ Lin Sun, ${ }^{\mathrm{C}}$ Chin-Ho Chen, ${ }^{\mathrm{d}}$ Dongwei Kang, (DD a Lanlan Jing, ${ }^{a}$ Ruifang Jia, ${ }^{a}$ \\ Simon Cocklin, ${ }^{\star c}$ Kuo-Hsiung Lee, (D) ${ }^{* e}$ Xinyong Liu*a and Peng Zhan ${ }^{\star a}$
}

The HIV-1 capsid (CA) protein plays crucial roles in both early and late stages of the viral life cycle, which has intrigued researchers to target it to develop anti-HIV drugs. Accordingly, in this research, we report the design, synthesis and biological evaluation of a series of novel phenylalanine derivatives as HIV-1 CA protein inhibitors using the $\mathrm{Cu}(\mathrm{I})$-catalyzed azide and alkyne 1,3-dipolar cycloaddition (CuAAC) reaction. Among this series of inhibitors, compound II-10c displayed a remarkable anti-HIV activity $\left(\mathrm{EC}_{50}=2.13\right.$ $\left.\mu \mathrm{M}, \mathrm{CC}_{50}>35.49 \mu \mathrm{M}\right)$. Furthermore, surface plasmon resonance (SPR) binding assays showed that compounds II-10c and PF-74 (lead compound) have similar affinities to HIV-1 CA monomer. Further investigation showed that the weak permeability and water solubility of representative compounds were probably the important factors that restricted their cell-based activity. Preliminary structure-activity relationships (SARs) were inferred based on the activities of these compounds, and their known structure. The most promising new compound was studied with molecular dynamics simulation (MD) to determine the preferred interactions with the drug target. Finally, the activities of members of this series of inhibitors were deeply inspected to find the potential reasons for their anti-HIV-1 activity from various perspectives. This highlights the important factors required to design compounds with improved potency.

Received 29th July 2019

Accepted 6th September 2019

DOI: $10.1039 /$ c9ra05869a

rsc.li/rsc-advances (assembly and maturation) stages of the viral life cycle. ${ }^{6,7}$ Once the viral core enters the cytoplasm of the host cell, the CA protein interacts with host cell factors such as Cyclophilin protein A (CypA), cleavage and polyadenylation specificity factor-6 (CPSF6), and nucleoporin 153 (NUP153) to promote timely capsid uncoating followed by coordinated reverse transcription, nuclear import of the pre-integration complex, and integration of double-stranded viral DNA into the host genome. ${ }^{8-10}$ In addition, in the late stage of HIV-1 replication, the assembly and maturation of CA protein is essential for the formation and release of infectious virus particles. ${ }^{11}$ If the formation of CA is inhibited, the viral replication process will be disturbed and the ability to infect host cells will be almost lost. ${ }^{12}$ Due to its high sequence conservation (around 70\%) and multiple functions in replication, HIV-1 CA protein has become an attractive therapeutic target for anti-HIV drug research. ${ }^{13,14}$

Due to its importance as an anti-HIV target, several chemotypes of HIV-1 CA protein inhibitors have been found. ${ }^{6,15}$ Among them, compound PF-74 (Fig. 1a) that has been widely studied as a functional small molecule. ${ }^{16} \mathbf{P F}-74$ is composed of a phenylalanine core (red part, Fig. 1a), an indole ring (pink part, Fig. 1a) and a linker connecting them (blue part, Fig. 1a). Recent research indicates that PF-74 binds an intermolecular interface which consists of the N-terminal domain (NTD) of one subunit and the C-terminal domain (CTD) of the adjacent subunit in a CA hexamer. ${ }^{17-19}$ The phenylalanine core forms interactions 
with ASN57, ILE73, ALA105, TYR130 and THR107 in the NTD interface; and the methylindole group interacts with ARG173, GLN63, and LYS182 which exist in the CTD interface of the neighboring subunit (Fig. 1b). ${ }^{20,21}$ Preliminary studies of PF-74 showed that capsid destabilization is its main mechanism of action. ${ }^{\mathbf{1 4}}$ Further capsid disassembly assays indicated that PF-74 induces viral uncoating. ${ }^{22,23}$ Since PF-74 competes with CPSF6 and NUP153 for the same binding site of the CA protein, it affects multiple processes of the HIV-1 life cycle by interfering with CA-host factor interactions. ${ }^{24,25}$ However, the low inhibitory activity and poor metabolic stability of PF-74, necessitates a further modification to address these issues. ${ }^{26,27}$ Preliminary optimization of PF-74 has been carried out by several research groups, as shown in compounds 1-3 with improved potency (Fig. 1c). Notably, 4-methoxyaniline and 3,5-difluorophenyl were frequently used as substituent groups around the phenylalanine core motif, which significantly improves the activity of the resulting compounds (Fig. 1c).
Inspired by the preliminary efforts, we focused our attention on further optimization of PF-74. Previously, we modified the linker region and indole substituents to obtain a series of phenylalanine derivatives. ${ }^{7}$ The 1,2,3-triazole was used as a linker in the structure to increase the stability and rigidity of compounds (Fig. 1d). Furthermore, the triazole has two H-bond acceptors, which provides potential additional interactions with the surrounding residues through H-bonding, $\pi-\pi$ stacking, and dipole interaction. ${ }^{28-30}$ Besides, the application of the $\mathrm{Cu}(\mathrm{I})$ catalyzed azide and alkyne 1,3-dipolar cycloaddition (CuAAC), often referred to as the "click reaction", makes it convenient to synthesize 1,4-disubstituted triazole. ${ }^{31-33}$ In this study, we continued to design and synthesize 51 other 1,2,3-triazole phenylalanine derivatives divided into three sub-series, to enrich structure-activity relationships (SARs). Specifically, methoxy and fluorine atoms were introduced into the substituent groups of the phenylalanine scaffold. Meanwhile, we replaced the linker with 1,2,3-triazole to obtain the compounds

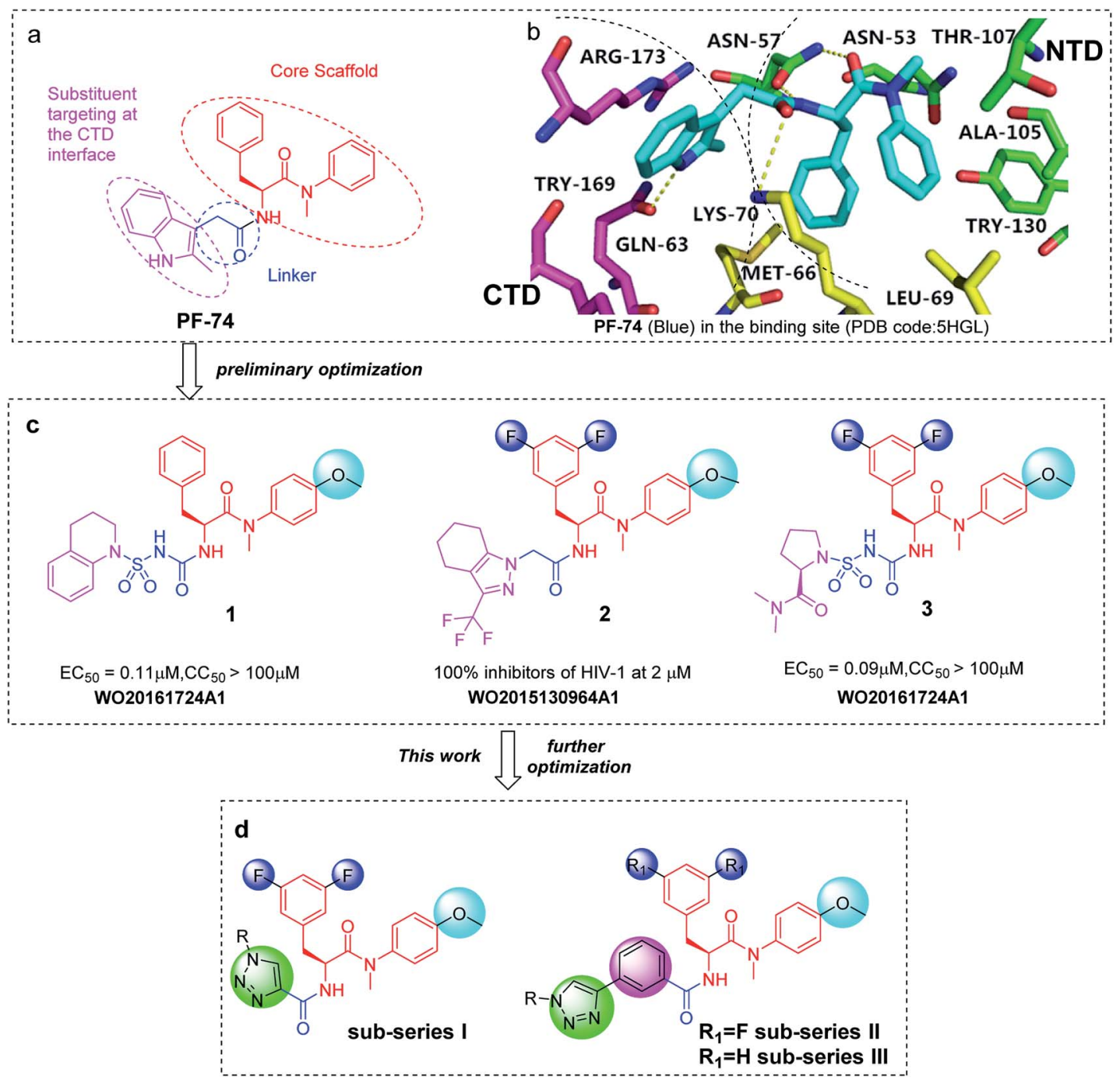

Fig. 1 The design of novel phenylalanine derivatives as HIV-1 CA inhibitors. (a) Structure of PF-74; (b) the binding mode of PF-74 in the NTD-CTD interface of CA protein hexamer. Yellow dashed lines indicate $\mathrm{H}$-bond interactions. (c) Several reported phenylalanine derivatives as HIV-1 CA protein inhibitors. (d) Target compounds designed in this work. 


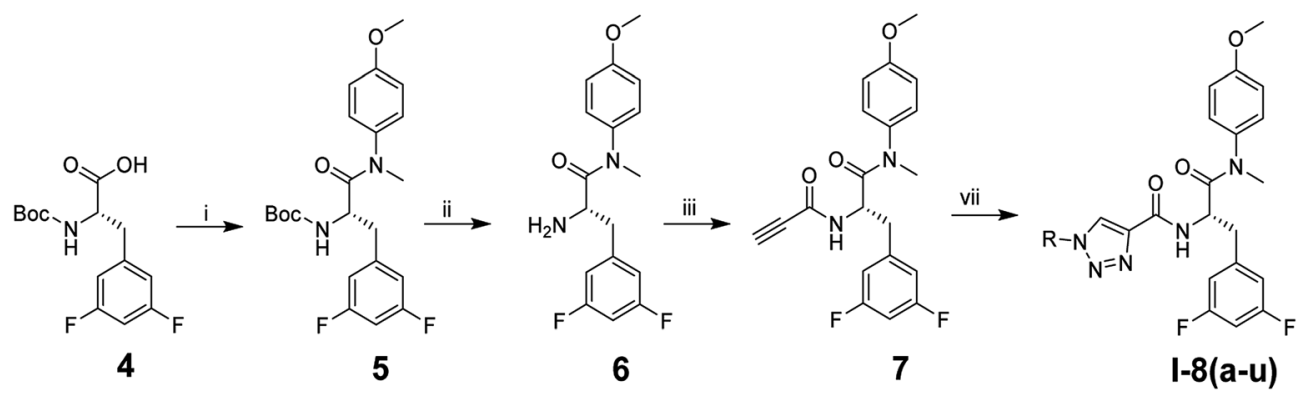

Scheme 1 Reagents and conditions used to synthesize I-8(a-u). (i) 4-methoxy-N-methylaniline, PyBop, DIEA, $\mathrm{CH}_{2} \mathrm{Cl}_{2}, \mathrm{r} . t ., 8-10$ h; (ii): $\mathrm{CF}_{3}$ $\mathrm{COOH}$; $\mathrm{CH}_{2} \mathrm{Cl}_{2}$, r.t., 5-6 h; (iii) propiolic acid, $\mathrm{HATU}$, DIEA, $\mathrm{CH}_{2} \mathrm{Cl}_{2}$, r.t., 10 h; (vii): azide substituents; $\mathrm{CuSO}_{4} \cdot 5 \mathrm{H}_{2} \mathrm{O}, \mathrm{VcNa}, \mathrm{THF} / \mathrm{H}_{2} \mathrm{O}(\mathrm{v}: \mathrm{v}=1: 1$ ), $30-60{ }^{\circ} \mathrm{C}, 4-6 \mathrm{~h}$.

I-8(a-u). Based on a sub-series I structure, the compounds II10(a-o) were yielded by introducing a benzene ring into the linker. This enabled the indole substituents to act more extensively on the CA protein CTD interface. Subsequently, fluorine atoms on phenylalanine skeleton were removed to obtain subseries III, which can help further the understanding of the effect of fluorine atoms on the anti-HIV-1 activity.

In the present study, we designed and synthesized 51 phenylalanine derivatives divided into three sub-series, and evaluated their anti-HIV-1 activities. Moreover, we have confirmed that representative compound II-10c can act on HIV1 CA with high specificity using surface plasmon resonance (SPR) binding assays. Molecular dynamics simulation (MD), water solubility and membrane permeability of representative compounds were performed to further understand the activities of these compounds. Results of this research could be used for further rational optimization and discovery of CA-targeting compounds with improved potency and drug-like qualities.

\section{Results and discussion}

\subsection{Chemistry}

The synthetic route of phenylalanine derivatives $\mathbf{I - 8}(\mathbf{a}-\mathbf{u})$ is illustrated in Scheme 1. (S)-2-((tert-Butoxycarbonyl)amino)-3(3,5-difluorophenyl)propanoic acid (4) was selected as the starting material, which was reacted with 4-methoxy- $N$-methylaniline to afford the intermediate 5 . After removal of the Boc group, free amino was treated with propiolic acid to yield the key intermediate 7. Finally, the desired compounds I-8(a-u) were obtained by CuAAC reaction between key intermediate 7 and various the azide substituents.

Scheme 2 illustrates the synthesis of compounds II-10(a-o). The intermediate 6 in sub-series I was used as the starting material, which was reacted with 3-ethynylbenzoic acid to afford the intermediate 9. The desired compounds II-10(a-o) were obtained through CuAAC reaction between intermediate 6 and diverse azide substituents.

As depicted in Scheme 3, compounds III-15(a-o) were synthesized according to the similar procedures from II-10(a-o). $\mathrm{N}$-(tert-Butoxycarbonyl)-L-phenylalanine (11) was reacted with 4methoxy- $N$-methylaniline, followed by removing the Boc protection to obtain the compound 13. Then, the resulting intermediate 13 was coupled with 3-ethynylbenzoic acid using HATU and DIEA as catalysts to afford the intermediate 14. Azide substituents reacted with $\mathbf{1 4}$ to produce target compounds III$\mathbf{1 5}(\mathbf{a}-\mathbf{o})$ in the presence of $\mathrm{Cu}(\mathrm{I})$.

All novel phenylalanine derivatives were characterized by electrospray ionization mass spectrometry (ESI-MS), proton nuclear magnetic resonance $\left({ }^{1} \mathrm{H} \mathrm{NMR}\right)$ spectroscopy, and carbon nuclear magnetic resonance $\left({ }^{13} \mathrm{C}\right.$ NMR) spectroscopy. The purity of all target compounds was higher than $95 \%$ as confirmed by HPLC analysis.

\subsection{Biological activity}

The newly synthesized compounds I-8(a-u), II-10(a-o) and III15(a-o) were tested in vitro for their anti-HIV-1 activity in
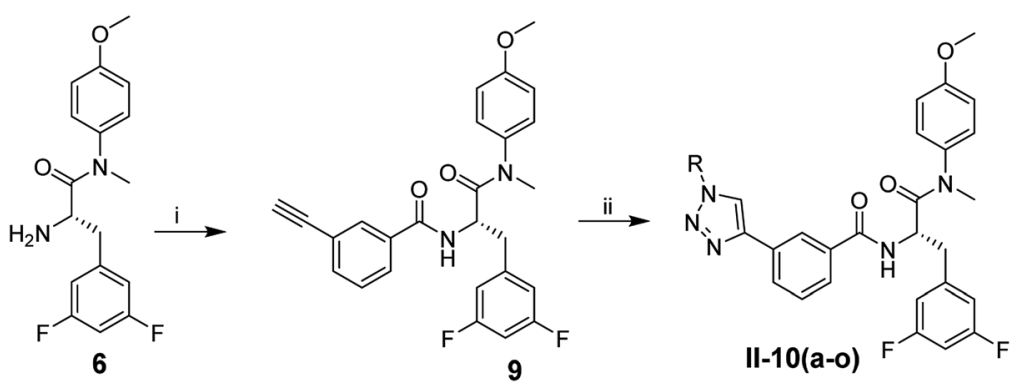

Scheme 2 Reagents and conditions used to synthesize II-10(a-o). (i) 3-ethynylbenzoic acid, HATU, DIEA, $\mathrm{CH}_{2} \mathrm{Cl}_{2}, \mathrm{r} . t ., 10$ h; (ii): azide substituents; $\mathrm{CuSO}_{4} \cdot 5 \mathrm{H}_{2} \mathrm{O}, \mathrm{VcNa}, \mathrm{THF} / \mathrm{H}_{2} \mathrm{O}(\mathrm{v}: \mathrm{v}=1: 1), 30-60{ }^{\circ} \mathrm{C}, 4-6 \mathrm{~h}$. 


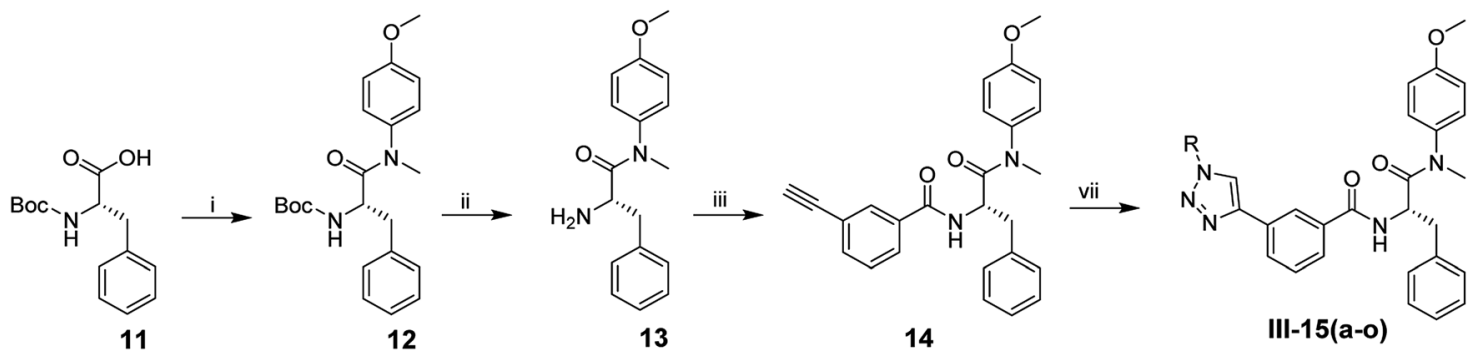

Scheme 3 Reagents and conditions used to synthesize III-15(a-o). (i) 4-methoxy- $N$-methylaniline, PyBop, DIEA, $\mathrm{CH}_{2} \mathrm{Cl}_{2}, \mathrm{r} . t ., 8-10$ h; (ii): $\mathrm{CF}_{3} \mathrm{COOH} ; \mathrm{CH}_{2} \mathrm{Cl}_{2}$, r.t., 5-6 h; (iii) 3-ethynylbenzoic acid, $\mathrm{HATU}$, DIEA, $\mathrm{CH}_{2} \mathrm{Cl}_{2}$, r.t., 10 h; (vii): azide substituents; $\mathrm{CuSO}_{4} \cdot 5 \mathrm{H}_{2} \mathrm{O}, \mathrm{VcNa}$, THF/ $\mathrm{H}_{2} \mathrm{O}$ ( $v: v=1: 1), 30-60^{\circ} \mathrm{C}, 4-6 \mathrm{~h}$.

a multicycle assay using fully infectious $\mathrm{HIV}-1 \mathrm{NL}_{4-3}$ virus and TZM-bl cells. During the assay PF-74 was used as a reference compound. The cytotoxicity of these compounds towards TZMbl cells was evaluated in parallel. The results, expressed as $\mathrm{EC}_{50}$, $\mathrm{CC}_{50}$ and SI (selectivity index, the ratio of $\mathrm{CC}_{50} / \mathrm{EC}_{50}$ ) are illustrated in Tables 1 and 2.

As shown in Table 1, most of the compounds exhibited preferred anti-HIV-1 (TZM-bl cell) activity with micromolar EC $_{50}$ values ranging from $3.27 \mu \mathrm{M}$ to $14.76 \mu \mathrm{M}$. Among them, two compounds with the most anti-HIV potency were $\mathbf{I - 8 h}\left(\mathrm{EC}_{50}=\right.$ $\left.3.58 \pm 0.64 \mu \mathrm{M}, \mathrm{CC}_{50}>18.85 \mu \mathrm{M}\right)$ and $\mathbf{I - 8 j}\left(\mathrm{EC}_{50}=3.27 \pm 0.78\right.$ $\left.\mu \mathrm{M}, \mathrm{CC}_{50}>18.16 \mu \mathrm{M}\right)$, however their activity was less potent than that of the lead compound PF-74 $\left(\mathrm{EC}_{50}=0.28 \mu \mathrm{M}, \mathrm{CC}_{50}>\right.$ $23.50 \mu \mathrm{M})$.

In sub-series I, 21 compounds were synthesized. According to the results of the activity we were able to draw preliminary structure-activity relationship (SAR). In the first subset we varied substitution at the triazole ring keeping the core region unvaried, compounds I-8(a-l) in Table 1 . We varied the position of the functional group on the benzene ring substituent, and observed the change of activity. When the substituent is electron donating group $\left(\mathrm{CH}_{3}\right.$ or $\left.\mathrm{Cl}\right)$, there does not appear to be any significant difference between the $\mathrm{EC}_{50} \mathrm{~s}$ of these compounds (I$\mathbf{8 a} / \mathbf{I}-\mathbf{8 b} / \mathbf{I}-\mathbf{8 c}$ and $\mathbf{I - 8 d} / \mathbf{I}-\mathbf{8 e} / \mathbf{I}-\mathbf{8 f}$ ). However, this pattern shows that the electron withdrawal effect $\left(\mathrm{NO}_{2}\right.$ or $\left.\mathrm{CN}\right)$ has a different effect on the activity than that of electron donating group $\left(\mathrm{CH}_{3}\right.$ or $\left.\mathrm{Cl}\right)$. Specifically, position 3 is the best position for CN $(\mathbf{I}-8 \mathbf{h}>\mathbf{I}-8 \mathbf{i}>\mathbf{I}-$ 8g). However, $\mathrm{NO}_{2}$ has a different pattern, where the best activity when it is positioned at position $2(\mathbf{I}-\mathbf{8 j}>\mathbf{I}-\mathbf{8} \mathbf{l} \approx \mathbf{I}-\mathbf{8} \mathbf{k})$. The analysis proved that benzyl substituents are more sensitive to CA CTD, especially for nitro or cyano groups. Accordingly, the activity is better for the substitution by an electron withdrawing group. Also, it was obvious that different substituents at the same site have significant effects on the activity by comparing I$\mathbf{8 a} / \mathbf{I}-8 \mathrm{~d} / \mathbf{I}-8 \mathrm{~g} / \mathbf{I}-\mathbf{8 j}$, I-8b/I-8e/I-8h/I-8k and I-8c/I-8f/I-8i/I-81.

Then, we turned our attention to the SAR of the other target compounds. Unfortunately, compared with substituted benzenes, the activity of compounds containing naphthalene (I$\mathbf{8 m} / \mathbf{I}-\mathbf{8 n}$ ) or quinoline (I-80) is extraordinary poor, or even disappears completely. However, the replacement of quinoline with benzo $[d][1,3]$ dioxole resulted in a slightly improved antiviral activity toward HIV-1 strains. Besides, the activity of I-8t was more potent than $\mathbf{I - 8 p}, \mathbf{I - 8 r}$ or $\mathbf{I - 8 s}$. The results showed that the position and type of hydrogen-bonding donors/acceptors in substituents had a significant effect on anti-HIV-1 activity. Finally, we introduced the structural fragment of zidovudine into the substituent part and obtained the compound $\mathbf{I - 8 u}$, which lost its anti-HIV-1 activity.

Table 2 illustrates the anti-HIV-1 activity and cytotoxicity of II-10(a-o) and III-15(a-o). Among 30 phenylalanine derivatives, only compounds II-10c, II-10d, II-10e, II-10h, II-10i, III-15d and III-15h exhibited anti-HIV-1 activity at the test concentration. Notably, compound II-10c displayed remarkable anti-HIV activity $\left(\mathrm{EC}_{50}=2.13 \pm 0.75 \mu \mathrm{M}, \mathrm{CC}_{50}>35.49 \mu \mathrm{M}\right)$. Compared to the most active compound I-8j in the sub-series I, its anti-HIV activity increased significantly.

A concise investigation of SARs was summarized as followed. Above all, in some cases, it is beneficial for increasing anti-HIV1 activity to introduce fluorine atoms on the phenylalanine scaffold by comparing II-10c/III-15c, II-10e/III-15e and II-10i/III15i. Interestingly, when the substituents targeting the CTD interface are non-aromatic structures, compounds (II-101/III15l, II-10m/III-15m and II-10n/III-15n) lost anti-HIV-1 activity completely. This indicates that $\pi-\pi$ stacking interactions between the indole fraction of PF-74 and the surrounding residues in the CTD interface has a great influence on the antiHIV activity. Also, if the nonpolar aromatic rings were introduced in this position, the activities of the resulting compounds (II-10g/III-15g, II-10j/III-15j and II-10k/III-15k) are also relatively poor.

All in all, some useful information was provided by the biological evaluation results and the SAR analysis above will be beneficial to future design of CA protein inhibitors targeting the CTD-NTD interface.

\subsection{Binding to HIV-1 CA protein}

Surface plasmon resonance (SPR) analysis was employed to quantify the binding interactions of CA-targeting small molecules to HIV-1 CA protein. The most active compound II-10c was selected, as a representative compound for the assay. PF-74 was used as the positive control. The isotherms are shown in Fig. 2.

Fig. 2 shows that PF-74 binds to HIV-1 CA protein firmly, with an equilibrium dissociation constant $\left(K_{\mathrm{D}}\right)$ values for monomer and hexamer of $2.8 \mu \mathrm{M}$ and $92.8 \mathrm{nM}$, respectively. The SPR results also indicate that $\mathbf{I I - 1 0 c}(2.20 \pm 0.23 \mu \mathrm{M})$ binds the CA 
Table 1 (Contd.)

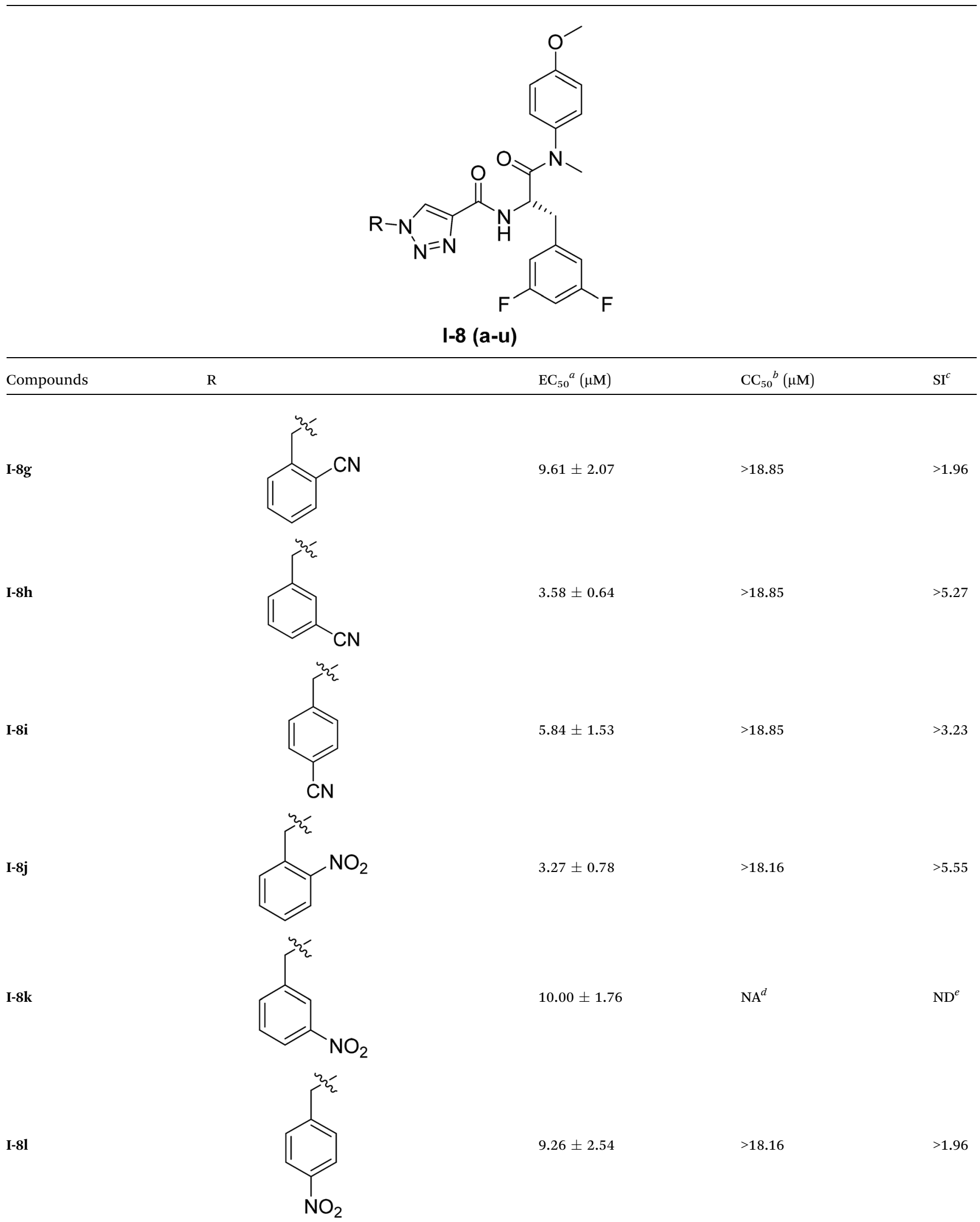


Table 1 (Contd.)

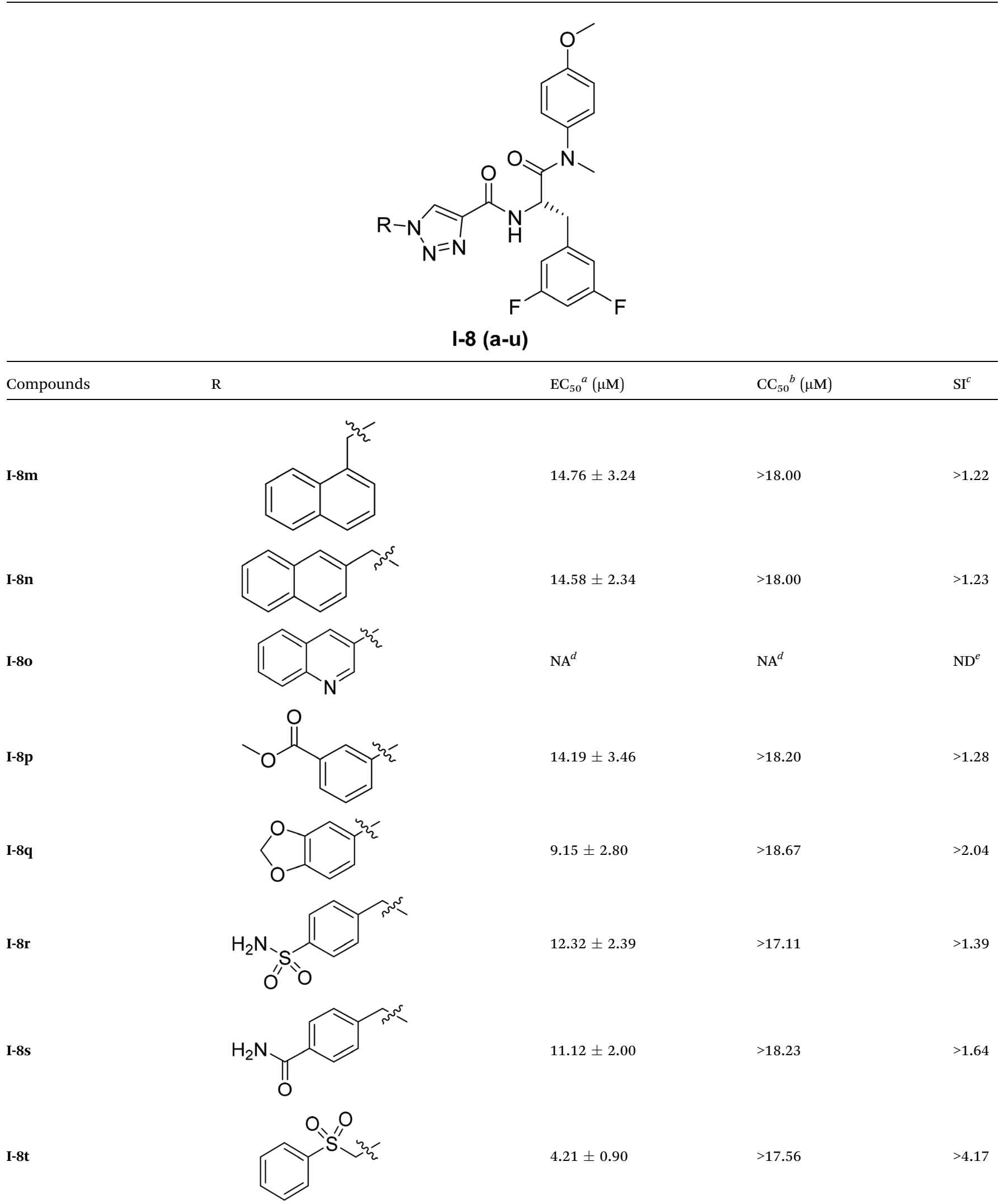


<smiles>[R]n1cc(C(=O)N[C@@H](Cc2cc(F)cc(F)c2)C(=O)N(C)c2ccc(OC)cc2)nn1</smiles>

Compounds

${ }^{a} \mathrm{EC}_{50}$ : the concentration of the compound required to achieve $50 \%$ protection of TZM-bl cells against HIV-1-induced cytopathic effect, as determined by the MTT method. ${ }^{b} \mathrm{CC}_{50}$ : the concentration of the compound required to reduce the viability of uninfected cells by $50 \%$, as determined by the MTT method. ${ }^{c}$ SI: selectivity index, the ratio of $\mathrm{CC}_{50} / \mathrm{EC}_{50}{ }^{d} \mathrm{NA}$ : no anti-HIV-1 activity or cytotoxicity at the test concentration. ${ }^{e}$ ND: not determined.

monomer with similar affinity compared to PF-74 $(2.80 \pm 1.40$ $\mu \mathrm{M})$. However, PF-74 prefers to interact with HIV-1 CA hexamer. This could explain PF-74 increased anti-HIV-1 activity compared to II-10c. In conclusion, the SPR analysis found no statistically significant difference between the binding affinities of compound II-10c and the lead PF-74 for HIV-1-CA monomer. Therefore, the novel 1,2,3-triazole phenylalanine derivatives can be defined as classical HIV-1-CA inhibitors.

\subsection{Molecular dynamics (MD) simulation}

Compound II-10c has been chosen for the MD simulation due to its high activity. II-10c was docked by Autodock 4.2.6 using default settings in a preparation step for the MD simulation. ${ }^{34}$ We used the same MD simulation and analysis procedures described in our previously published research to keep consistency of the simulation between different CA HIV-1 monomer inhibitors series. ${ }^{7}$

II-10c, which is the most active compound of this series as CA HIV-1 monomer inhibitors was simulated for $1 \mu$ s to explore its interactions with the active site amino acids as well as its binding modes. The root mean square deviation (RMSD) of amino acids during the simulation is plotted in Fig. 3a. The figure shows that the structure has deviated from the X-ray structure and existed in different conformational ensembles. This shows that the binding of the inhibitor-induced these conformational forms which are also accompanied by different conformations of the inhibitor. Accordingly, the RMSD of II-10c was calculated and plotted in Fig. 3b. The figure shows that II10c exists in few conformational forms with most abundant form after $500 \mathrm{~ns}$ of the MD simulation.

The entire trajectory underwent cluster analysis based on II-10c (no fit) according to the results of RMSD of the protein and the inhibitor, which show that the inhibitor binds with different modes. The clustering analysis retained four different clusters with two being the most populated. Fig. 4a and $b$ show the representative structure interactions of the first $(32.7 \%)$ and second $(30.0 \%)$ clusters respectively. The binding of II-10c to the CA HIV-1 monomer is different from that of PF-74, where the core scaffold is oriented to the outside of the active site.

In the first cluster representative structure the nitro group undergoes electrostatic interactions with LYS70, where the nitro group does not interact with amino acids in the second cluster structure. However, the phenyl ring of the 
Table 2 Anti-HIV-1 activity and cytotoxicity of the novel phenylalanine derivatives II-10(a-o) and III-15(a-o)

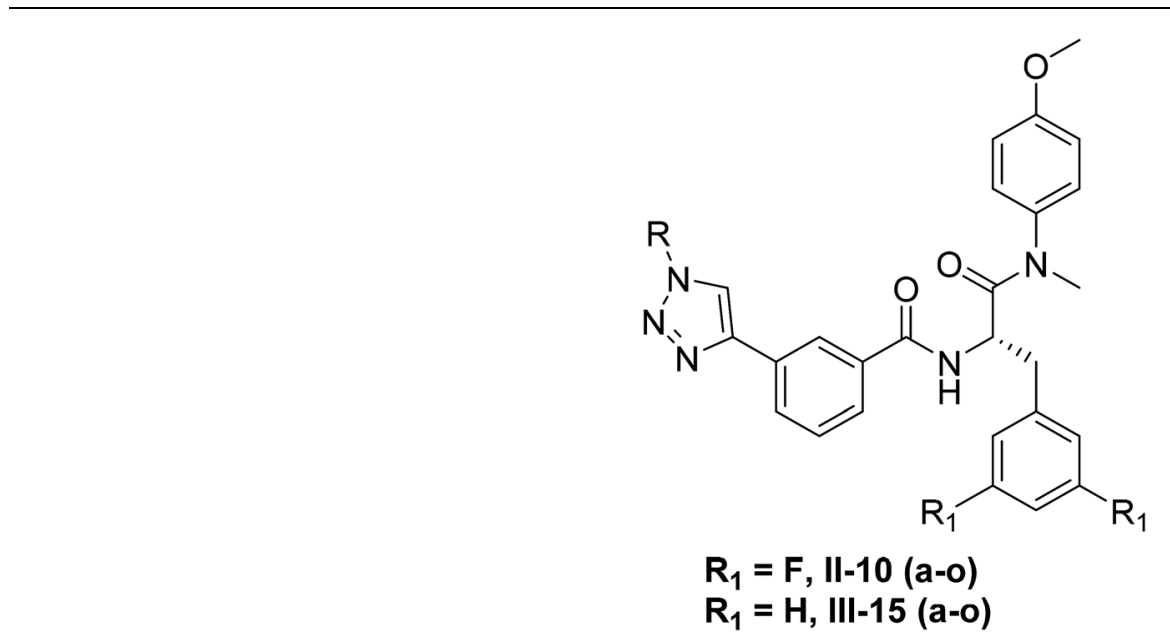

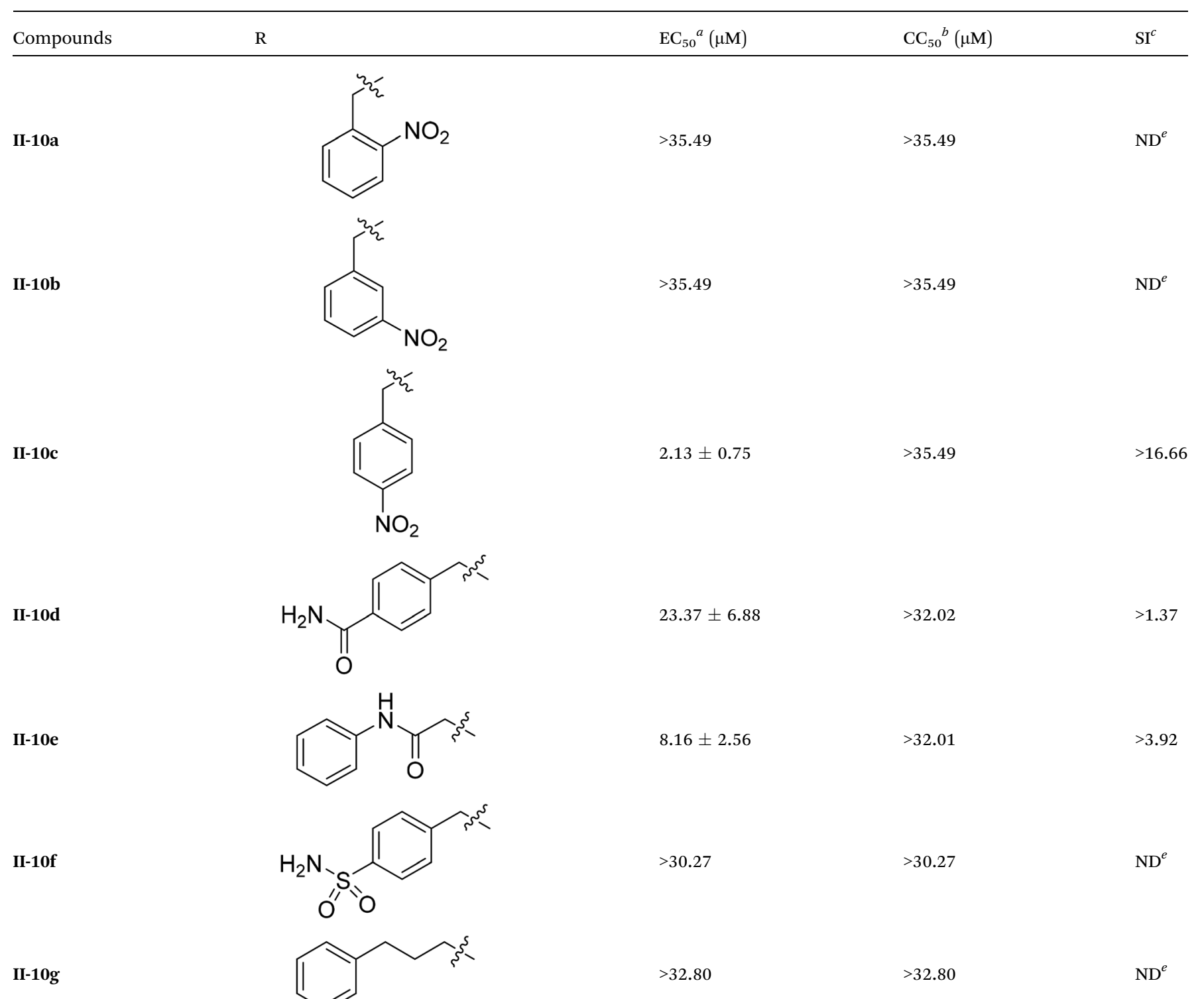


Table 2 (Contd.)

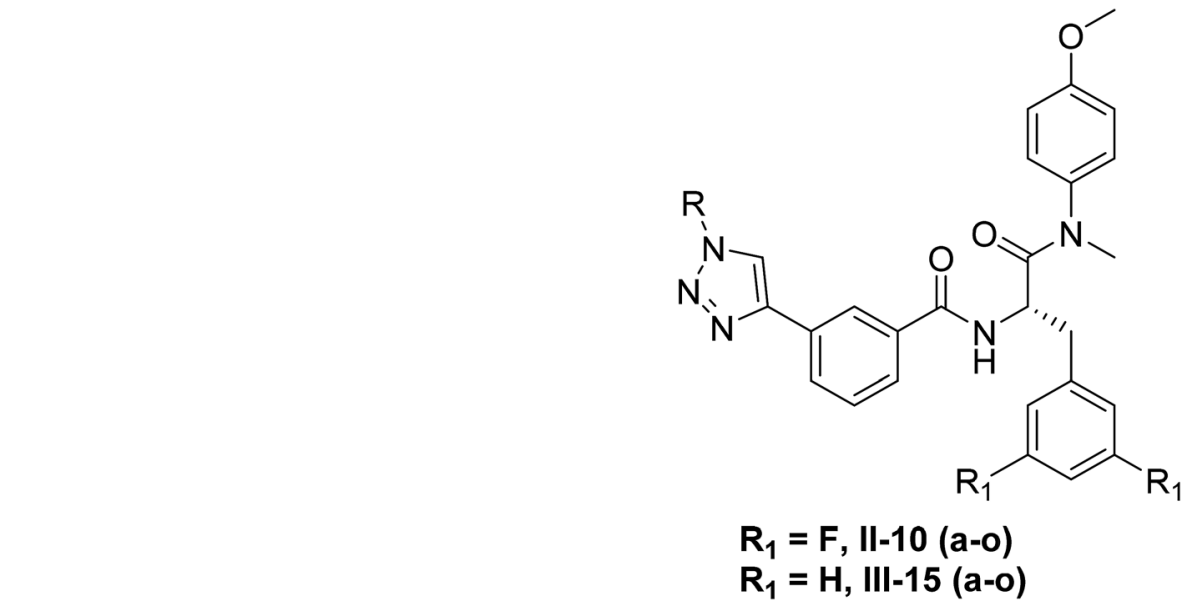

Compounds $\quad$ R $a^{a}(\mu \mathrm{M})$

III-15c<smiles>CCc1ccc([N+](=O)[O-])cc1</smiles>

III-15d<smiles>CC(C)(C)Cc1ccc(C(N)=O)cc1</smiles><smiles>CCCC(=O)Nc1ccccc1</smiles><smiles>CC(C)(C)Cc1ccc(S(N)(=O)=O)cc1</smiles>

III-15g

III-15h

III-15i

III-15j<smiles>C[14CH2]Cc1ccsc1</smiles><smiles>Cc1cnc2ccccc2c1</smiles><smiles>CC(C)(C)Cc1ccc2ccccc2c1</smiles><smiles>CC(C)(C)CCCc1ccccc1</smiles>

$>34.86$

$9.37 \pm 3.18$

$>34.33$

$>33.57$

$26.16 \pm 7.30$

$>33.97$

$>32.01$

$>32.01$

$\mathrm{ND}^{e}$ 


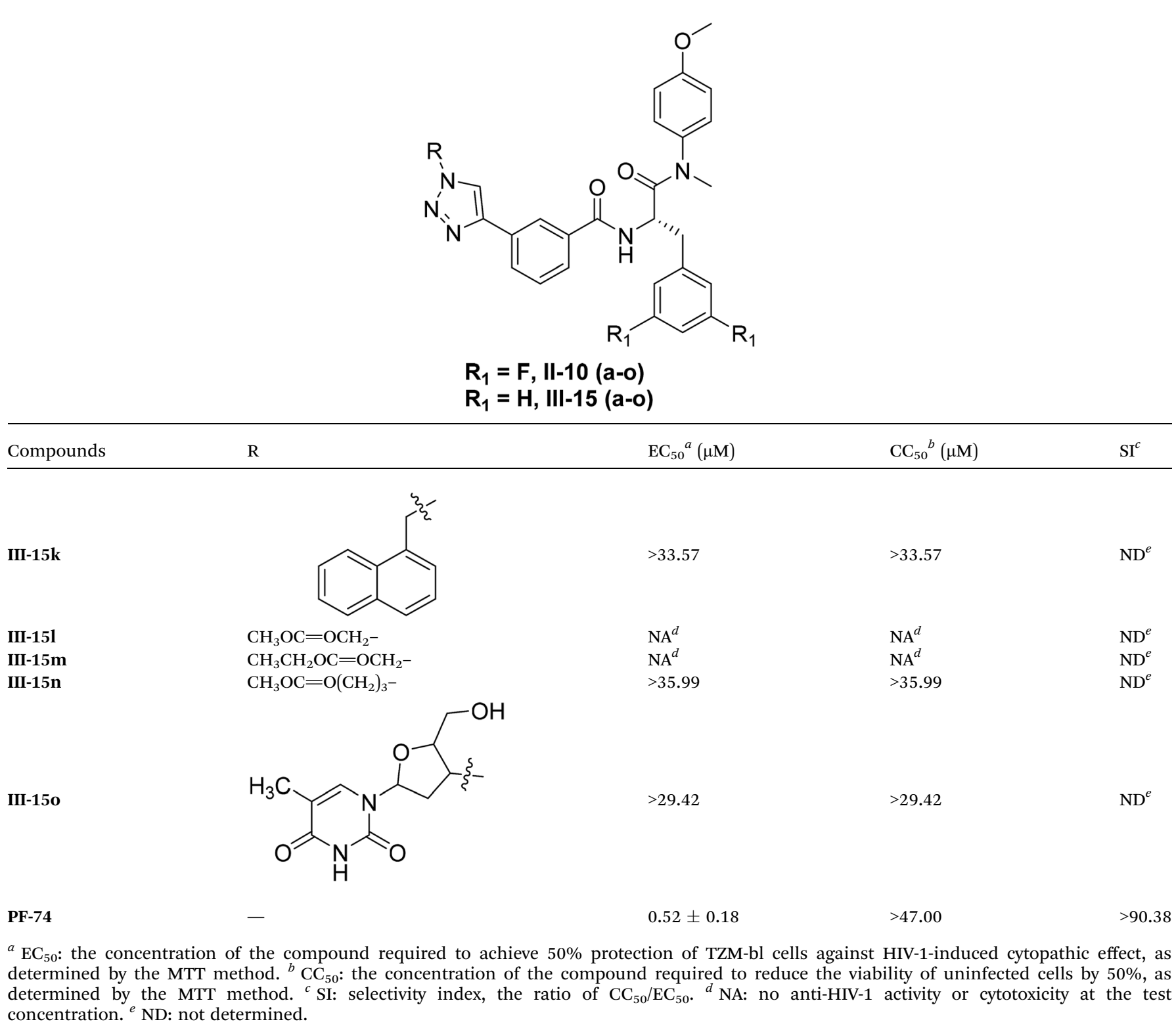

nitrobenzene ring in the second structure forms hydrophobic interactions with LYS70, or it could be involved in ion-induced dipole interactions with the positively charged lysine amino acid. The fluorophenyl ring of the core region forms hydrophobic interactions with PRO17 in the first cluster structure, while it is distant for it in the second cluster structure. The methoxyphenyl ring of the core region forms hydrophobic interactions with CYS14 in the second structure, where this ring is distant from CYS17 in the first structure. The methoxy group of the methoxyphenyl ring in the second structure forms aliphatic hydrogen bond with the backbone of ILE15. The methyl group of the core region forms hydrophobic interactions with LEU20 in the second structure. The results of hydrogen bond analysis showed that there is no stable hydrogen bond during the MD simulation between II-10c and the binding site. The results of MD simulation showed that the binding between II-10c and CA HIV-1 monomer is not strong in both clusters, which explains the difference in the activities between PF-74 and II-10c.

\subsection{Cell permeability}

In order to further explore the reason why II-10c has similar target affinity but lower anti-HIV-1 activity compared with PF74. The unidirectional cell permeability of compound II-10c was studied. As shown in Table 3, cell permeability assays revealed that II-10c had poor membrane permeability. More concretely, in experiments carried out with Caco-2 cells, the apparent permeability $\left(P_{\text {app }}\right)$ of II-10c was below $0.1 \times 10^{-7} \mathrm{~cm} \mathrm{~s}^{-1}$, while 
(a)

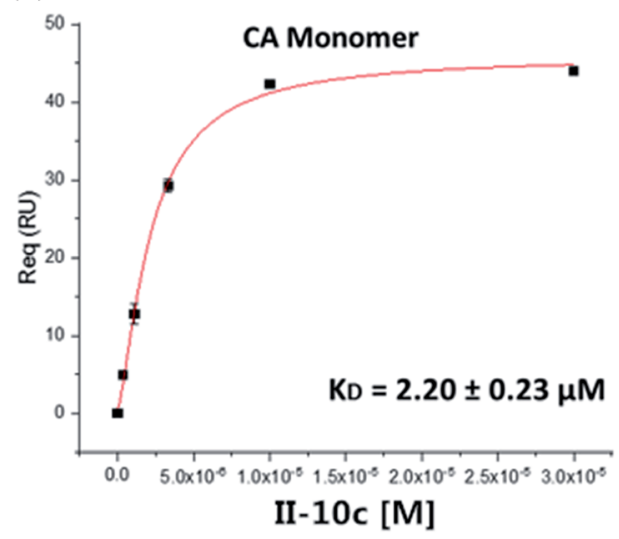

(b)

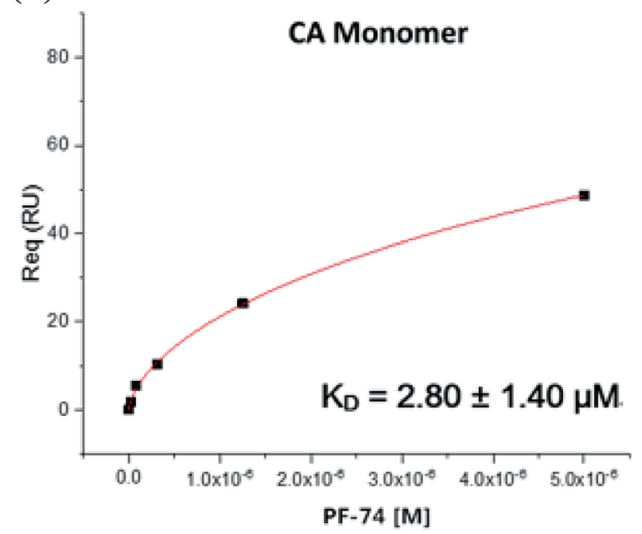

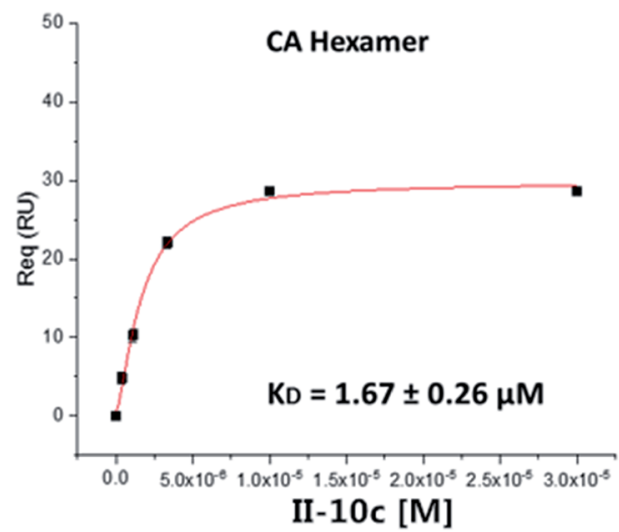

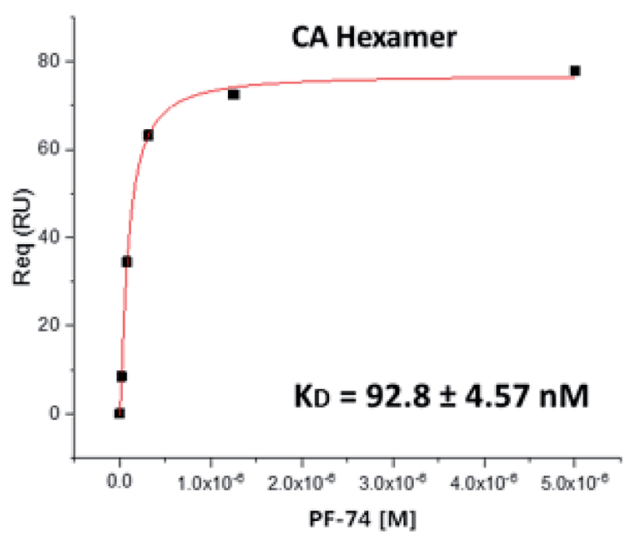

Fig. 2 SPR isotherms of compound II-10c (a) binding to two variants of the CA protein (monomer and disulfide-stabilized hexamer) respectively with PF-74 as the reference (b). Isotherms are an average of 3 replicates with error bars indicating SEM.

reference compounds for low and high permeability, such as nadolol and metoprolol, showed $P_{\text {app }}$ values of $0.8 \times 10^{-7} \mathrm{~cm}$ $\mathrm{s}^{-1}$ and $1.64 \times 10^{-5} \mathrm{~cm} \mathrm{~s}^{-1}$, respectively. This suggests that the permeability of the novel designed compounds may weaken the anti-HIV-1 activity at the cellular level.

\subsection{Water solubility}

Because water solubility and lipid-water partition coefficient are also important factors in evaluating the newly designed compounds, the solubility and $\log P$ of representative compounds II-10c, II-10h, and III-15h were studied by highperformance liquid chromatography (HPLC). Table 4 displayed the $\log P$ of the selected compounds is at the appropriate value (accepted range: $1-5$ ). However, the water solubility of the selected compounds is slightly lower than that of PF-74 at three different $\mathrm{pH}$ values (7.4, 7.0 and 2.0), which may be a reason for the decrease of anti-HIV-1 activity at the cellular level.

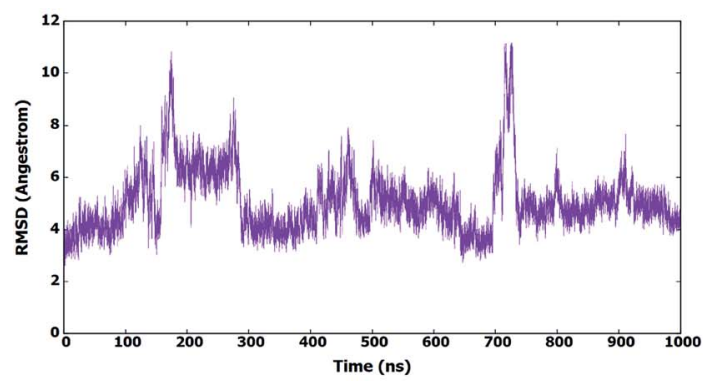

(a)

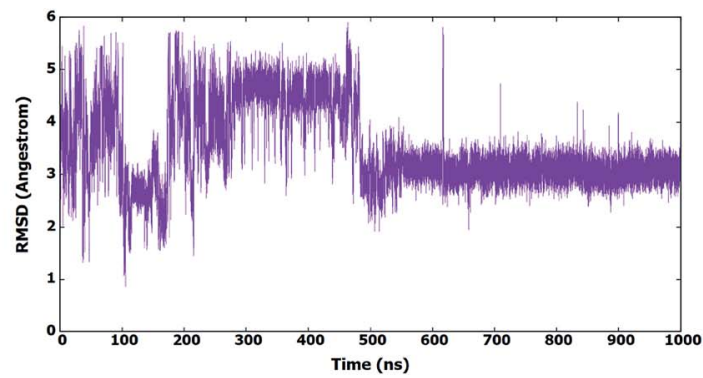

(b)

Fig. 3 (a) RMSD (heavy atoms) of amino acids of CA HIV-1 monomer in reference to the first frame of the MD simulation. (b) RMSD (heavy atoms) of the bound $\mathrm{II}-10 \mathrm{c}$ in reference to the docked conformer. 


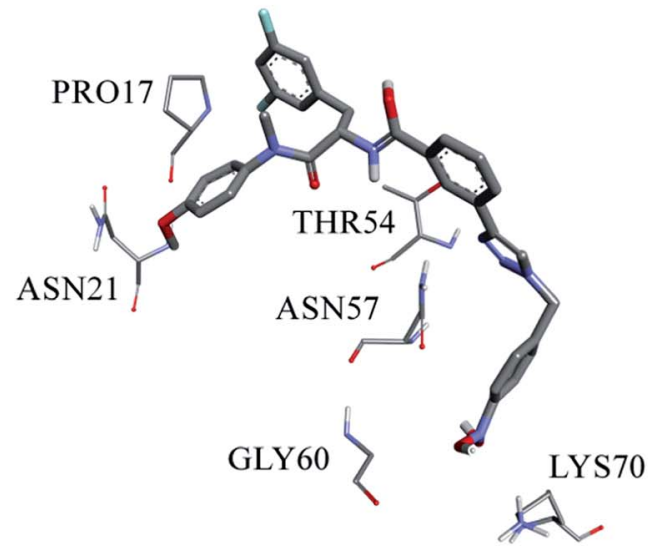

(a)

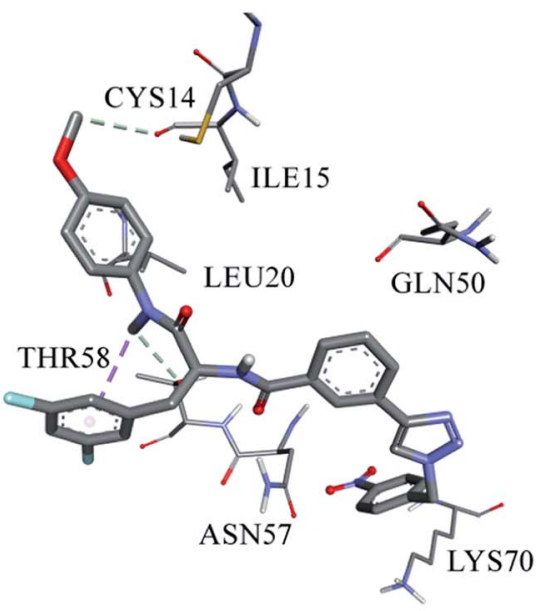

(b)

Fig. 4 Binding interactions of II-10c in the first (a) and second (b) clusters.

Table 3 Cell permeability assay of II-10 $\mathrm{c}^{a}$

\begin{tabular}{lll}
\hline & Mean $P_{\text {app }}\left(10^{-6} \mathrm{~cm} \mathrm{~s}^{-1}\right)$ & Rank \\
\cline { 2 - 2 } Compound & A to B & $P_{\text {app }}$ \\
\hline Nadolol & 0.08 & Low \\
Metoprolol & 16.40 & High \\
II-10c & $<0.01$ & Low
\end{tabular}

${ }^{a}$ Binning criteria: low permeability: $P_{\text {app }} \leq 0.5\left(\times 10^{-6} \mathrm{~cm} \mathrm{~s}^{-1}\right)$; moderate permeability: $0.5<P_{\text {app }}<2.5\left(\times 10^{-6} \mathrm{~cm} \mathrm{~s}^{-1}\right) ;$ high permeability: $P_{\text {app }} \geq 2.5\left(\times 10^{-6} \mathrm{~cm} \mathrm{~s}^{-1}\right)$.

Table 4 The water solubility of II-10c, II-10h and III-15h

\begin{tabular}{|c|c|c|c|c|c|c|c|}
\hline \multirow[b]{2}{*}{ Compound } & \multirow[b]{2}{*}{$\log P^{a}$} & \multicolumn{2}{|c|}{$\begin{array}{l}\mathrm{pH}=7.0^{b} \\
\left(\mu \mathrm{g} \mathrm{mL} L^{-1}\right)\end{array}$} & \multicolumn{2}{|c|}{$\begin{array}{l}\mathrm{pH}=7.4^{b} \\
\left(\mu \mathrm{g} \mathrm{mL}^{-1}\right)\end{array}$} & \multicolumn{2}{|c|}{$\begin{array}{l}\mathrm{pH}=2.0^{b}(\mu \mathrm{g} \\
\left.\mathrm{mL}^{-1}\right)\end{array}$} \\
\hline & & $\mathbf{1}^{c}$ & $2^{d}$ & $\mathbf{1}^{c}$ & $2^{d}$ & $1^{c}$ & $2^{d}$ \\
\hline PF-74 & 1.96 & 7.85 & 7.84 & 9.30 & 9.37 & 17.96 & 18.01 \\
\hline II-10c & 2.29 & 4.02 & 4.09 & 3.92 & 3.89 & 9.29 & 9.35 \\
\hline II-10h & 2.07 & 2.71 & 2.69 & 2.66 & 2.73 & 5.05 & 5.14 \\
\hline III-15h & 2.36 & 3.23 & 3.29 & 3.01 & 3.10 & 5.94 & 5.85 \\
\hline
\end{tabular}

${ }^{a} \log P$ : $\operatorname{logarithm}$ of partition coefficient, measured by HPLC. ${ }^{b}$ Measured in phosphate buffer by HPLC method in duplicate. ${ }^{c}$ Data from the first test. ${ }^{d}$ Data from the second test.

\section{Conclusion}

In summary, taking the most extensively studied HIV-1 capsid inhibitor PF-74 as lead compound, a novel series of 1,2,3-triazole phenylalanine derivatives were designed, synthesized and biologically evaluated. Among them, compound II-10c $\left(\mathrm{EC}_{50}=\right.$ $2.13 \mu \mathrm{M}, \mathrm{CC}_{50}>35.49 \mu \mathrm{M}$ ) exhibited remarkable anti-HIV-1 activity. Then, the preliminary SARs were discussed comprehensively to obtain valuable information. Of course, there is no reasonable explanation for some SARs at present, which reflects the unpredictability of structural modification of the proteinsolvent interface due to flexibility. ${ }^{35}$ To better understand the interactions between HIV-1 CA protein and the newly synthesized compounds, MD simulation was performed for the representative compounds. SPR binding assays shown that II10c and lead compound PF-74 have similar affinity for HIV-1 CA monomer, but PF-74 prefers to interact with HIV-1 CA hexamer. Therefore, in the further design, we should focus on the modification of PF-74 within the CTD-NTD interface, which may improve the affinity of the compounds with HIV-1 CA hexamer to improve the antiviral activity. Further investigation showed that the weak permeability and water solubility of these compounds were probably the important factors that are restricting their cell-based activity. Thus, in future research, we should pay attention to the evaluation of drug-like properties ${ }^{36}$ while improving the activity of compounds. Generally, we analyzed the potential reasons for the anti-HIV-1 activity of compounds from various perspectives, which set the foundation for further design and optimization of CA-targeting compounds with improved potency. Further optimizations of this series of compounds are currently ongoing and will be reported in due course.

\section{Experimental section}

\subsection{Chemistry}

All melting points of the compounds were determined on a micro melting point apparatus and were uncorrected. ${ }^{1} \mathrm{H}$ NMR and ${ }^{13} \mathrm{C}$ NMR spectra were recorded on a Bruker Avance-400 NMR spectrometer in DMSO or $\mathrm{CDCl}_{3}$ using TMS as an internal reference. Chemical shifts were expressed in $\delta$ units (ppm), and $J$ values were presented in hertz (Hz). Related mass spectra dates were determined by a LC Autosampler Device: Standard G1313A instrument. TLC was performed on Silica Gel GF254 for TLC and spots were visualized by irradiation with UV light $(\lambda=254 \mathrm{~nm})$. Meanwhile, flash column chromatography was performed on column packed with Silica Gel 60 (200-300 
mesh). Rotary evaporator under reduced pressure condition was used to concentrate the reaction solutions. Solvents were of reagent grade and purified with standard methods when necessary. All azide substituents were synthesized by our group in the early stage. ${ }^{7}$

4.1.1. tert-Butyl (S)-(3-(3,5-difluorophenyl)-1-((4-methoxyphenyl) (methyl)amino)-1-oxopropan-2-yl)carbamate (5). A solution of (S)-2((tert-butoxycarbonyl)amino)-3-(3,5-difluorophenyl)propanoic acid (4, $8.75 \mathrm{mmol}, 2.7 \mathrm{~g}$ ) in $15 \mathrm{~mL}$ dichloromethane was added PyBop (10.9 mmol, $5.7 \mathrm{~g}$ ) at $0{ }^{\circ} \mathrm{C}$, and the mixture stirred for $0.5 \mathrm{~h}$. Subsequently, DIEA (21.87 mmol, $3.61 \mathrm{~mL}$ ) and 4-methoxy- $N$-methylaniline (7.29 mmol, $1.0 \mathrm{~g})$ were added to the mixture and then stirred at room temperature for another 8-9 $\mathrm{h}$ (monitored by TLC). The resulting mixture was evaporated under reduced pressure and the residue was initially washed by $1 \mathrm{~N} \mathrm{HCl}$ and extracted with ethyl acetate $(3 \times 20 \mathrm{~mL})$. Then, the combined organic layer was washed with saturated sodium bicarbonate $(3 \times 50 \mathrm{~mL})$, dried over anhydrous $\mathrm{Na}_{2} \mathrm{SO}_{4}$, filtered, and concentrated under reduced pressure to afford corresponding crude intermediate $\mathbf{5}$ as yellow oil with a yield of $88 \% .{ }^{1} \mathrm{H}$ NMR (400 MHz, DMSO- $\left.d_{6}\right) \delta 7.31(\mathrm{~d}, J=8.4 \mathrm{~Hz}, 2 \mathrm{H}), 7.22-$ $6.89(\mathrm{~m}, 4 \mathrm{H}), 6.43(\mathrm{~d}, J=8.0 \mathrm{~Hz}), 4.27-4.05(\mathrm{~m}, 1 \mathrm{H}), 3.80(\mathrm{~s}, 3 \mathrm{H}), 3.14$ (s, 3H), 2.92-2.55 (m, 2H), 1.29 (s, 9H). ESI-MS: $m / z 421.21(\mathrm{M}+\mathrm{H})^{+}$, $\mathrm{C}_{22} \mathrm{H}_{26} \mathrm{~F}_{2} \mathrm{~N}_{2} \mathrm{O}_{4}$ (420.19).

4.1.2. (S)-2-Amino-3-(3,5-difluorophenyl)- $N$-(4-methoxyphenyl)$N$-methylpropanamide (6). Trifluoroacetic acid (34.2 mmol, 5.0 eq.) was added dropwise to intermediate 5 (2.86 g, $6.84 \mathrm{mmol}$, 1.0 eq.) in $30 \mathrm{~mL}$ dichloromethane and stirred at room temperature for 6-7 h. Then, the resulting mixture solution was alkalized to $\mathrm{pH}=9$ with saturated sodium bicarbonate solution, and then extracted with dichloromethane $(3 \times 20 \mathrm{~mL})$. The combined organic layer was dried over anhydrous $\mathrm{Na}_{2} \mathrm{SO}_{4}$, filtered, and concentrated under reduced pressure to yield the crude product 6 as yellow oil, which was directly injected the next step. ESI-MS: $m / z 321.00(\mathrm{M}+\mathrm{H})^{+}, 343.08(\mathrm{M}+\mathrm{Na})^{+}$, $\mathrm{C}_{17} \mathrm{H}_{18} \mathrm{~F}_{2} \mathrm{~N}_{2} \mathrm{O}_{2}$ (320.13).

4.1.3. (S)- $N$-(3-(3,5-Difluorophenyl)-1-((4-methoxyphenyl)(methyl)amino)-1-oxopropan-2-yl)propiolamide (7). Propiolic acid (4.22 mmol, $0.3 \mathrm{~g}$ ) and HATU (5.28 mmol, $2.0 \mathrm{~g}$ ) were mixed in dichloromethane and stirred in an ice bath for $1 \mathrm{~h}$. Then, the intermediate 6 (6.33 mmol, $2.35 \mathrm{~g}$ ) and DIEA (7.03 mmol, 1.16 $\mathrm{mL}$ ) were added to the above solution slowly at $0{ }^{\circ} \mathrm{C}$. The reaction system was then stirred at room temperature for additional $12 \mathrm{~h}$. The solvent was removed under reduced pressure and then $1 \mathrm{~N} \mathrm{HCl} \mathrm{(30} \mathrm{mL)} \mathrm{was} \mathrm{added,} \mathrm{extracted} \mathrm{with} \mathrm{ethyl} \mathrm{acetate} \mathrm{(3}$ $\times 30 \mathrm{~mL}$ ). The combined organic layer was washed with saturated sodium bicarbonate $(3 \times 50 \mathrm{~mL})$. The resulting organic layer was washed with saturated salt water, dried over anhydrous $\mathrm{Na}_{2} \mathrm{SO}_{4}$, filtered, and concentrated under reduced pressure to afford corresponding crude product, which was purified by flash column chromatography to yield compound 7 as yellow oil with the yield of $42 \% .{ }^{1} \mathrm{H}$ NMR (400 MHz, DMSO- $\left.d_{6}\right) \delta 9.17$ (d, $J=7.7 \mathrm{~Hz}, 1 \mathrm{H}), 7.27$ (d, $J=8.4 \mathrm{~Hz}, 2 \mathrm{H}), 7.12-6.93(\mathrm{~m}, 3 \mathrm{H}), 6.57-$ $6.36(\mathrm{~m}, 2 \mathrm{H}), 4.47-4.29(\mathrm{~m}, 1 \mathrm{H}), 4.18(\mathrm{~s}, 1 \mathrm{H}), 3.80(\mathrm{~s}, 3 \mathrm{H}), 3.13(\mathrm{~s}$, $3 \mathrm{H}), 2.90-2.70(\mathrm{~m}, 2 \mathrm{H}) .{ }^{13} \mathrm{C}$ NMR (100 MHz, DMSO) $\delta 170.33$, $163.64\left(\mathrm{dd},{ }^{1} J_{\mathrm{CF}}=246.4 \mathrm{~Hz},{ }^{3} J_{\mathrm{CF}}=13.1 \mathrm{~Hz}, 2 \mathrm{C}\right), 159.24,151.89$, $142.49\left(\mathrm{t},{ }^{2} J_{\mathrm{CF}}=9.1 \mathrm{~Hz}, 1 \mathrm{C}\right), 135.74,129.22,115.30,112.35$ (dd, $\left.{ }^{2} J_{\mathrm{CF}}=19.2 \mathrm{~Hz},{ }^{4} J_{\mathrm{CF}}=6.1 \mathrm{~Hz}, 2 \mathrm{C}\right), 102.64\left(\mathrm{t},{ }^{3} J_{\mathrm{CF}}=25.3 \mathrm{~Hz}, 1 \mathrm{C}\right)$,
78.14, 77.10, 55.95, 52.20, 37.81, 36.21. ESI-MS: $m / z 373.2(\mathrm{M}+$ $\mathrm{H})^{+}, \mathrm{C}_{20} \mathrm{H}_{18} \mathrm{~F}_{2} \mathrm{~N}_{2} \mathrm{O}_{3}$ (372.13).

4.1.4. General procedure for the synthesis of target compounds I-8(a-u). The key intermediate 7 (1.0 eq.), azide substituents (1.1 eq.), ascorbic acid sodium (0.6 eq.) and $\mathrm{CuSO}_{4} \cdot 5 \mathrm{H}_{2} \mathrm{O}$ (0.3 eq.) were dissolved in the solution of tetrahydrofuran/water $(\mathrm{v}: \mathrm{v}=1: 1)$. The resulting mixture was stirred at $30-60{ }^{\circ} \mathrm{C}$ for $4-6 \mathrm{~h}$. Then the reaction mixture was extracted with ethyl acetate $(3 \times 10 \mathrm{~mL})$, and the combined organic phase was washed with saturated salt water $(3 \times 10$ $\mathrm{mL}$ ), dried over anhydrous $\mathrm{MgSO}_{4}$, filtered, and concentrated under reduced pressure to give the corresponding crude target product, which was purified by flash column chromatography to afford product I-8(a-u). Yield: $60-80 \%$.

(S)-N-(3-(3,5-Difluorophenyl)-1-((4-methoxyphenyl)(methyl)amino)1-oxopropan-2-yl)-1-(2-methylbenzyl)-1H-1,2,3-triazole-4-carboxamide (I-8a). Pale green solid, yield: $61 \%$, mp: $76-78{ }^{\circ} \mathrm{C} .{ }^{1} \mathrm{H}$ NMR $(400$ MHz, DMSO- $\left.d_{6}\right) \delta 8.52(\mathrm{~d}, J=8.2 \mathrm{~Hz}, 1 \mathrm{H}), 8.49(\mathrm{~s}, 1 \mathrm{H}), 7.34(\mathrm{~d}, J=$ $8.4 \mathrm{~Hz}, 2 \mathrm{H}), 7.31-7.23(\mathrm{~m}, 2 \mathrm{H}), 7.20(\mathrm{td}, J=7.1,2.2 \mathrm{~Hz}, 1 \mathrm{H}), 7.07(\mathrm{t}$, $J=7.6 \mathrm{~Hz}, 3 \mathrm{H}), 7.00(\mathrm{td}, J=8.3,7.1,4.6 \mathrm{~Hz}, 1 \mathrm{H}), 6.62-6.40(\mathrm{~m}, 2 \mathrm{H})$, $5.67(\mathrm{~s}, 2 \mathrm{H}), 4.66(\mathrm{td}, J=8.9,4.1 \mathrm{~Hz}, 1 \mathrm{H}), 3.81(\mathrm{~s}, 3 \mathrm{H}), 3.15(\mathrm{~s}, 3 \mathrm{H})$, 3.05-2.84 (m, 2H), 2.31 (s, 3H). ${ }^{13} \mathrm{C}$ NMR (100 MHz, DMSO) $\delta 170.85,163.60\left(\mathrm{dd},{ }^{1} J_{\mathrm{CF}}=246.4 \mathrm{~Hz},{ }^{3} J_{\mathrm{CF}}=13.1 \mathrm{~Hz}, 2 \mathrm{C}\right), 159.74$, 159.23, $142.82\left(\mathrm{t},{ }^{2} J_{\mathrm{CF}}=9.1 \mathrm{~Hz}, 1 \mathrm{C}\right), 142.47,136.74,135.85,134.21$, 130.94, 129.31, 129.06, 128.92, 127.17, 126.79, 115.31, 112.46 (dd, $\left.{ }^{2} J_{\mathrm{CF}}=19.2 \mathrm{~Hz},{ }^{4} J_{\mathrm{CF}}=6.1 \mathrm{~Hz}, 2 \mathrm{C}\right), 102.48\left(\mathrm{t},{ }^{3} J_{\mathrm{CF}}=25.3 \mathrm{~Hz}, 1 \mathrm{C}\right)$, $55.95,51.69,51.58,37.83,36.47,19.08$. ESI-MS: $m / z 520.4(\mathrm{M}+\mathrm{H})^{+}$, $\mathrm{C}_{28} \mathrm{H}_{27} \mathrm{~F}_{2} \mathrm{~N}_{5} \mathrm{O}_{3}$ (519.21).

(S)-N-(3-(3,5-Difluorophenyl)-1-((4-methoxyphenyl)(methyl)amino)1-oxopropan-2-yl)-1-(3-methylbenzyl)-1H-1,2,3-triazole-4-carboxamide (I-8b). Pale green solid, yield: 66\%, mp: 78-80 ${ }^{\circ} \mathrm{C} .{ }^{1} \mathrm{H}$ NMR $(400$ MHz, DMSO- $\left.d_{6}\right) \delta 8.53(\mathrm{~d}, J=8.1 \mathrm{~Hz}, 1 \mathrm{H}), 8.49(\mathrm{~s}, 1 \mathrm{H}), 7.34(\mathrm{~d}, J$ $=8.5 \mathrm{~Hz}, 2 \mathrm{H}), 7.30-7.17(\mathrm{~m}, 3 \mathrm{H}), 7.07(\mathrm{dd}, J=7.8,5.5 \mathrm{~Hz}, 3 \mathrm{H})$, 7.01 (ddd, $J=9.6,7.1,2.4 \mathrm{~Hz}, 1 \mathrm{H}), 6.61-6.45(\mathrm{~m}, 2 \mathrm{H}), 5.67$ (s, $2 \mathrm{H}), 4.66(\mathrm{t}, J=4.4 \mathrm{~Hz}, 1 \mathrm{H}), 3.81(\mathrm{~s}, 3 \mathrm{H}), 3.15(\mathrm{~s}, 3 \mathrm{H}), 3.05-2.79$ $(\mathrm{m}, 2 \mathrm{H}), 2.31(\mathrm{~s}, 3 \mathrm{H}) .{ }^{13} \mathrm{C}$ NMR (100 MHz, DMSO) $\delta 170.85$, $163.59\left(\mathrm{dd},{ }^{1} J_{\mathrm{CF}}=246.4 \mathrm{~Hz},{ }^{1} J_{\mathrm{CF}}=13.1 \mathrm{~Hz}, 2 \mathrm{C}\right), 159.74,159.23$, $142.82\left(\mathrm{t},{ }^{2} J_{\mathrm{CF}}=9.1 \mathrm{~Hz}, 1 \mathrm{C}\right), 142.47,136.74,135.85,134.21$, $130.94,129.31,129.05,128.92,127.18,126.79,115.30,112.45$ $\left(\mathrm{dd},{ }^{2} J_{\mathrm{CF}}=19.2 \mathrm{~Hz},{ }^{4} J_{\mathrm{CF}}=6.1 \mathrm{~Hz}, 2 \mathrm{C}\right), 102.48\left(\mathrm{t},{ }^{3} J_{\mathrm{CF}}=25.3 \mathrm{~Hz}\right.$, 1C), 55.95, 51.69, 51.59, 37.83, 36.46, 19.08. ESI-MS: $\mathrm{m} / z$ 520.5 $(\mathrm{M}+\mathrm{H})^{+}, \mathrm{C}_{28} \mathrm{H}_{27} \mathrm{~F}_{2} \mathrm{~N}_{5} \mathrm{O}_{3}$ (519.21).

(S)-N-(3-(3,5-Difluorophenyl)-1-((4-methoxyphenyl)(methyl)amino)1-oxopropan-2-yl)-1-(4-methylbenzyl)-1H-1,2,3-triazole-4-carboxamide (I-8c). Pale green solid, yield: 69\%, mp: 82-84 ${ }^{\circ} \mathrm{C} .{ }^{1} \mathrm{H}$ NMR $(400$ MHz, DMSO- $\left.d_{6}\right) \delta 8.56(\mathrm{~s}, 1 \mathrm{H}), 8.50(\mathrm{~d}, J=8.1 \mathrm{~Hz}, 1 \mathrm{H}), 7.34(\mathrm{~d}, J=$ $8.4 \mathrm{~Hz}, 2 \mathrm{H}), 7.21$ (q, $J=8.0 \mathrm{~Hz}, 3 \mathrm{H}), 7.14-6.89$ (m, 4H), 6.62-6.43 $(\mathrm{m}, 2 \mathrm{H}), 5.59(\mathrm{~s}, 2 \mathrm{H}), 4.66(\mathrm{td}, J=9.0,4.2 \mathrm{~Hz}, 1 \mathrm{H}), 3.81(\mathrm{~s}, 3 \mathrm{H}), 3.15$ (s, 3H), 3.05-2.77 (m, 2H), 2.28 (s, 3H). ${ }^{13} \mathrm{C}$ NMR (100 MHz, DMSO) $\delta 170.85,163.59\left(\mathrm{dd},{ }^{1} J_{\mathrm{CF}}=246.4 \mathrm{~Hz},{ }^{3} J_{\mathrm{CF}}=13.1 \mathrm{~Hz}, 2 \mathrm{C}\right), 159.78$, $159.23,142.83\left(\mathrm{t},{ }^{2} J_{\mathrm{CF}}=9.1 \mathrm{~Hz}, 1 \mathrm{C}\right), 142.59,138.11,135.85,133.10$, $131.90,129.80,129.31,128.44,127.04,115.31,112.45\left(\mathrm{dd},{ }^{2} J_{\mathrm{CF}}=\right.$ $\left.19.2 \mathrm{~Hz},{ }^{4} J_{\mathrm{CF}}=6.1 \mathrm{~Hz}, 2 \mathrm{C}\right), 102.47\left(\mathrm{t},{ }^{3} J_{\mathrm{CF}}=25.3 \mathrm{~Hz}, 1 \mathrm{C}\right), 55.95$, 53.34, 51.57, 37.83, 36.45, 21.16. ESI-MS: $m / z 520.4(\mathrm{M}+\mathrm{H})^{+}$, $\mathrm{C}_{28} \mathrm{H}_{27} \mathrm{~F}_{2} \mathrm{~N}_{5} \mathrm{O}_{3}$ (519.21).

(S)-1-(2-Chlorobenzyl)-N-(3-(3,5-difluorophenyl)-1-((4-methoxyphenyl)(methyl)amino)-1-oxopropan-2-yl)-1H-1,2,3-triazole-4- 
carboxamide (I-8d). White solid, yield: $64 \%$, mp: $92-94{ }^{\circ} \mathrm{C} .{ }^{1} \mathrm{H}$ NMR (400 MHz, DMSO- $\left.d_{6}\right) \delta 8.54(\mathrm{~s}, 1 \mathrm{H}), 8.50(\mathrm{~d}, J=8.1 \mathrm{~Hz}, 1 \mathrm{H})$, $7.53(\mathrm{dd}, J=7.6,1.6 \mathrm{~Hz}, 1 \mathrm{H}), 7.47-7.36(\mathrm{~m}, 2 \mathrm{H}), 7.33$ (d, $J=$ $8.4 \mathrm{~Hz}, 2 \mathrm{H}), 7.25(\mathrm{dd}, J=7.3,2.0 \mathrm{~Hz}, 1 \mathrm{H}), 7.14-6.90(\mathrm{~m}, 3 \mathrm{H}), 6.51$ $(\mathrm{d}, J=7.7 \mathrm{~Hz}, 2 \mathrm{H}), 5.76(\mathrm{~s}, 2 \mathrm{H}), 4.67(\mathrm{td}, J=8.7,4.1 \mathrm{~Hz}, 1 \mathrm{H}), 3.81$ $(\mathrm{s}, 3 \mathrm{H}), 3.15(\mathrm{~s}, 3 \mathrm{H}), 3.05-2.77(\mathrm{~m}, 2 \mathrm{H}) .{ }^{13} \mathrm{C} \mathrm{NMR}(100 \mathrm{MHz}$, DMSO) $\delta 170.85,163.74\left(\mathrm{dd},{ }^{1} J_{\mathrm{CF}}=246.4 \mathrm{~Hz},{ }^{3} J_{\mathrm{CF}}=13 \mathrm{~Hz}, 2 \mathrm{C}\right)$, $159.70,159.24,142.41\left(\mathrm{t},{ }^{2} J_{\mathrm{CF}}=9 \mathrm{~Hz}, 1 \mathrm{C}\right), 135.86,133.31$, $133.11,131.02,130.87,130.15,129.31,128.25,127.58,115.32$, $112.46\left(\mathrm{dd},{ }^{2} J_{\mathrm{CF}}=19.2 \mathrm{~Hz},{ }^{4} J_{\mathrm{CF}}=6.1 \mathrm{~Hz}, 2 \mathrm{C}\right), 102.48\left(\mathrm{t},{ }^{3} J_{\mathrm{CF}}=\right.$ $25.3 \mathrm{~Hz}, 1 \mathrm{C}), 55.96,51.60,51.42,37.84,36.47$. ESI-MS: $\mathrm{m} / z$ 540.4 $(\mathrm{M}+\mathrm{H})^{+}, \mathrm{C}_{27} \mathrm{H}_{24} \mathrm{ClF}_{2} \mathrm{~N}_{5} \mathrm{O}_{5}$ (539.15).

(S)-1-(3-Chlorobenzyl)-N-(3-(3,5-difluorophenyl)-1-((4-methoxyphenyl)(methyl)amino)-1-oxopropan-2-yl)-1H-1,2,3-triazole-4carboxamide (I-8e). Pale yellow solid, yield: $65 \%$, mp: $75-77{ }^{\circ} \mathrm{C}$. ${ }^{1} \mathrm{H}$ NMR (400 MHz, DMSO- $\left.d_{6}\right) \delta 8.65(\mathrm{~s}, 1 \mathrm{H}), 8.54(\mathrm{~d}, J=8.1 \mathrm{~Hz}$, $1 \mathrm{H}), 7.50-7.40(\mathrm{~m}, 3 \mathrm{H}), 7.35(\mathrm{dd}, J=9.5,2.9 \mathrm{~Hz}, 2 \mathrm{H}), 7.28(\mathrm{td}, J=$ 5.1, $2.3 \mathrm{~Hz}, 1 \mathrm{H}), 7.06(\mathrm{~d}, J=8.6 \mathrm{~Hz}, 2 \mathrm{H}), 7.00(\mathrm{tt}, J=9.3,2.3 \mathrm{~Hz}$, $1 \mathrm{H}), 6.65-6.41(\mathrm{~m}, 2 \mathrm{H}), 5.68(\mathrm{~s}, 2 \mathrm{H}), 4.67(\mathrm{td}, J=8.9,4.0 \mathrm{~Hz}, 1 \mathrm{H})$, 3.81 (s, 3H), 3.15 (s, 3H), 3.06-2.81 (m, 2H). ${ }^{13} \mathrm{C}$ NMR $(100 \mathrm{MHz}$, DMSO) $\delta 170.83,163.73\left(\mathrm{dd},{ }^{1} J_{\mathrm{CF}}=246.4 \mathrm{~Hz},{ }^{3} J_{\mathrm{CF}}=13.1 \mathrm{~Hz}, 2 \mathrm{C}\right)$, $159.73,159.23,142.69\left(\mathrm{t},{ }^{2} J_{\mathrm{CF}}=9.1 \mathrm{~Hz}, 1 \mathrm{C}\right), 138.44,135.85$, $133.78,131.23,129.32,128.74,128.35,127.39,127.15,115.31$, $112.45\left(\mathrm{dd},{ }^{2} J_{\mathrm{CF}}=19.2 \mathrm{~Hz},{ }^{4} J_{\mathrm{CF}}=6.1 \mathrm{~Hz}, 2 \mathrm{C}\right), 102.48\left(\mathrm{t},{ }^{3} J_{\mathrm{CF}}=\right.$ $25.3 \mathrm{~Hz}, 1 \mathrm{C}), 55.95,52.76,51.61,37.84,36.44$. ESI-MS: $m / z 540.4$ $(\mathrm{M}+\mathrm{H})^{+}, \mathrm{C}_{27} \mathrm{H}_{24} \mathrm{ClF}_{2} \mathrm{~N}_{5} \mathrm{O}_{5}$ (539.15).

(S)-1-(4-chlorobenzyl)-N-(3-(3,5-difluorophenyl)-1-((4-methoxyphenyl)(methyl)amino)-1-oxopropan-2-yl)-1H-1,2,3-triazole-4-carboxamide (I-8f). White solid, yield: 74\%, mp: $86-88{ }^{\circ} \mathrm{C} .{ }^{1} \mathrm{H}$ NMR $(400 \mathrm{MHz}$, DMSO- $\left.d_{6}\right) \delta 8.62(\mathrm{~s}, 1 \mathrm{H}), 8.53(\mathrm{~d}, J=8.1 \mathrm{~Hz}, 1 \mathrm{H}), 7.45(\mathrm{~d}, J=$ $8.3 \mathrm{~Hz}, 2 \mathrm{H}), 7.35$ (dd, $J=8.5,4.4 \mathrm{~Hz}, 4 \mathrm{H}), 7.06$ (d, $J=8.5 \mathrm{~Hz}$, $2 \mathrm{H}), 7.00(\mathrm{tt}, J=9.5,2.4 \mathrm{~Hz}, 1 \mathrm{H}), 6.51(\mathrm{~h}, J=4.3 \mathrm{~Hz}, 2 \mathrm{H}), 5.66(\mathrm{~s}$, $2 \mathrm{H}), 4.67(\mathrm{td}, J=9.0,4.0 \mathrm{~Hz}, 1 \mathrm{H}), 3.81(\mathrm{~s}, 3 \mathrm{H}), 3.15(\mathrm{~s}, 3 \mathrm{H}), 3.04-$ $2.86(\mathrm{~m}, 2 \mathrm{H}) .{ }^{13} \mathrm{C}$ NMR (100 MHz, DMSO) $\delta 170.84,163.73$ (dd, $\left.{ }^{1} J_{\mathrm{CF}}=246.4 \mathrm{~Hz},{ }^{3} J_{\mathrm{CF}}=13 \mathrm{~Hz}, 2 \mathrm{C}\right), 159.75,159.24,142.67\left(\mathrm{t},{ }^{2} J_{\mathrm{CF}}\right.$ $=9.1 \mathrm{~Hz}, 1 \mathrm{C}$ ), 135.85, 135.07, 133.47, 130.37, 129.27, 127.29, 115.32, $112.45\left(\mathrm{dd},{ }^{2} J_{\mathrm{CF}}=19.2 \mathrm{~Hz},{ }^{4} J_{\mathrm{CF}}=6.1 \mathrm{~Hz}, 2 \mathrm{C}\right), 102.47(\mathrm{t}$, $\left.{ }^{3} J_{\mathrm{CF}}=25.3 \mathrm{~Hz}, 1 \mathrm{C}\right), 55.95,52.73,51.60,37.83,36.45$. ESI-MS: $\mathrm{m} / z$ $540.4(\mathrm{M}+\mathrm{H})^{+}, \mathrm{C}_{27} \mathrm{H}_{24} \mathrm{ClF}_{2} \mathrm{~N}_{5} \mathrm{O}_{5}$ (539.15).

(S)-1-(2-Cyanobenzyl)-N-(3-(3,5-difluorophenyl)-1-((4-methoxyphenyl)(methyl)amino)-1-oxopropan-2-yl)-1H-1,2,3-triazole-4carboxamide $(\mathbf{I}-\mathbf{8 g})$. Brownish yellow solid, yield: $78 \%, \mathrm{mp}$ : 80-82 ${ }^{\circ} \mathrm{C} .{ }^{1} \mathrm{H}$ NMR $\left(400 \mathrm{MHz}, \mathrm{DMSO}-d_{6}\right) \delta 8.63(\mathrm{~s}, 1 \mathrm{H}), 8.56$ $(\mathrm{d}, J=8.1 \mathrm{~Hz}, 1 \mathrm{H}), 7.97-7.89(\mathrm{~m}, 1 \mathrm{H}), 7.74(\mathrm{td}, J=7.7,1.3 \mathrm{~Hz}$, $1 \mathrm{H}), 7.58(\mathrm{t}, J=7.6 \mathrm{~Hz}, 1 \mathrm{H}), 7.37(\mathrm{dd}, J=14.4,8.2 \mathrm{~Hz}, 3 \mathrm{H})$, $7.07(\mathrm{~d}, J=8.4 \mathrm{~Hz}, 2 \mathrm{H}), 7.04-6.90(\mathrm{~m}, 1 \mathrm{H}), 6.64-6.34(\mathrm{~m}, 2 \mathrm{H})$, $5.88(\mathrm{~s}, 2 \mathrm{H}), 4.84-4.53(\mathrm{~m}, 1 \mathrm{H}), 3.82(\mathrm{~s}, 3 \mathrm{H}), 3.16(\mathrm{~s}, 3 \mathrm{H})$, 3.04-2.80 (m, 2H). ${ }^{13} \mathrm{C}$ NMR (100 MHz, DMSO) $\delta 170.84$, $163.73\left(\mathrm{dd},{ }^{1} J_{\mathrm{CF}}=246.4 \mathrm{~Hz},{ }^{3} J_{\mathrm{CF}}=13.1 \mathrm{~Hz}, 2 \mathrm{C}\right), 159.66$, $159.24,142.56\left(\mathrm{t},{ }^{2} J_{\mathrm{CF}}=9.1 \mathrm{~Hz}, 1 \mathrm{C}\right), 138.84,135.86,134.35$, $133.91,129.88,129.78,129.32,127.78,117.38,115.32$, $112.46\left(\mathrm{dd},{ }^{2} J_{\mathrm{CF}}=19.2 \mathrm{~Hz},{ }^{4} J_{\mathrm{CF}}=6.1 \mathrm{~Hz}, 2 \mathrm{C}\right), 111.65,102.48$ $\left(\mathrm{t},{ }^{3} J_{\mathrm{CF}}=25.3 \mathrm{~Hz}, 1 \mathrm{C}\right), 55.96,51.78,51.62,37.84,36.45$. ESIMS: $m / z 531.4(\mathrm{M}+\mathrm{H})^{+}, \mathrm{C}_{28} \mathrm{H}_{24} \mathrm{~F}_{2} \mathrm{~N}_{6} \mathrm{O}_{3}$ (530.19).

(S)-1-(3-Cyanobenzyl)-N-(3-(3,5-difluorophenyl)-1-((4-methoxyphenyl)(methyl)amino)-1-oxopropan-2-yl)-1H-1,2,3-triazole-4- carboxamide (I-8h). Pale yellow solid, yield: 67\%, mp: 79$81{ }^{\circ} \mathrm{C} .{ }^{1} \mathrm{H}$ NMR $\left(400 \mathrm{MHz}, \mathrm{DMSO}-d_{6}\right) \delta 8.71(\mathrm{~s}, 1 \mathrm{H}), 8.58(\mathrm{~d}, J$ $=8.7 \mathrm{~Hz}, 1 \mathrm{H}), 7.97-7.83(\mathrm{~m}, 2 \mathrm{H}), 7.67(\mathrm{dt}, J=15.2,7.8 \mathrm{~Hz}$, $2 \mathrm{H}), 7.39(\mathrm{~d}, J=8.6 \mathrm{~Hz}, 2 \mathrm{H}), 7.19-6.94(\mathrm{~m}, 3 \mathrm{H}), 6.72-6.44(\mathrm{~m}$, $2 \mathrm{H}), 5.78(\mathrm{~s}, 2 \mathrm{H}), 4.72(\mathrm{td}, J=8.9,4.0 \mathrm{~Hz}, 1 \mathrm{H}), 3.86(\mathrm{~s}, 3 \mathrm{H})$, 3.20 (s, 3H), 3.11-2.82 (m, 2H). ${ }^{13} \mathrm{C}$ NMR (100 MHz, DMSO) $\delta 170.82,163.73\left(\mathrm{dd},{ }^{1} J_{\mathrm{CF}}=246.4 \mathrm{~Hz},{ }^{3} J_{\mathrm{CF}}=13.1 \mathrm{~Hz}, 2 \mathrm{C}\right)$, $159.70,159.24,142.73\left(\mathrm{t},{ }^{2} J_{\mathrm{CF}}=9.1 \mathrm{~Hz}, 1 \mathrm{C}\right), 137.57,135.85$, $133.43,132.59,132.25,130.60,129.31,127.49,118.84$, $115.32,112.46\left(\mathrm{dd},{ }^{2} J_{\mathrm{CF}}=19.2 \mathrm{~Hz},{ }^{4} J_{\mathrm{CF}}=6.1 \mathrm{~Hz}, 2 \mathrm{C}\right), 102.47$ $\left(\mathrm{t},{ }^{3} J_{\mathrm{CF}}=25.3 \mathrm{~Hz}, 1 \mathrm{C}\right), 55.96,52.60,51.58,37.84,36.46$. ESIMS: $m / z 531.4(\mathrm{M}+\mathrm{H})^{+}, \mathrm{C}_{28} \mathrm{H}_{24} \mathrm{~F}_{2} \mathrm{~N}_{6} \mathrm{O}_{3}$ (530.19).

(S)-1-(4-Cyanobenzyl)-N-(3-(3,5-difluorophenyl)-1-((4-methoxyphenyl)(methyl)amino)-1-oxopropan-2-yl)-1H-1,2,3-triazole-4carboxamide (I-8i). White solid, yield: $75 \%$, mp: $82-84{ }^{\circ} \mathrm{C} .{ }^{1} \mathrm{H}$ NMR (400 MHz, DMSO- $\left.d_{6}\right) \delta 8.66(\mathrm{~s}, 1 \mathrm{H}), 8.55(\mathrm{~d}, J=8.1 \mathrm{~Hz}$, $1 \mathrm{H}), 7.87$ (d, $J=8.1 \mathrm{~Hz}, 2 \mathrm{H}), 7.48$ (d, $J=8.0 \mathrm{~Hz}, 2 \mathrm{H}), 7.43-$ $7.29(\mathrm{~m}, 2 \mathrm{H}), 7.07(\mathrm{~d}, J=8.6 \mathrm{~Hz}, 2 \mathrm{H}), 6.99(\mathrm{dt}, J=9.3,2.5 \mathrm{~Hz}$, $1 \mathrm{H}), 6.67-6.40(\mathrm{~m}, 2 \mathrm{H}), 5.78(\mathrm{~s}, 2 \mathrm{H}), 4.67(\mathrm{td}, J=8.9,3.9 \mathrm{~Hz}$, $1 \mathrm{H}), 3.81(\mathrm{~s}, 3 \mathrm{H}), 3.16(\mathrm{~s}, 3 \mathrm{H}), 3.11-2.77(\mathrm{~m}, 2 \mathrm{H}) .{ }^{13} \mathrm{C} \mathrm{NMR}$ (100 MHz, DMSO) $\delta 170.83,163.59\left(\mathrm{dd},{ }^{1} J_{\mathrm{CF}}=246.4 \mathrm{~Hz},{ }^{3} J_{\mathrm{CF}}\right.$ $=13.1 \mathrm{~Hz}, 2 \mathrm{C}), 159.71,159.24,142.73\left(\mathrm{t},{ }^{2} J_{\mathrm{CF}}=9.1 \mathrm{~Hz}, 1 \mathrm{C}\right)$, $141.50,135.85,133.24,129.32,129.19,127.65,118.96$, $115.32,112.45\left(\mathrm{dd},{ }^{2} J_{\mathrm{CF}}=19.2 \mathrm{~Hz},{ }^{4} J_{\mathrm{CF}}=6.1 \mathrm{~Hz}, 2 \mathrm{C}\right), 111.51$, $102.48\left(\mathrm{t},{ }^{3} J_{\mathrm{CF}}=25.3 \mathrm{~Hz}, 1 \mathrm{C}\right), 55.96,52.91,51.63,37.84$, 36.42. ESI-MS: $m / z 531.4(\mathrm{M}+\mathrm{H})^{+}, \mathrm{C}_{28} \mathrm{H}_{24} \mathrm{~F}_{2} \mathrm{~N}_{6} \mathrm{O}_{3}$ (530.19).

(S)-N-(3-(3,5-Difluorophenyl)-1-((4-methoxyphenyl)(methyl)amino)1-oxopropan-2-yl)-1-(2-nitrobenzyl)-1H-1,2,3-triazole-4-carboxamide (I-8j). Yellow solid, yield: 65\%, mp: $84-86{ }^{\circ} \mathrm{C} .{ }^{1} \mathrm{H}$ NMR $(400 \mathrm{MHz}$, DMSO- $\left.d_{6}\right) \delta 8.72-8.51(\mathrm{~m}, 2 \mathrm{H}), 8.17(\mathrm{dd}, J=8.2,1.3 \mathrm{~Hz}, 1 \mathrm{H}), 7.76$ $(\mathrm{td}, J=7.6,1.3 \mathrm{~Hz}, 1 \mathrm{H}), 7.66(\mathrm{td}, J=7.8,1.4 \mathrm{~Hz}, 1 \mathrm{H}), 7.35(\mathrm{~d}, J=$ $8.5 \mathrm{~Hz}, 2 \mathrm{H}), 7.17-6.92(\mathrm{~m}, 4 \mathrm{H}), 6.52(\mathrm{~h}, J=4.3 \mathrm{~Hz}, 2 \mathrm{H}), 6.03(\mathrm{~s}, 2 \mathrm{H})$, $4.68(\mathrm{td}, J=8.9,4.0 \mathrm{~Hz}, 1 \mathrm{H}), 3.82(\mathrm{~s}, 3 \mathrm{H}), 3.16(\mathrm{~s}, 3 \mathrm{H}), 3.06-2.82(\mathrm{~m}$, $2 \mathrm{H}) .{ }^{13} \mathrm{C}$ NMR (100 MHz, DMSO) $\delta 170.85,163.74\left(\mathrm{dd},{ }^{1} J_{\mathrm{CF}}=\right.$ $\left.246.4 \mathrm{~Hz},{ }^{3} J_{\mathrm{CF}}=13.1 \mathrm{~Hz}, 2 \mathrm{C}\right), 159.70,159.25,147.99,142.55\left(\mathrm{t},{ }^{2} J_{\mathrm{CF}}\right.$ $=9.1 \mathrm{~Hz}, 1 \mathrm{C}), 135.86,134.93,130.86,130.62,130.26,129.32$, 128.01, 125.64, 115.32, $112.46\left(\mathrm{dd},{ }^{2} J_{\mathrm{CF}}=19.2 \mathrm{~Hz},{ }^{4} J_{\mathrm{CF}}=6.1 \mathrm{~Hz}\right.$, 2C), $102.49\left(\mathrm{t},{ }^{3} J_{\mathrm{CF}}=25.3 \mathrm{~Hz}, 1 \mathrm{C}\right), 55.96,51.65,50.81,37.84,36.43$. ESI-MS: $m / z 551.4(\mathrm{M}+\mathrm{H})^{+}, \mathrm{C}_{27} \mathrm{H}_{24} \mathrm{~F}_{2} \mathrm{~N}_{6} \mathrm{O}_{5}$ (550.18).

(S)-N-(3-(3,5-Difluorophenyl)-1-((4-methoxyphenyl)(methyl)amino)1-oxopropan-2-yl)-1-(3-nitrobenzyl)-1H-1,2,3-triazole-4-carboxamide (I-8k). White solid, yield: 65\%, mp: $84-86{ }^{\circ} \mathrm{C} .{ }^{1} \mathrm{H}$ NMR $(400 \mathrm{MHz}$, DMSO- $\left.d_{6}\right) \delta 8.68(\mathrm{~s}, 1 \mathrm{H}), 8.50(\mathrm{~d}, J=8.1 \mathrm{~Hz}, 1 \mathrm{H}), 8.25(\mathrm{~d}, J=1.9 \mathrm{~Hz}$, $1 \mathrm{H}), 8.21(\mathrm{dd}, J=8.0,2.3 \mathrm{~Hz}, 1 \mathrm{H}), 7.78(\mathrm{~d}, J=7.7 \mathrm{~Hz}, 1 \mathrm{H}), 7.69(\mathrm{t}, J$ $=7.9 \mathrm{~Hz}, 1 \mathrm{H}), 7.33(\mathrm{~d}, J=8.4 \mathrm{~Hz}, 2 \mathrm{H}), 7.05(\mathrm{~d}, J=8.4 \mathrm{~Hz}, 2 \mathrm{H}), 6.98$ $(\mathrm{td}, J=9.4,4.6 \mathrm{~Hz}, 1 \mathrm{H}), 6.63-6.40(\mathrm{~m}, 2 \mathrm{H}), 5.83(\mathrm{~s}, 2 \mathrm{H}), 4.68(\mathrm{td}, J=$ 8.9, $4.1 \mathrm{~Hz}, 1 \mathrm{H}), 3.32$ (s, 3H), 3.15 (s, 3H), 3.06-2.80 (m, $2 \mathrm{H}) .{ }^{13} \mathrm{C}$ NMR (100 MHz, DMSO) $\delta 170.81,163.74\left(\mathrm{dd},{ }^{1} J_{\mathrm{CF}}=246.4 \mathrm{~Hz},{ }^{3} J_{\mathrm{CF}}\right.$ $=13.1 \mathrm{~Hz}, 2 \mathrm{C}), 159.68,159.25,148.39,142.76\left(\mathrm{t},{ }^{2} J_{\mathrm{CF}}=9.1 \mathrm{~Hz}, 1 \mathrm{C}\right)$, $135.86,135.21,130.93,129.29,127.54,123.72,123.38,115.33$, $112.46\left(\mathrm{dd},{ }^{2} J_{\mathrm{CF}}=19.2 \mathrm{~Hz},{ }^{4} J_{\mathrm{CF}}=6.1 \mathrm{~Hz}, 2 \mathrm{C}\right), 102.46\left(\mathrm{t},{ }^{3} J_{\mathrm{CF}}=\right.$ $25.3 \mathrm{~Hz}, 1 \mathrm{C}), 55.96,52.53,51.56,37.84,36.53$. ESI-MS: $m / z 551.3$ $(\mathrm{M}+\mathrm{H})^{+}, \mathrm{C}_{27} \mathrm{H}_{24} \mathrm{~F}_{2} \mathrm{~N}_{6} \mathrm{O}_{5}$ (550.18).

(S)-N-(3-(3,5-Difluorophenyl)-1-((4-methoxyphenyl)(methyl)amino)1-oxopropan-2-yl)-1-(4-nitrobenzyl)-1H-1,2,3-triazole-4-carboxamide (I-8l). Brown solid, yield: 63\%, mp: $182-184{ }^{\circ} \mathrm{C} .{ }^{1} \mathrm{H}$ NMR (400 
MHz, DMSO- $\left.d_{6}\right) \delta 8.67(\mathrm{~s}, 1 \mathrm{H}), 8.51(\mathrm{~d}, J=8.1 \mathrm{~Hz}, 1 \mathrm{H}), 8.24(\mathrm{~d}, J=$ $8.4 \mathrm{~Hz}, 2 \mathrm{H}), 7.55$ (d, $J=8.4 \mathrm{~Hz}, 2 \mathrm{H}), 7.34$ (d, $J=8.4 \mathrm{~Hz}, 2 \mathrm{H}), 7.06$ $(\mathrm{d}, J=8.5 \mathrm{~Hz}, 2 \mathrm{H}), 6.99(\mathrm{t}, J=9.3 \mathrm{~Hz}, 1 \mathrm{H}), 6.52(\mathrm{~d}, J=7.7 \mathrm{~Hz}, 2 \mathrm{H})$, $5.84(\mathrm{~s}, 2 \mathrm{H}), 4.69(\mathrm{dt}, J=8.8,4.5 \mathrm{~Hz}, 1 \mathrm{H}), 3.81(\mathrm{~s}, 3 \mathrm{H}), 3.16(\mathrm{~s}, 3 \mathrm{H})$, 3.05-2.82 (m, 2H). ${ }^{13} \mathrm{C}$ NMR (100 MHz, DMSO) $\delta$ 170.82, 163.75 $\left(\mathrm{dd},{ }^{1} J_{\mathrm{CF}}=246.4 \mathrm{~Hz},{ }^{3} J_{\mathrm{CF}}=13.1 \mathrm{~Hz}, 2 \mathrm{C}\right), 161.17,159.68,159.26$, $147.79,143.42,142.77\left(\mathrm{t},{ }^{2} J_{\mathrm{CF}}=9.1 \mathrm{~Hz}, 1 \mathrm{C}\right), 135.87,129.52,129.30$, $129.12,127.70,124.40,115.34,112.46\left(\mathrm{dd},{ }^{2} J_{\mathrm{CF}}=19.2 \mathrm{~Hz},{ }^{4} J_{\mathrm{CF}}=\right.$ $6.1 \mathrm{~Hz}, 2 \mathrm{C}), 102.47\left(\mathrm{t},{ }^{3} J_{\mathrm{CF}}=25.3 \mathrm{~Hz}, 1 \mathrm{C}\right), 55.97,52.66,51.58$, 37.84, 36.51. ESI-MS: $m / z 551.4(\mathrm{M}+\mathrm{H})^{+}, \mathrm{C}_{27} \mathrm{H}_{24} \mathrm{~F}_{2} \mathrm{~N}_{6} \mathrm{O}_{5}$ (550.18).

(S)-N-(3-(3,5-Difluorophenyl)-1-((4-methoxyphenyl)(methyl)amino)1-oxopropan-2-yl)-1-(naphthalen-1-ylmethyl)-1H-1,2,3-triazole-4carboxamide (I-8m). White solid, yield: $68 \%$, mp: $90-92{ }^{\circ} \mathrm{C} .{ }^{1} \mathrm{H}$ NMR (400 MHz, DMSO- $\left.d_{6}\right) \delta 8.54(\mathrm{~s}, 1 \mathrm{H}), 8.49(\mathrm{~d}, J=8.1 \mathrm{~Hz}$, $1 \mathrm{H}), 8.16(\mathrm{~d}, J=8.0 \mathrm{~Hz}, 1 \mathrm{H}), 7.99(\mathrm{dd}, J=9.6,7.6 \mathrm{~Hz}, 2 \mathrm{H}), 7.66-$ $7.46(\mathrm{~m}, 3 \mathrm{H}), 7.42(\mathrm{~d}, J=7.0 \mathrm{~Hz}, 1 \mathrm{H}), 7.31(\mathrm{~d}, J=8.4 \mathrm{~Hz}, 2 \mathrm{H})$, $7.12-6.89(\mathrm{~m}, 3 \mathrm{H}), 6.63-6.41(\mathrm{~m}, 2 \mathrm{H}), 6.15(\mathrm{~s}, 2 \mathrm{H}), 4.64(\mathrm{td}, J=$ 8.8, 4.2 Hz, 1H), $3.79(\mathrm{~s}, 3 \mathrm{H}), 3.13(\mathrm{~s}, 3 \mathrm{H}), 3.03-2.83(\mathrm{~m}, 2 \mathrm{H})$. ${ }^{13} \mathrm{C}$ NMR (100 MHz, DMSO) $\delta 170.83,163.72\left(\mathrm{dd},{ }^{1} J_{\mathrm{CF}}=\right.$ $\left.246.4 \mathrm{~Hz},{ }^{3} J_{\mathrm{CF}}=13.1 \mathrm{~Hz}, 2 \mathrm{C}\right), 159.70,159.22,142.48\left(\mathrm{t},{ }^{2} J_{\mathrm{CF}}=\right.$ $9.1 \mathrm{~Hz}, 1 \mathrm{C}), 135.84,133.83,131.55,130.97,129.65,129.28$, 129.19, 127.77, 127.34, 127.25, 126.69, 126.04, 123.58, 115.29, $112.20\left(\mathrm{dd},{ }^{2} J_{\mathrm{CF}}=19.2 \mathrm{~Hz},{ }^{4} J_{\mathrm{CF}}=6.1 \mathrm{~Hz}, 2 \mathrm{C}\right), 102.47\left(\mathrm{t},{ }^{3} J_{\mathrm{CF}}=\right.$ $25.3 \mathrm{~Hz}, 1 \mathrm{C}), 55.94,51.55,37.82$, 36.48. ESI-MS: $m / z 556.3(\mathrm{M}+$ $\mathrm{H})^{+}, \mathrm{C}_{31} \mathrm{H}_{27} \mathrm{~F}_{2} \mathrm{~N}_{5} \mathrm{O}_{3}$ (555.21).

(S)-N-(3-(3,5-Difluorophenyl)-1-((4-methoxyphenyl)(methyl)amino)1-oxopropan-2-yl)-1-(naphthalen-2-ylmethyl)-1H-1,2,3-triazole-4carboxamide (I-8n). White solid, yield: 67\%, mp: 89-91 ${ }^{\circ} \mathrm{C} .{ }^{1} \mathrm{H}$ NMR (400 MHz, DMSO- $\left.d_{6}\right) \delta 8.66(\mathrm{~s}, 1 \mathrm{H}), 8.50(\mathrm{~d}, J=8.1 \mathrm{~Hz}$, 1H), 7.99-7.89 (m, 3H), $7.87(\mathrm{~s}, 1 \mathrm{H}), 7.59-7.50(\mathrm{~m}, 2 \mathrm{H}), 7.45$ $(\mathrm{dd}, J=8.4,1.8 \mathrm{~Hz}, 1 \mathrm{H}), 7.33(\mathrm{~d}, J=8.4 \mathrm{~Hz}, 2 \mathrm{H}), 7.05(\mathrm{~d}, J=$ $8.5 \mathrm{~Hz}, 2 \mathrm{H}), 6.99(\mathrm{td}, J=8.2,7.0,4.6 \mathrm{~Hz}, 1 \mathrm{H}), 6.59-6.40(\mathrm{~m}$, $2 \mathrm{H}), 5.83(\mathrm{~s}, 2 \mathrm{H}), 4.67(\mathrm{td}, J=8.9,4.2 \mathrm{~Hz}, 1 \mathrm{H}), 3.80(\mathrm{~s}, 3 \mathrm{H}), 3.15$ (s, 3H), 3.06-2.81 (m, 2H). ${ }^{13} \mathrm{C}$ NMR (100 MHz, DMSO) $\delta 170.83,163.72\left(\mathrm{dd},{ }^{1} J_{\mathrm{CF}}=246.4 \mathrm{~Hz},{ }^{3} J_{\mathrm{CF}}=13.1 \mathrm{~Hz}, 2 \mathrm{C}\right.$ ), 159.76, 159.23, $142.65\left(\mathrm{t},{ }^{2} J_{\mathrm{CF}}=9.1 \mathrm{~Hz}, 1 \mathrm{C}\right), 135.86,133.58$, 133.21, 133.00, 129.30, 129.04, 128.30, 128.09, 127.41, 127.32, 127.07, 126.97, 126.07, 115.32, $112.21\left(\mathrm{dd},{ }^{2} J_{\mathrm{CF}}=19.2 \mathrm{~Hz},{ }^{4} J_{\mathrm{CF}}\right.$ $=6.1 \mathrm{~Hz}, 2 \mathrm{C}), 102.47\left(\mathrm{t},{ }^{3} J_{\mathrm{CF}}=25.3 \mathrm{~Hz}, 1 \mathrm{C}\right), 55.95,53.73,51.56$, 37.83, 36.51. ESI-MS: $m / z 556.3(\mathrm{M}+\mathrm{H})^{+}, \mathrm{C}_{31} \mathrm{H}_{27} \mathrm{~F}_{2} \mathrm{~N}_{5} \mathrm{O}_{3}$ (555.21).

(S)-N-(3-(3,5-Difluorophenyl)-1-((4-methoxyphenyl)(methyl)amino)1-oxopropan-2-yl)-1-(quinolin-2-yl)-1H-1,2,3-triazole-4-carboxamide (I-8o). White solid, yield: $71 \%, \mathrm{mp}: 205-207{ }^{\circ} \mathrm{C} .{ }^{1} \mathrm{H}$ NMR (400 MHz, DMSO- $\left.d_{6}\right) \delta 9.48(\mathrm{~d}, J=2.6 \mathrm{~Hz}, 1 \mathrm{H}), 9.44(\mathrm{~s}, 1 \mathrm{H}), 9.01(\mathrm{~d}, J=$ $2.6 \mathrm{~Hz}, 1 \mathrm{H}), 8.75$ (d, $J=8.1 \mathrm{~Hz}, 1 \mathrm{H}), 8.25-8.05$ (m, 2H), 7.90 (ddd, $J$ $=8.5,6.9,1.4 \mathrm{~Hz}, 1 \mathrm{H}), 7.83-7.69(\mathrm{~m}, 1 \mathrm{H}), 7.39(\mathrm{~d}, J=8.5 \mathrm{~Hz}, 2 \mathrm{H})$, 7.24-6.90 (m, 3H), 6.75-6.32 (m, 2H), 4.89-4.61 (m, 1H), 3.83 (s, $3 \mathrm{H}), 3.19$ (s, 3H), 3.16-2.84 (m, 2H). ${ }^{13} \mathrm{C}$ NMR (100 MHz, DMSO) $\delta 170.79,163.76\left(\mathrm{dd},{ }^{1} J_{\mathrm{CF}}=246.4 \mathrm{~Hz},{ }^{3} J_{\mathrm{CF}}=13.1 \mathrm{~Hz}, 2 \mathrm{C}\right), 159.44$, $159.27,147.55,143.87,143.56,142.86\left(\mathrm{t},{ }^{2} J_{\mathrm{CF}}=9.1 \mathrm{~Hz}, 1 \mathrm{C}\right), 135.88$, 131.22 , 130.31, 129.39, 129.19, 128.64, 127.39, 127.24, 126.20, $115.36,112.20\left(\mathrm{dd},{ }^{2} J_{\mathrm{CF}}=19.2 \mathrm{~Hz},{ }^{4} J_{\mathrm{CF}}=6.1 \mathrm{~Hz}, 2 \mathrm{C}\right), 102.52\left(\mathrm{t},{ }^{3} J_{\mathrm{CF}}\right.$ $=25.3 \mathrm{~Hz}, 1 \mathrm{C}), 55.97,51.75,37.90,36.46$. ESI-MS: $m / z 543.5(\mathrm{M}+$ $\mathrm{H})^{+}, \mathrm{C}_{29} \mathrm{H}_{24} \mathrm{~F}_{2} \mathrm{~N}_{6} \mathrm{O}_{3}$ (542.19).

Methyl (S)-4-(4-((3-(3,5-difluorophenyl)-1-((4-methoxyphenyl)(methyl) amino)-1-oxopropan-2-yl)carbamoyl)-1H-1,2,3-triazol-1-yl)benzoate (I- 8p). White solid, yield: $65 \%$, mp: $85-87{ }^{\circ} \mathrm{C} .{ }^{1} \mathrm{H}$ NMR $(400 \mathrm{MHz}$, DMSO- $\left.d_{6}\right) \delta 9.37(\mathrm{~s}, 1 \mathrm{H}), 8.70(\mathrm{~d}, J=8.1 \mathrm{~Hz}, 1 \mathrm{H}), 8.48(\mathrm{t}, J=1.8 \mathrm{~Hz}$, $1 \mathrm{H}), 8.29-8.18(\mathrm{~m}, 1 \mathrm{H}), 8.09$ (dd, $J=7.9,1.4 \mathrm{~Hz}, 1 \mathrm{H}), 7.78(\mathrm{t}, J=$ $8.0 \mathrm{~Hz}, 1 \mathrm{H}), 7.37$ (d, $J=8.5 \mathrm{~Hz}, 2 \mathrm{H}), 7.23-6.93(\mathrm{~m}, 3 \mathrm{H}), 6.66-6.41(\mathrm{~m}$, $2 \mathrm{H}), 4.73(\mathrm{td}, J=8.9,4.0 \mathrm{~Hz}, 1 \mathrm{H}, \mathrm{CHCO}), 3.92\left(\mathrm{~s}, 3 \mathrm{H}, \mathrm{COOCH}_{3}\right), 3.82$ $\left(\mathrm{s}, 3 \mathrm{H}, \mathrm{OCH}_{3}\right), 3.18\left(\mathrm{~s}, 3 \mathrm{H}, \mathrm{NCH}_{3}\right), 3.11-2.79\left(\mathrm{~m}, 2 \mathrm{H}, \mathrm{CH}_{2}\right) \cdot{ }^{13} \mathrm{C} \mathrm{NMR}$ (100 MHz, DMSO) $\delta 170.79,165.66,163.75\left(\mathrm{dd},{ }^{1} J_{\mathrm{CF}}=246.4 \mathrm{~Hz},{ }^{3} J_{\mathrm{CF}}\right.$ $=13.1 \mathrm{~Hz}, 2 \mathrm{C}), 159.44,159.26,143.49,142.83\left(\mathrm{t},{ }^{2} J_{\mathrm{CF}}=9.1 \mathrm{~Hz}, 1 \mathrm{C}\right)$, $136.97,135.87,131.73,131.08,130.01,129.34,125.73,125.50$, $121.26,115.34,112.26\left(\mathrm{dd},{ }^{2} J_{\mathrm{CF}}=19.2 \mathrm{~Hz},{ }^{4} J_{\mathrm{CF}}=6.1 \mathrm{~Hz}, 2 \mathrm{C}\right), 102.51$ $\left(\mathrm{t},{ }^{3} J_{\mathrm{CF}}=25.3 \mathrm{~Hz}, 1 \mathrm{C}\right), 55.96,53.07,51.71,37.88,36.49$. ESI-MS: $\mathrm{m} / \mathrm{z}$ $550.4(\mathrm{M}+\mathrm{H})^{+}, \mathrm{C}_{28} \mathrm{H}_{25} \mathrm{~F}_{2} \mathrm{~N}_{5} \mathrm{O}_{5}$ (549.18).

(S)-1-(Benzo[d][1,3]dioxol-5-yl)-N-(3-(3,5-difluorophenyl)-1-((4methoxyphenyl)(methyl)amino)-1-oxopropan-2-yl)-1H-1,2,3-triazole4-carboxamide (I-8q). White solid, yield: $78 \%$, mp: $83-85{ }^{\circ} \mathrm{C} .{ }^{1} \mathrm{H}$ NMR (400 MHz, DMSO- $\left.d_{6}\right) \delta 9.10(\mathrm{~s}, 1 \mathrm{H}), 8.62(\mathrm{~d}, J=8.0 \mathrm{~Hz}, 1 \mathrm{H})$, $7.54(\mathrm{~d}, J=2.2 \mathrm{~Hz}, 1 \mathrm{H}), 7.45-7.26(\mathrm{~m}, 3 \mathrm{H}), 7.10(\mathrm{dd}, J=16.7$, $8.5 \mathrm{~Hz}, 3 \mathrm{H}), 7.05-6.96(\mathrm{~m}, 1 \mathrm{H}), 6.66-6.46(\mathrm{~m}, 2 \mathrm{H}), 6.16(\mathrm{~s}, 2 \mathrm{H})$, $4.71(\mathrm{td}, J=8.9,4.0 \mathrm{~Hz}, 1 \mathrm{H}), 3.35(\mathrm{~s}, 3 \mathrm{H}), 3.17$ (s, 3H), 3.09-2.89 $(\mathrm{m}, 2 \mathrm{H}) .{ }^{13} \mathrm{C}$ NMR $(100 \mathrm{MHz}, \mathrm{DMSO}) \delta 170.81,163.75\left(\mathrm{dd},{ }^{1} J_{\mathrm{CF}}=\right.$ $\left.246.4 \mathrm{~Hz},{ }^{3} J_{\mathrm{CF}}=13.1 \mathrm{~Hz}, 2 \mathrm{C}\right), 159.57,159.26,148.63,148.29$, 143.12, $142.82\left(\mathrm{t},{ }^{2} J_{\mathrm{CF}}=9.1 \mathrm{~Hz}, 1 \mathrm{C}\right), 135.87,131.03,129.33$, $125.52,115.33,114.91,112.26\left(\mathrm{dd},{ }^{2} J_{\mathrm{CF}}=19.2 \mathrm{~Hz},{ }^{4} J_{\mathrm{CF}}=6.1 \mathrm{~Hz}\right.$, 2C), 109.10, 102.85, 102.71, 102.50, 102.20 (t, $\left.{ }^{3} J_{\mathrm{CF}}=25.3 \mathrm{~Hz}, 1 \mathrm{C}\right)$, 55.96, 51.65, 37.87, 36.51. ESI-MS: $m / z 536.3(\mathrm{M}+\mathrm{H})^{+}$, $\mathrm{C}_{27} \mathrm{H}_{23} \mathrm{~F}_{2} \mathrm{~N}_{5} \mathrm{O}_{5}$ (535.17).

(S)-N-(3-(3,5-Difluorophenyl)-1-((4-methoxyphenyl)(methyl)amino)1-oxopropan-2-yl)-1-(4-sulfamoylbenzyl)-1H-1,2,3-triazole-4-carboxamide (I-8r). White solid, yield: $80 \%$, mp: $107-109{ }^{\circ} \mathrm{C} .{ }^{1} \mathrm{H}$ NMR (400 MHz, DMSO- $\left.d_{6}\right) \delta 8.65(\mathrm{~s}, 1 \mathrm{H}), 8.54(\mathrm{~d}, J=8.1 \mathrm{~Hz}, 1 \mathrm{H}), 7.83(\mathrm{~d}, J$ $=8.1 \mathrm{~Hz}, 2 \mathrm{H}), 7.48(\mathrm{~d}, J=8.1 \mathrm{~Hz}, 2 \mathrm{H}), 7.42-7.31(\mathrm{~m}, 4 \mathrm{H}), 7.12-$ $6.96(\mathrm{~m}, 3 \mathrm{H}), 6.62-6.39(\mathrm{~m}, 2 \mathrm{H}), 5.76(\mathrm{~s}, 2 \mathrm{H}), 4.67(\mathrm{~d}, J=3.8 \mathrm{~Hz}$, $1 \mathrm{H}), 3.81$ (s, 3H), 3.15 (s, 3H), 3.05-2.80 (m, 2H). ${ }^{13} \mathrm{C}$ NMR $(100$ $\mathrm{MHz}, \mathrm{DMSO}) \delta 170.84,163.60\left(\mathrm{dd},{ }^{1} J_{\mathrm{CF}}=246.4 \mathrm{~Hz},{ }^{3} J_{\mathrm{CF}}=\right.$ $13.1 \mathrm{~Hz}, 2 \mathrm{C}), 159.74,159.24,144.36,142.70\left(\mathrm{t},{ }^{2} J_{\mathrm{CF}}=9.1 \mathrm{~Hz}, 1 \mathrm{C}\right)$, $139.84,135.85,129.32,128.83,127.51,126.64,115.32,112.46$ $\left(\mathrm{dd},{ }^{2} J_{\mathrm{CF}}=19.2 \mathrm{~Hz},{ }^{4} J_{\mathrm{CF}}=6.1 \mathrm{~Hz}, 2 \mathrm{C}\right), 102.49\left(\mathrm{t},{ }^{3} J_{\mathrm{CF}}=25.3 \mathrm{~Hz}\right.$, 1C), 55.96, 52.92, 51.62, 37.84, 36.43. ESI-MS: $m / z 585.3(\mathrm{M}+$ $\mathrm{H})^{+}, \mathrm{C}_{27} \mathrm{H}_{26} \mathrm{~F}_{2} \mathrm{~N}_{6} \mathrm{O}_{5} \mathrm{~S}$ (584.17).

(S)-1-(4-Carbamoylbenzyl)-N-(3-(3,5-difluorophenyl)-1-((4-methoxy phenyl)(methyl)amino)-1-oxopropan-2-yl)-1H-1,2,3-triazole-4-carboxami de (I-8s). White solid, yield: 76\%, mp: $109-111{ }^{\circ} \mathrm{C} .{ }^{1} \mathrm{H}$ NMR $(400$ MHz, DMSO- $\left.d_{6}\right) \delta 8.63(\mathrm{~s}, 1 \mathrm{H}), 8.51(\mathrm{~d}, J=8.1 \mathrm{~Hz}, 1 \mathrm{H}), 7.98(\mathrm{~s}$, $1 \mathrm{H}), 7.87(\mathrm{~d}, J=7.9 \mathrm{~Hz}, 2 \mathrm{H}), 7.37(\mathrm{dt}, J=13.8,7.2 \mathrm{~Hz}, 5 \mathrm{H}), 7.15-$ $6.93(\mathrm{~m}, 3 \mathrm{H}), 6.52(\mathrm{~d}, J=7.7 \mathrm{~Hz}, 2 \mathrm{H}), 5.72(\mathrm{~s}, 2 \mathrm{H}), 4.68(\mathrm{td}, J=$ 9.0, $4.1 \mathrm{~Hz}, 1 \mathrm{H}), 3.82(\mathrm{~s}, 3 \mathrm{H}), 3.16(\mathrm{~s}, 3 \mathrm{H}), 3.07-2.81(\mathrm{~m}, 2 \mathrm{H}) .{ }^{13} \mathrm{C}$ NMR (100 MHz, DMSO) $\delta 170.84,167.86,163.74\left(\mathrm{dd},{ }^{1} J_{\mathrm{CF}}=\right.$ $\left.246.4 \mathrm{~Hz},{ }^{3} J_{\mathrm{CF}}=13.1 \mathrm{~Hz}, 2 \mathrm{C}\right), 159.74,159.24,142.67\left(\mathrm{t},{ }^{2} J_{\mathrm{CF}}=\right.$ $9.1 \mathrm{~Hz}, 1 \mathrm{C}), 139.06,135.86,134.66,129.31,128.42,128.15$, 127.38, 115.33, $112.47\left(\mathrm{dd},{ }^{2} J_{\mathrm{CF}}=19.2 \mathrm{~Hz},{ }^{4} J_{\mathrm{CF}}=6.1 \mathrm{~Hz}, 2 \mathrm{C}\right)$, $102.48\left(\mathrm{t},{ }^{3} J_{\mathrm{CF}}=25.3 \mathrm{~Hz}, 1 \mathrm{C}\right), 55.96,53.14,51.58,37.85,36.50$. ESI-MS: $m / z 549.4(\mathrm{M}+\mathrm{H})^{+}, \mathrm{C}_{27} \mathrm{H}_{26} \mathrm{~F}_{2} \mathrm{~N}_{6} \mathrm{O}_{4}$ (548.20).

(S)-N-(3-(3,5-Difluorophenyl)-1-((4-methoxyphenyl)(methyl)amino)1-oxopropan-2-yl)-1-((phenylsulfonyl)methyl)-1H-1,2,3-triazole-4carboxamide (I-8t). White solid, yield: $62 \%$, mp: $95-97{ }^{\circ} \mathrm{C} .{ }^{1} \mathrm{H}$ NMR (400 MHz, DMSO- $\left.d_{6}\right) \delta 8.71(\mathrm{~d}, J=8.0 \mathrm{~Hz}, 1 \mathrm{H}), 8.49$ (s, 
1H), 7.96-7.78 (m, 1H), 7.75-7.69 (m, 2H), $7.65(\mathrm{t}, J=7.7 \mathrm{~Hz}$, $2 \mathrm{H}), 7.37$ (d, $J=8.5 \mathrm{~Hz}, 2 \mathrm{H}), 7.08(\mathrm{~d}, J=8.6 \mathrm{~Hz}, 2 \mathrm{H}), 7.05-6.96$ $(\mathrm{m}, 1 \mathrm{H}), 6.65-6.47(\mathrm{~m}, 2 \mathrm{H}), 6.40(\mathrm{~d}, J=2.6 \mathrm{~Hz}, 2 \mathrm{H}), 4.64(\mathrm{td}, J=$ 9.0, 3.9 Hz, 1H), $3.82(\mathrm{~s}, 3 \mathrm{H}), 3.17(\mathrm{~s}, 3 \mathrm{H}), 3.02-2.76(\mathrm{~m}, 2 \mathrm{H})$. ${ }^{13} \mathrm{C}$ NMR (100 MHz, DMSO) $\delta 170.80,163.60\left(\mathrm{dd},{ }^{1} J_{\mathrm{CF}}=\right.$ $\left.246.4 \mathrm{~Hz},{ }^{3} J_{\mathrm{CF}}=13.1 \mathrm{~Hz}, 2 \mathrm{C}\right), 159.26,159.21,142.49\left(\mathrm{t},{ }^{2} J_{\mathrm{CF}}=\right.$ $9.1 \mathrm{~Hz}, 1 \mathrm{C}), 136.22,135.85,135.48,130.07,129.35,129.00$, 128.57, 115.33, $112.43\left(\mathrm{dd},{ }^{2} J_{\mathrm{CF}}=19.2 \mathrm{~Hz},{ }^{4} J_{\mathrm{CF}}=6.1 \mathrm{~Hz}, 2 \mathrm{C}\right)$, $102.52\left(\mathrm{t},{ }^{3} J_{\mathrm{CF}}=25.3 \mathrm{~Hz}, 1 \mathrm{C}\right), 67.45,55.97,51.83,37.85,36.26$. ESI-MS: $m / z 570.4(\mathrm{M}+\mathrm{H})^{+}, \mathrm{C}_{27} \mathrm{H}_{25} \mathrm{~F}_{2} \mathrm{~N}_{5} \mathrm{O}_{5} \mathrm{~S}$ (569.15).

$N$-((S)-3-(3,5-Difluorophenyl)-1-((4-methoxyphenyl)(methyl) amino)-1-oxopropan-2-yl)-1-(2-(hydroxymethyl)-5-(5-methyl-2,6dioxo-1,2,3,6-tetrahydropyridin-3-yl)tetrahydrofuran-3-yl)- $1 H$ 1,2,3-triazole-4-carboxamide (I-8u).

White solid, yield: $66 \%$, mp: $142-144{ }^{\circ} \mathrm{C} .{ }^{1} \mathrm{H}$ NMR $(400 \mathrm{MHz}$, DMSO- $\left.d_{6}\right) \delta 11.38(\mathrm{~s}, 1 \mathrm{H}), 8.73(\mathrm{~s}, 1 \mathrm{H}), 8.55(\mathrm{~d}, J=8.2 \mathrm{~Hz}, 1 \mathrm{H})$, $7.82(\mathrm{~s}, 1 \mathrm{H}), 7.36(\mathrm{~d}, J=8.4 \mathrm{~Hz}, 2 \mathrm{H}), 7.16-6.93(\mathrm{~m}, 3 \mathrm{H}), 6.64-6.48$ $(\mathrm{m}, 2 \mathrm{H}), 6.42(\mathrm{t}, J=6.6 \mathrm{~Hz}, 1 \mathrm{H}), 5.54-5.34(\mathrm{~m}, 1 \mathrm{H}), 5.29(\mathrm{t}, J=$ $5.2 \mathrm{~Hz}, 1 \mathrm{H}), 4.69$ (d, $J=3.9 \mathrm{~Hz}, 1 \mathrm{H}), 4.34-4.16(\mathrm{~m}, 1 \mathrm{H}), 3.82(\mathrm{~s}$, $3 \mathrm{H}), 3.66(\mathrm{dt}, J=20.3,4.7 \mathrm{~Hz}, 2 \mathrm{H}), 3.16(\mathrm{~s}, 3 \mathrm{H}), 3.06-2.84(\mathrm{~m}$, 2H), 2.83-2.59 (m, 2H), 1.82 (s, 3H). ${ }^{13} \mathrm{C} \mathrm{NMR} \mathrm{(100} \mathrm{MHz,} \mathrm{DMSO)}$ $\delta 170.84,164.20\left(\mathrm{dd},{ }^{1} J_{\mathrm{CF}}=246.4 \mathrm{~Hz},{ }^{3} J_{\mathrm{CF}}=13.1 \mathrm{~Hz}, 2 \mathrm{C}\right), 159.74$, 159.25, 150.89, $142.61\left(\mathrm{t},{ }^{2} J_{\mathrm{CF}}=9.1 \mathrm{~Hz}, 1 \mathrm{C}\right), 136.73,135.85$, $129.33,126.83,115.34,112.46\left(\mathrm{dd},{ }^{2} J_{\mathrm{CF}}=19.2 \mathrm{~Hz},{ }^{4} J_{\mathrm{CF}}=6.1 \mathrm{~Hz}\right.$, 2C), 110.12, $102.49\left(\mathrm{t},{ }^{3} J_{\mathrm{CF}}=25.3 \mathrm{~Hz}, 1 \mathrm{C}\right), 84.72,84.28,61.09$, 60.06, 55.97, 51.59, 37.85, 36.46, 12.73. ESI-MS: $m / z 640.4(\mathrm{M}+$ $\mathrm{H})^{+}, \mathrm{C}_{30} \mathrm{H}_{31} \mathrm{~F}_{2} \mathrm{~N}_{7} \mathrm{O}_{7}(639.23)$.

4.1.5. (S)-N-(3-(3,5-Difluorophenyl)-1-((4-methoxyphenyl)(methyl)amino)-1-oxopropan-2-yl)-3-ethynylbenzamide (9). 3Ethynylbenzoic acid (4.22 mmol, $0.62 \mathrm{~g}$ ) and HATU (5.28 mmol, $2.0 \mathrm{~g}$ ) were mixed in dichloromethane and stirred in an ice bath for $1 \mathrm{~h}$. Then, the intermediate $6(6.33 \mathrm{mmol}, 2.35 \mathrm{~g})$ and DIEA $(7.03 \mathrm{mmol}, 1.16 \mathrm{~mL})$ were added to the above solution slowly at $0{ }^{\circ} \mathrm{C}$. The reaction system was then stirred at room temperature for additional $12 \mathrm{~h}$. The solvent was removed under reduced pressure and then $1 \mathrm{~N} \mathrm{HCl}(30 \mathrm{~mL})$ was added, extracted with ethyl acetate $(3 \times 30 \mathrm{~mL})$. The combined organic layer was washed with saturated sodium bicarbonate $(3 \times 50 \mathrm{~mL})$. The resulting organic layer was washed with saturated salt water, dried over anhydrous $\mathrm{Na}_{2} \mathrm{SO}_{4}$, filtered, and concentrated under reduced pressure to afford corresponding crude product, which was purified by flash column chromatography to yield compound 9 as pale yellow solid with the yield of $39 \% .{ }^{1} \mathrm{H}$ NMR $\left(400 \mathrm{MHz}, \mathrm{DMSO}-d_{6}\right) \delta 8.85(\mathrm{~d}, J=7.9 \mathrm{~Hz}, 1 \mathrm{H}), 7.95(\mathrm{t}, J=1.7 \mathrm{~Hz}$, $1 \mathrm{H}), 7.82(\mathrm{dt}, J=7.8,1.5 \mathrm{~Hz}, 1 \mathrm{H}), 7.64(\mathrm{dt}, J=7.6,1.4 \mathrm{~Hz}, 1 \mathrm{H})$, $7.49(\mathrm{t}, J=7.7 \mathrm{~Hz}, 1 \mathrm{H}), 7.40(\mathrm{~d}, J=8.4 \mathrm{~Hz}, 2 \mathrm{H}), 7.10(\mathrm{~s}, 1 \mathrm{H}), 7.05-$ $6.96(\mathrm{~m}, 1 \mathrm{H}), 6.61-6.35(\mathrm{~m}, 2 \mathrm{H}), 4.74-4.55(\mathrm{~m}, 1 \mathrm{H}), 4.32(\mathrm{~s}, 1 \mathrm{H})$, $3.82(\mathrm{~s}, 3 \mathrm{H}), 3.17$ (s, 3H), 3.01-2.84 (m, 2H), $2.69(\mathrm{~s}, 1 \mathrm{H}) .{ }^{13} \mathrm{C}$ NMR (100 MHz, DMSO) $\delta 171.16,165.82,163.62\left(\mathrm{dd},{ }^{1} J_{\mathrm{CF}}=\right.$ $\left.246.4 \mathrm{~Hz},{ }^{3} J_{\mathrm{CF}}=13.1 \mathrm{~Hz}, 2 \mathrm{C}\right), 159.24,143.12\left(\mathrm{t},{ }^{2} J_{\mathrm{CF}}=9.1 \mathrm{~Hz}\right.$, 1C), 135.95, 134.91, 134.41, 130.92, 129.35, 128.50, 122.20, 115.31, $112.08\left(\mathrm{dd},{ }^{2} J_{\mathrm{CF}}=19.2 \mathrm{~Hz},{ }^{4} J_{\mathrm{CF}}=6.1 \mathrm{~Hz}, 2 \mathrm{C}\right), 102.49(\mathrm{t}$, $\left.{ }^{3} J_{\mathrm{CF}}=25.3 \mathrm{~Hz}, 1 \mathrm{C}\right) 83.24,81.96,55.97,52.73,38.70,37.84,36.21$. ESI-MS: $m / z 447.07(\mathrm{M}-\mathrm{H})^{-}, \mathrm{C}_{26} \mathrm{H}_{22} \mathrm{~F}_{2} \mathrm{~N}_{2} \mathrm{O}_{3}$ (448.16).

4.1.6. General procedure for the synthesis of target compounds II-10(a-o). The key intermediate 9 (1.0 eq.), azide substituents (1.1 eq.), ascorbic acid sodium (0.6 eq.) and
$\mathrm{CuSO}_{4} \cdot 5 \mathrm{H}_{2} \mathrm{O}$ (0.3 eq.) were dissolved in the solution of tetrahydrofuran/water $(\mathrm{v}: \mathrm{v}=1: 1)$. The resulting mixture was stirred at $30-60{ }^{\circ} \mathrm{C}$ for $4-6 \mathrm{~h}$. Then the reaction mixture was extracted with ethyl acetate $(3 \times 10 \mathrm{~mL})$, and the combined organic phase was washed with saturated salt water $(3 \times 10$ $\mathrm{mL}$ ), dried over anhydrous $\mathrm{MgSO}_{4}$, filtered, and concentrated under reduced pressure to give the corresponding crude target product, which was purified by flash column chromatography to afford product II-10(a-o). Yield: $65-80 \%$.

(S)-N-(3-(3,5-Difluorophenyl)-1-((4-methoxyphenyl)(methyl)amino)1-oxopropan-2-yl)-3-(1-(2-nitrobenzyl)-1H-1,2,3-triazol-4-yl)benzamide (II-10a). Pale yellow solid, yield: 78\%, mp: 70-72 ${ }^{\circ} \mathrm{C} .{ }^{1} \mathrm{H}$ NMR (400 MHz, DMSO- $\left.d_{6}\right) \delta 8.87(\mathrm{~d}, J=7.8 \mathrm{~Hz}, 1 \mathrm{H}), 8.67(\mathrm{~s}, 1 \mathrm{H}), 8.32(\mathrm{t}, J=$ $1.8 \mathrm{~Hz}, 1 \mathrm{H}), 8.19$ (dd, $J=8.2,1.3 \mathrm{~Hz}, 1 \mathrm{H}), 8.01$ (d, $J=7.7 \mathrm{~Hz}, 1 \mathrm{H})$, $7.78(\mathrm{td}, J=7.6,1.4 \mathrm{~Hz}, 2 \mathrm{H}), 7.71-7.62(\mathrm{~m}, 1 \mathrm{H}), 7.55(\mathrm{t}, J=7.8 \mathrm{~Hz}$, $1 \mathrm{H}), 7.40(\mathrm{~d}, J=8.4 \mathrm{~Hz}, 2 \mathrm{H}), 7.19(\mathrm{~d}, J=7.7 \mathrm{~Hz}, 1 \mathrm{H}), 7.09$ (d, $J=$ $8.4 \mathrm{~Hz}, 2 \mathrm{H}), 7.06-6.87(\mathrm{~m}, 1 \mathrm{H}), 6.63-6.48(\mathrm{~m}, 2 \mathrm{H}), 6.06(\mathrm{~s}, 2 \mathrm{H})$, 4.74-4.63 (m, 1H), 3.82 (s, 3H), 3.18 (s, 3H), 2.98 (h, $J=9.3,8.9 \mathrm{~Hz}$, $2 \mathrm{H}) .{ }^{13} \mathrm{C}$ NMR (100 MHz, DMSO) $\delta 171.30,166.50,163.75\left(\mathrm{dd},{ }^{1} J_{\mathrm{CF}}\right.$ $\left.=246.4 \mathrm{~Hz},{ }^{3} J_{\mathrm{CF}}=13.1 \mathrm{~Hz}, 2 \mathrm{C}\right), 159.22,148.06,146.50,143.15(\mathrm{t}$, $\left.{ }^{2} J_{\mathrm{CF}}=9.1 \mathrm{~Hz}, 1 \mathrm{C}\right), 135.99,134.96,134.75,131.10,131.06,130.78$, 130.22 , 129.41, 129.36, 128.56, 127.39, 125.63, 124.76, 123.12, $115.28,112.37\left(\mathrm{dd},{ }^{2} J_{\mathrm{CF}}=19.2 \mathrm{~Hz},{ }^{4} J_{\mathrm{CF}}=6.1 \mathrm{~Hz}, 2 \mathrm{C}\right), 102.49\left(\mathrm{t},{ }^{3} J_{\mathrm{CF}}\right.$ $=25.3 \mathrm{~Hz}, 1 \mathrm{C}), 55.97,52.67,50.74,37.84,36.31$. ESI-MS: $m / z 627.3$ $(\mathrm{M}+\mathrm{H})^{+}, \mathrm{C}_{33} \mathrm{H}_{28} \mathrm{~F}_{2} \mathrm{~N}_{6} \mathrm{O}_{5}$ (626.61).

(S)-N-(3-(3,5-Difluorophenyl)-1-((4-methoxyphenyl)(methyl)amino)1-oxopropan-2-yl)-3-(1-(3-nitrobenzyl)-1H-1,2,3-triazol-4-yl)benzamide (II-10b). Pale yellow solid, yield: $72 \%$, mp: $69-71{ }^{\circ} \mathrm{C} .{ }^{1} \mathrm{H}$ NMR (400 MHz, DMSO- $\left.d_{6}\right) \delta 8.86(\mathrm{~d}, J=7.8 \mathrm{~Hz}, 1 \mathrm{H}), 8.76(\mathrm{~s}, 1 \mathrm{H}), 8.42-8.28$ $(\mathrm{m}, 2 \mathrm{H}), 8.24(\mathrm{dd}, J=8.2,2.3 \mathrm{~Hz}, 1 \mathrm{H}), 8.00(\mathrm{~d}, J=7.7 \mathrm{~Hz}, 1 \mathrm{H}), 7.83$ $(\mathrm{d}, J=7.7 \mathrm{~Hz}, 1 \mathrm{H}), 7.77(\mathrm{~d}, J=7.8 \mathrm{~Hz}, 1 \mathrm{H}), 7.72(\mathrm{t}, J=8.0 \mathrm{~Hz}, 1 \mathrm{H})$, $7.55(\mathrm{t}, J=7.8 \mathrm{~Hz}, 1 \mathrm{H}), 7.40(\mathrm{~d}, J=8.3 \mathrm{~Hz}, 2 \mathrm{H}), 7.09(\mathrm{~d}, J=8.4 \mathrm{~Hz}$, $2 \mathrm{H}), 7.01(\mathrm{tt}, J=9.6,2.4 \mathrm{~Hz}, 1 \mathrm{H}), 6.65-6.46(\mathrm{~m}, 2 \mathrm{H}), 5.88(\mathrm{~s}, 2 \mathrm{H})$, $4.67(\mathrm{td}, J=8.5,4.6 \mathrm{~Hz}, 1 \mathrm{H}), 3.82(\mathrm{~s}, 3 \mathrm{H}), 3.18(\mathrm{~s}, 3 \mathrm{H}), 2.98$ (h, $J=$ $9.3 \mathrm{~Hz}, 2 \mathrm{H}) .{ }^{13} \mathrm{C}$ NMR (100 MHz, DMSO) $\delta$ 171.30, 166.50, 163.75 $\left(\mathrm{dd},{ }^{1} J_{\mathrm{CF}}=246.4 \mathrm{~Hz},{ }^{3} J_{\mathrm{CF}}=13.1 \mathrm{~Hz}, 2 \mathrm{C}\right), 159.22,148.39,146.70$, $143.15\left(\mathrm{t},{ }^{2} J_{\mathrm{CF}}=9.1 \mathrm{~Hz}, 1 \mathrm{C}\right), 138.41,135.99,135.25,134.76,131.07$, $130.97,129.40,129.35,128.52,127.35,124.76,123.69,123.39$, 122.66, 115.28, 112.37 (dd, ${ }^{2} J_{\mathrm{CF}}=19.2 \mathrm{~Hz},{ }^{4} J_{\mathrm{CF}}=6.1 \mathrm{~Hz}, 2 \mathrm{C}$ ), $102.48\left(\mathrm{t},{ }^{3} J_{\mathrm{CF}}=25.3 \mathrm{~Hz}, 1 \mathrm{C}\right), 65.50,55.96,52.67,52.52,37.84$, 36.29. ESI-MS: $m / z 627.3(\mathrm{M}+\mathrm{H})^{+}, \mathrm{C}_{33} \mathrm{H}_{28} \mathrm{~F}_{2} \mathrm{~N}_{6} \mathrm{O}_{5}(626.61)$.

(S)-N-(3-(3,5-Difluorophenyl)-1-((4-methoxyphenyl)(methyl)amino)1-oxopropan-2-yl)-3-(1-(4-nitrobenzyl)-1H-1,2,3-triazol-4-yl)benzamide (II-10c). Yellow solid, yield: 77\%, mp: $82-84{ }^{\circ} \mathrm{C}$. ${ }^{1} \mathrm{H}$ NMR $(400 \mathrm{MHz}$, DMSO- $\left.d_{6}\right) \delta 8.86(\mathrm{~d}, J=7.9 \mathrm{~Hz}, 1 \mathrm{H}), 8.76(\mathrm{~s}, 1 \mathrm{H}), 8.33(\mathrm{~s}, 1 \mathrm{H}), 8.27$ $(\mathrm{d}, J=8.4 \mathrm{~Hz}, 2 \mathrm{H}), 8.00(\mathrm{~d}, J=7.7 \mathrm{~Hz}, 1 \mathrm{H}), 7.78(\mathrm{~d}, J=7.8 \mathrm{~Hz}, 1 \mathrm{H})$, $7.64-7.50(\mathrm{~m}, 3 \mathrm{H}), 7.40(\mathrm{~d}, J=8.3 \mathrm{~Hz}, 2 \mathrm{H}), 7.09(\mathrm{~d}, J=8.4 \mathrm{~Hz}, 2 \mathrm{H})$, $7.01(\mathrm{td}, J=8.3,7.4,4.7 \mathrm{~Hz}, 1 \mathrm{H}), 6.66-6.38(\mathrm{~m}, 2 \mathrm{H}), 5.88(\mathrm{~s}, 2 \mathrm{H})$, $4.67(\mathrm{td}, J=8.7,4.6 \mathrm{~Hz}, 1 \mathrm{H}), 3.82(\mathrm{~s}, 3 \mathrm{H}), 3.18(\mathrm{~s}, 3 \mathrm{H}), 2.98$ (h, $J=$ 9.3, $8.8 \mathrm{~Hz}, 2 \mathrm{H}) .{ }^{13} \mathrm{C}$ NMR (100 MHz, DMSO) $\delta$ 171.30, 166.49, $163.76\left(\mathrm{dd},{ }^{1} J_{\mathrm{CF}}=246.4 \mathrm{~Hz},{ }^{3} J_{\mathrm{CF}}=13.1 \mathrm{~Hz}, 2 \mathrm{C}\right), 159.23,147.74$, $146.72,143.79,143.16\left(\mathrm{t},{ }^{2} J_{\mathrm{CF}}=9.1 \mathrm{~Hz}, 1 \mathrm{C}\right), 135.99,134.75,131.06$, 129.52 , 129.41, 129.36, 128.53, 127.37, 124.77, 124.45, 122.84, $115.28,112.37\left(\mathrm{dd},{ }^{2} J_{\mathrm{CF}}=19.1 \mathrm{~Hz},{ }^{4} J_{\mathrm{CF}}=6.1 \mathrm{~Hz}, 2 \mathrm{C}\right), 102.49\left(\mathrm{t},{ }^{3} J_{\mathrm{CF}}\right.$ $=25.3 \mathrm{~Hz}, 1 \mathrm{C}), 65.50,55.97,52.66,37.84$, 36.30. ESI-MS: $m / z 627.3$ $(\mathrm{M}+\mathrm{H})^{+}, \mathrm{C}_{33} \mathrm{H}_{28} \mathrm{~F}_{2} \mathrm{~N}_{6} \mathrm{O}_{5}$ (626.61). 
(S)-3-(1-(4-Carbamoylbenzyl)-1H-1,2,3-triazol-4-yl)-N-(3-(3,5difluorophenyl)-1-((4-methoxyphenyl)(methyl)amino)-1-oxopropan2-yl)benzamide (II-10d). Pale yellow solid, yield: $80 \%$, mp: $94-$ $96{ }^{\circ} \mathrm{C} .{ }^{1} \mathrm{H}$ NMR $\left(400 \mathrm{MHz}\right.$, DMSO- $\left.d_{6}\right) \delta 8.84(\mathrm{~d}, J=7.9 \mathrm{~Hz}, 1 \mathrm{H})$, $8.71(\mathrm{~s}, 1 \mathrm{H}), 8.32(\mathrm{~s}, 1 \mathrm{H}), 8.00(\mathrm{~d}, J=6.2 \mathrm{~Hz}, 2 \mathrm{H}), 7.90(\mathrm{~d}, J=$ $8.0 \mathrm{~Hz}, 2 \mathrm{H}), 7.86-7.65(\mathrm{~m}, 2 \mathrm{H}), 7.54(\mathrm{t}, J=7.8 \mathrm{~Hz}, 1 \mathrm{H}), 7.41(\mathrm{dd}, J$ $=13.3,8.4 \mathrm{~Hz}, 5 \mathrm{H}), 7.08(\mathrm{~d}, J=8.3 \mathrm{~Hz}, 2 \mathrm{H}), 7.05-6.87(\mathrm{~m}, 1 \mathrm{H})$, 6.63-6.40 (m, 2H), $5.75(\mathrm{~s}, 2 \mathrm{H}), 4.68(\mathrm{td}, J=8.5,4.6 \mathrm{~Hz}, 1 \mathrm{H}), 3.82$ (s, 3H), 3.18 (s, 3H), 3.06-2.86 (m, 2H). ${ }^{13} \mathrm{C}$ NMR $(100 \mathrm{MHz}$, DMSO) $\delta 171.29,167.88,166.52,163.63\left(\mathrm{dd},{ }^{1} J_{\mathrm{CF}}=246.4 \mathrm{~Hz},{ }^{3} J_{\mathrm{CF}}\right.$ $=13.1 \mathrm{~Hz}, 2 \mathrm{C}), 159.22,146.64,143.15\left(\mathrm{t},{ }^{2} J_{\mathrm{CF}}=9.1 \mathrm{~Hz}, 1 \mathrm{C}\right)$, 139.37, 136.00, 134.76, 134.59, 131.16, 129.38, 128.45, 128.18, $127.30,124.73,122.54,115.28,112.38\left(\mathrm{dd},{ }^{2} J_{\mathrm{CF}}=19.2 \mathrm{~Hz},{ }^{4} J_{\mathrm{CF}}=\right.$ $6.1 \mathrm{~Hz}, 2 \mathrm{C}), 102.48\left(\mathrm{t},{ }^{3} J_{\mathrm{CF}}=25.3 \mathrm{~Hz}, 1 \mathrm{C}\right), 55.97,53.16,52.64$, 37.85, 36.33. ESI-MS: $m / z 625.4(\mathrm{M}+\mathrm{H})^{+}, \mathrm{C}_{34} \mathrm{H}_{30} \mathrm{~F}_{2} \mathrm{~N}_{6} \mathrm{O}_{4}$ (624.23).

(S)-N-(3-(3,5-Difluorophenyl)-1-((4-methoxyphenyl)(methyl)amino)1-oxopropan-2-yl)-3-(1-(2-oxo-2-(phenylamino)ethyl)-1H-1,2,3-triazol4-yl)benzamide (II-10e). Pale yellow solid, yield: 66\%, mp: 189$191{ }^{\circ} \mathrm{C} .{ }^{1} \mathrm{H}$ NMR $\left(400 \mathrm{MHz}\right.$, DMSO- $\left.d_{6}\right) \delta 10.56(\mathrm{~s}, 1 \mathrm{H}), 8.88(\mathrm{~d}, J=$ $7.9 \mathrm{~Hz}, 1 \mathrm{H}), 8.67(\mathrm{~s}, 1 \mathrm{H}), 8.36(\mathrm{t}, J=1.8 \mathrm{~Hz}, 1 \mathrm{H}), 8.03(\mathrm{~d}, J=7.7 \mathrm{~Hz}$, $1 \mathrm{H}), 7.78(\mathrm{~d}, J=7.8 \mathrm{~Hz}, 1 \mathrm{H}), 7.62(\mathrm{~d}, J=8.0 \mathrm{~Hz}, 2 \mathrm{H}), 7.56(\mathrm{t}, J=$ $7.7 \mathrm{~Hz}, 1 \mathrm{H}), 7.45-7.32(\mathrm{~m}, 4 \mathrm{H}), 7.09(\mathrm{dd}, J=8.4,2.5 \mathrm{~Hz}, 3 \mathrm{H}), 7.06-$ $6.95(\mathrm{~m}, 1 \mathrm{H}), 6.63-6.44(\mathrm{~m}, 2 \mathrm{H}), 5.43(\mathrm{~s}, 2 \mathrm{H}), 4.69(\mathrm{td}, J=8.6$, $4.6 \mathrm{~Hz}, 1 \mathrm{H}), 3.82(\mathrm{~s}, 3 \mathrm{H}), 3.18$ (s, 3H), 3.08-2.80 (m, 2H). ${ }^{13} \mathrm{C}$ NMR (100 MHz, DMSO) $\delta 171.30,166.49,164.60,163.63\left(\mathrm{dd},{ }^{1} J_{\mathrm{CF}}=\right.$ $\left.246.4 \mathrm{~Hz},{ }^{3} J_{\mathrm{CF}}=13.1 \mathrm{~Hz}, 2 \mathrm{C}\right), 159.22,146.14,143.16\left(\mathrm{t},{ }^{2} J_{\mathrm{CF}}=\right.$ $9.1 \mathrm{~Hz}, 1 \mathrm{C}), 138.87,136.00,134.75,131.26,129.41,128.48,127.30$, $124.60,123.92,119.70,115.29,112.38\left(\mathrm{dd},{ }^{2} J_{\mathrm{CF}}=19.2 \mathrm{~Hz},{ }^{4} J_{\mathrm{CF}}=\right.$ $6.1 \mathrm{~Hz}, 2 \mathrm{C}), 112.14,102.50$ (t, $\left.{ }^{3} J_{\mathrm{CF}}=25.3 \mathrm{~Hz}, 1 \mathrm{C}\right), 55.97,52.90$, 52.64, 37.86, 36.34. ESI-MS: $m / z 625.3(\mathrm{M}+\mathrm{H})^{+}, \mathrm{C}_{34} \mathrm{H}_{30} \mathrm{~F}_{2} \mathrm{~N}_{6} \mathrm{O}_{4}$ (624.23).

(S)-N-(3-(3,5-Difluorophenyl)-1-((4-methoxyphenyl)(methyl)amino)1-oxopropan-2-yl)-3-(1-(4-sulfamoylbenzyl)-1H-1,2,3-triazol-4-yl) benzamide (II-10f). Pale yellow solid, yield: 68\%, mp: 122$124{ }^{\circ} \mathrm{C} .{ }^{1} \mathrm{H}$ NMR $\left(400 \mathrm{MHz}\right.$, DMSO- $\left.d_{6}\right) \delta 8.85(\mathrm{~d}, J=7.9 \mathrm{~Hz}, 1 \mathrm{H})$, $8.73(\mathrm{~s}, 1 \mathrm{H}), 8.32(\mathrm{t}, J=1.8 \mathrm{~Hz}, 1 \mathrm{H}), 8.00(\mathrm{dt}, J=7.7,1.4 \mathrm{~Hz}$, $1 \mathrm{H}), 7.93-7.82(\mathrm{~m}, 2 \mathrm{H}), 7.77(\mathrm{dt}, J=7.8,1.4 \mathrm{~Hz}, 1 \mathrm{H}), 7.55(\mathrm{t}, J=$ $7.6 \mathrm{~Hz}, 3 \mathrm{H}), 7.47-7.32(\mathrm{~m}, 4 \mathrm{H}), 7.10(\mathrm{~s}, 2 \mathrm{H}), 7.05-6.88(\mathrm{~m}, 1 \mathrm{H})$, 6.62-6.46 (m, 2H), $5.79(\mathrm{~s}, 2 \mathrm{H}), 4.68(\mathrm{td}, J=8.7,4.8 \mathrm{~Hz}, 1 \mathrm{H})$, $3.82(\mathrm{~s}, 3 \mathrm{H}), 3.18(\mathrm{~s}, 3 \mathrm{H}), 2.98(\mathrm{t}, J=6.6 \mathrm{~Hz}, 2 \mathrm{H}) .{ }^{13} \mathrm{C}$ NMR $(100$ $\mathrm{MHz}, \mathrm{DMSO}) \delta 171.30,166.50,163.76\left(\mathrm{dd},{ }^{1} J_{\mathrm{CF}}=246.4 \mathrm{~Hz},{ }^{3} J_{\mathrm{CF}}\right.$ $=13.1 \mathrm{~Hz}, 2 \mathrm{C}), 159.23,146.68,144.34,143.15\left(\mathrm{t},{ }^{2} J_{\mathrm{CF}}=9.1 \mathrm{~Hz}\right.$, 1C), 140.14, 136.00, 134.76, 129.39, 129.35, 128.85, 128.52, $127.32,126.65,124.75,122.63,115.29,112.38\left(\mathrm{dd},{ }^{2} J_{\mathrm{CF}}=\right.$ $\left.19.2 \mathrm{~Hz},{ }^{4} J_{\mathrm{CF}}=6.1 \mathrm{~Hz}, 2 \mathrm{C}\right), 112.13,102.49\left(\mathrm{t},{ }^{3} J_{\mathrm{CF}}=25.3 \mathrm{~Hz}\right.$, 1C), $55.97,52.95,52.64,37.85,36.33$. ESI-MS: $m / z 661.2(\mathrm{M}+$ $\mathrm{H})^{+}, \mathrm{C}_{33} \mathrm{H}_{30} \mathrm{~F}_{2} \mathrm{~N}_{6} \mathrm{O}_{5} \mathrm{~S}(660.20)$.

(S)-N-(3-(3,5-Difluorophenyl)-1-((4-methoxyphenyl)(methyl)amino)1-oxopropan-2-yl)-3-(1-(3-phenylpropyl)-1H-1,2,3-triazol-4-yl) benzamide (II-10g). White solid, yield: $80 \%$, mp: $119-121{ }^{\circ} \mathrm{C}$. ${ }^{1} \mathrm{H}$ NMR $\left(400 \mathrm{MHz}\right.$, DMSO- $\left.d_{6}\right) \delta 8.86(\mathrm{~d}, J=7.8 \mathrm{~Hz}, 1 \mathrm{H}), 8.69(\mathrm{~s}$, $1 \mathrm{H}), 8.33(\mathrm{~s}, 1 \mathrm{H}), 8.00(\mathrm{~d}, J=7.7 \mathrm{~Hz}, 1 \mathrm{H}), 7.77(\mathrm{~d}, J=7.8 \mathrm{~Hz}, 1 \mathrm{H})$, $7.55(\mathrm{t}, J=7.7 \mathrm{~Hz}, 1 \mathrm{H}), 7.41(\mathrm{~d}, J=8.3 \mathrm{~Hz}, 2 \mathrm{H}), 7.31(\mathrm{t}, J=7.5 \mathrm{~Hz}$, $2 \mathrm{H}), 7.27-7.18(\mathrm{~m}, 3 \mathrm{H}), 7.09(\mathrm{~d}, J=8.4 \mathrm{~Hz}, 2 \mathrm{H}), 7.01(\mathrm{tt}, J=9.4$, $2.3 \mathrm{~Hz}, 1 \mathrm{H}), 6.55(\mathrm{~h}, J=4.2 \mathrm{~Hz}, 2 \mathrm{H}), 4.68(\mathrm{td}, J=9.2,8.7,4.3 \mathrm{~Hz}$, $1 \mathrm{H}), 4.44(\mathrm{t}, J=7.0 \mathrm{~Hz}, 2 \mathrm{H}), 3.82(\mathrm{~s}, 3 \mathrm{H}), 3.18(\mathrm{~s}, 3 \mathrm{H}), 2.99(\mathrm{td}, J=$
14.7, 14.2, $9.6 \mathrm{~Hz}, 2 \mathrm{H}), 2.62(\mathrm{t}, J=7.6 \mathrm{~Hz}, 2 \mathrm{H}), 2.21(\mathrm{p}, J=7.2 \mathrm{~Hz}$, 2H). ${ }^{13} \mathrm{C}$ NMR (100 MHz, DMSO) $\delta 171.32,166.57,163.76$ (dd, $\left.{ }^{1} J_{\mathrm{CF}}=246.4 \mathrm{~Hz},{ }^{3} J_{\mathrm{CF}}=13.1 \mathrm{~Hz}, 2 \mathrm{C}\right), 159.23,146.31,143.18(\mathrm{t}$, $\left.{ }^{2} J_{\mathrm{CF}}=9.1 \mathrm{~Hz}, 1 \mathrm{C}\right), 141.20,136.01,134.75,131.42,129.35$, $128.83,128.44,127.14,126.49,124.71,122.13,115.29,112.14$ $\left(\mathrm{dd},{ }^{2} J_{\mathrm{CF}}=19.2 \mathrm{~Hz},{ }^{4} J_{\mathrm{CF}}=6.1 \mathrm{~Hz}, 2 \mathrm{C}\right), 102.49\left(\mathrm{t},{ }^{3} J_{\mathrm{CF}}=25.3 \mathrm{~Hz}\right.$, 1C), 55.97, 52.69, 49.61, 37.84, 36.29, 32.36, 31.72. ESI-MS: $\mathrm{m} / \mathrm{z}$ $610.3(\mathrm{M}+\mathrm{H})^{+}, \mathrm{C}_{35} \mathrm{H}_{33} \mathrm{~F}_{2} \mathrm{~N}_{5} \mathrm{O}_{3}(609.26)$.

(S)-N-(3-(3,5-Difluorophenyl)-1-((4-methoxyphenyl)(methyl)amino)1-oxopropan-2-yl)-3-(1-(2-(thiophen-3-yl)ethyl)-1 H-1,2,3-triazol-4yl)benzamide (II-10h). White solid, yield: $79 \%$, mp: $73-75^{\circ} \mathrm{C} .{ }^{1} \mathrm{H}$ NMR (400 MHz, DMSO- $\left.d_{6}\right) \delta 8.86(\mathrm{~d}, J=7.9 \mathrm{~Hz}, 1 \mathrm{H}), 8.59(\mathrm{~s}, 1 \mathrm{H})$, $8.30(\mathrm{t}, J=1.7 \mathrm{~Hz}, 1 \mathrm{H}), 7.96(\mathrm{dt}, J=7.7,1.4 \mathrm{~Hz}, 1 \mathrm{H}), 7.77(\mathrm{dt}, J=$ $7.7,1.4 \mathrm{~Hz}, 1 \mathrm{H}), 7.54(\mathrm{t}, J=7.7 \mathrm{~Hz}, 1 \mathrm{H}), 7.48(\mathrm{dd}, J=4.9,2.9 \mathrm{~Hz}$, $1 \mathrm{H}), 7.41(\mathrm{~d}, J=8.5 \mathrm{~Hz}, 2 \mathrm{H}), 7.25(\mathrm{dd}, J=2.9,1.2 \mathrm{~Hz}, 1 \mathrm{H}), 7.09$ $(\mathrm{d}, J=8.9 \mathrm{~Hz}, 2 \mathrm{H}), 7.02(\mathrm{tt}, J=8.1,2.8 \mathrm{~Hz}, 2 \mathrm{H}), 6.64-6.44(\mathrm{~m}$, $2 \mathrm{H}), 4.69(\mathrm{t}, J=7.1 \mathrm{~Hz}, 3 \mathrm{H}), 3.82(\mathrm{~s}, 3 \mathrm{H}), 3.27(\mathrm{t}, J=7.2 \mathrm{~Hz}, 2 \mathrm{H})$, $3.18(\mathrm{~s}, 3 \mathrm{H}), 2.99(\mathrm{td}, J=14.1,9.5 \mathrm{~Hz}, 2 \mathrm{H}) .{ }^{13} \mathrm{C}$ NMR $(100 \mathrm{MHz}$, DMSO) $\delta 171.31,166.55,163.77\left(\mathrm{dd},{ }^{1} J_{\mathrm{CF}}=246.4 \mathrm{~Hz},{ }^{3} J_{\mathrm{CF}}=\right.$ $13.1 \mathrm{~Hz}, 2 \mathrm{C}), 159.23,146.09,143.17\left(\mathrm{t},{ }^{2} J_{\mathrm{CF}}=9.1 \mathrm{~Hz}, 1 \mathrm{C}\right), 138.24$, 136.00, 134.76, 131.37, 129.37, 128.68, 128.39, 127.14, 126.71, $124.65,122.60,122.14,115.29,112.38\left(\mathrm{dd},{ }^{2} J_{\mathrm{CF}}=19.2 \mathrm{~Hz},{ }^{4} J_{\mathrm{CF}}=\right.$ $6.1 \mathrm{~Hz}, 2 \mathrm{C}), 112.13,102.49\left(\mathrm{t},{ }^{3} J_{\mathrm{CF}}=25.3 \mathrm{~Hz}, 1 \mathrm{C}\right), 55.97,52.68$, 50.55, 37.85, 36.30, 30.68. ESI-MS: $m / z 602.4(\mathrm{M}+\mathrm{H})^{+}$, $\mathrm{C}_{32} \mathrm{H}_{29} \mathrm{~F}_{2} \mathrm{~N}_{5} \mathrm{O}_{3} \mathrm{~S}$ (601.20).

(S)-N-(3-(3,5-Difluorophenyl)-1-((4-methoxyphenyl)(methyl)amino)1-oxopropan-2-yl)-3-(1-(quinolin-2-yl)-1H-1,2,3-triazol-4-yl)benzamide (II-10i). White solid, yield: $65 \%$, mp: $85-87^{\circ} \mathrm{C} .{ }^{1} \mathrm{H}$ NMR ( $400 \mathrm{MHz}$, DMSO- $\left.d_{6}\right) \delta 9.62(\mathrm{~s}, 1 \mathrm{H}), 9.55(\mathrm{~d}, J=2.6 \mathrm{~Hz}, 1 \mathrm{H}), 9.02(\mathrm{~d}, J=2.5 \mathrm{~Hz}$, $1 \mathrm{H}), 8.93(\mathrm{~d}, J=7.8 \mathrm{~Hz}, 1 \mathrm{H}), 8.48(\mathrm{t}, J=1.7 \mathrm{~Hz}, 1 \mathrm{H}), 8.22-8.15(\mathrm{~m}$, $2 \mathrm{H}), 8.13(\mathrm{dt}, J=7.7,1.3 \mathrm{~Hz}, 1 \mathrm{H}), 7.93-7.84(\mathrm{~m}, 2 \mathrm{H}), 7.77$ (ddd, $J=$ 8.1, 6.8, $1.2 \mathrm{~Hz}, 1 \mathrm{H}), 7.65(\mathrm{q}, J=7.6 \mathrm{~Hz}, 1 \mathrm{H}), 7.43(\mathrm{~d}, J=8.3 \mathrm{~Hz}$, $2 \mathrm{H}), 7.25-7.06(\mathrm{~m}, 2 \mathrm{H}), 7.02(\mathrm{tt}, J=9.4,2.4 \mathrm{~Hz}, 1 \mathrm{H}), 6.56(\mathrm{~h}, J=$ $4.2 \mathrm{~Hz}, 2 \mathrm{H}), 4.70$ (ddd, $J=9.7,7.6,4.3 \mathrm{~Hz}, 1 \mathrm{H}), 3.83(\mathrm{~s}, 3 \mathrm{H}), 3.20$ (s, $3 \mathrm{H}), 3.00$ (qd, $J=13.8,7.1 \mathrm{~Hz}, 2 \mathrm{H}) .{ }^{13} \mathrm{C}$ NMR $(100 \mathrm{MHz}, \mathrm{DMSO})$ $\delta 171.33,166.54,163.79\left(\mathrm{dd},{ }^{1} J_{\mathrm{CF}}=246.4 \mathrm{~Hz},{ }^{3} J_{\mathrm{CF}}=13.1 \mathrm{~Hz}, 2 \mathrm{C}\right)$, 159.25, 147.49, 143.56, 143.17 ( $\left.\mathrm{t},{ }^{2} J_{\mathrm{CF}}=9.1 \mathrm{~Hz}, 1 \mathrm{C}\right), 136.03,134.97$, 131.01, 130.66, 130.63, 129.55, 129.43, 129.37, 129.12, 128.66, $127.62,127.57,126.34,125.11,121.07,115.30,112.39\left(\mathrm{dd},{ }^{2} J_{\mathrm{CF}}=\right.$ $\left.19.2 \mathrm{~Hz},{ }^{4} J_{\mathrm{CF}}=6.1 \mathrm{~Hz}, 2 \mathrm{C}\right), 112.15,102.50\left(\mathrm{t},{ }^{3} J_{\mathrm{CF}}=25.3 \mathrm{~Hz}, 1 \mathrm{C}\right)$, 55.99, 52.76, 37.86, 36.30. ESI-MS: $m / z$ 619.4 (M $+\mathrm{H})^{+}$, $\mathrm{C}_{35} \mathrm{H}_{28} \mathrm{~F}_{2} \mathrm{~N}_{6} \mathrm{O}_{3}$ (618.22).

(S)-N-(3-(3,5-Difluorophenyl)-1-((4-methoxyphenyl)(methyl)amino)1-oxopropan-2-yl)-3-(1-(naphthalen-2-ylmethyl)-1 H-1,2,3-triazol-4-yl) benzamide (II-10j). White solid, yield: $69 \%$, mp: $128-130{ }^{\circ} \mathrm{C} .{ }^{1} \mathrm{H}$ NMR (400 MHz, DMSO- $\left.d_{6}\right) \delta 8.84(\mathrm{~d}, J=7.9 \mathrm{~Hz}, 1 \mathrm{H}), 8.74(\mathrm{~s}, 1 \mathrm{H})$, $8.32(\mathrm{t}, J=1.7 \mathrm{~Hz}, 1 \mathrm{H}), 8.00(\mathrm{dt}, J=7.7,1.4 \mathrm{~Hz}, 1 \mathrm{H}), 7.98-7.88(\mathrm{~m}$, $4 \mathrm{H}), 7.84-7.69(\mathrm{~m}, 1 \mathrm{H}), 7.59-7.48(\mathrm{~m}, 4 \mathrm{H}), 7.39(\mathrm{~d}, J=8.5 \mathrm{~Hz}, 2 \mathrm{H})$, $7.08(\mathrm{~d}, J=8.8 \mathrm{~Hz}, 2 \mathrm{H}), 7.01(\mathrm{td}, J=9.3,4.7 \mathrm{~Hz}, 1 \mathrm{H}), 6.63-6.46(\mathrm{~m}$, $2 \mathrm{H}), 5.86(\mathrm{~s}, 2 \mathrm{H}), 4.67(\mathrm{td}, J=8.6,4.7 \mathrm{~Hz}, 1 \mathrm{H}), 3.82(\mathrm{~s}, 3 \mathrm{H}), 3.17(\mathrm{~s}$, $3 \mathrm{H}), 3.05-2.82(\mathrm{~m}, 2 \mathrm{H}) .{ }^{13} \mathrm{C}$ NMR (100 MHz, DMSO) $\delta$ 171.29, $166.52,163.62\left(\mathrm{dd},{ }^{1} J_{\mathrm{CF}}=246.4 \mathrm{~Hz},{ }^{3} J_{\mathrm{CF}}=13.1 \mathrm{~Hz}, 2 \mathrm{C}\right), 159.22$, $146.63,143.14\left(\mathrm{t},{ }^{2} J_{\mathrm{CF}}=9.1 \mathrm{~Hz}, 1 \mathrm{C}\right), 135.99,134.74,133.84,133.25$, 131.21, 129.36, 129.06, 128.50, 128.31, 128.10, 127.45, 127.27, $127.06,126.94,126.19,124.70,122.48,115.28,112.37$ (dd, ${ }^{2} J_{\mathrm{CF}}=$ $\left.19.2 \mathrm{~Hz},{ }^{4} J_{\mathrm{CF}}=6.1 \mathrm{~Hz}, 2 \mathrm{C}\right), 112.13,102.48\left(\mathrm{t},{ }^{3} J_{\mathrm{CF}}=25.3 \mathrm{~Hz}, 1 \mathrm{C}\right)$, 
55.96, 53.77, 52.64, 37.84, 36.32. ESI-MS: $m / z 632.4(\mathrm{M}+\mathrm{H})^{+}$, $\mathrm{C}_{37} \mathrm{H}_{31} \mathrm{~F}_{2} \mathrm{~N}_{5} \mathrm{O}_{3}$ (631.24).

(S)-N-(3-(3,5-Difluorophenyl)-1-((4-methoxyphenyl)(methyl)amino)1-oxopropan-2-yl)-3-(1-(naphthalen-1-ylmethyl)-1H-1,2,3-triazol-4-yl) benzamide (II-10k). White solid, yield: $68 \%$, mp: $87-89{ }^{\circ} \mathrm{C} .{ }^{1} \mathrm{H}$ NMR $\left(400 \mathrm{MHz}, \mathrm{DMSO}-d_{6}\right) \delta 8.83(\mathrm{~d}, J=7.8 \mathrm{~Hz}, 1 \mathrm{H}), 8.64(\mathrm{~s}, 1 \mathrm{H}), 8.28(\mathrm{t}, J$ $=1.7 \mathrm{~Hz}, 1 \mathrm{H}), 8.22(\mathrm{~d}, J=8.2 \mathrm{~Hz}, 1 \mathrm{H}), 7.99(\mathrm{dd}, J=9.0,7.2 \mathrm{~Hz}, 3 \mathrm{H})$, $7.74(\mathrm{dt}, J=7.7,1.4 \mathrm{~Hz}, 1 \mathrm{H}), 7.64-7.54(\mathrm{~m}, 3 \mathrm{H}), 7.54-7.45(\mathrm{~m}, 2 \mathrm{H})$, $7.39(\mathrm{~d}, J=8.4 \mathrm{~Hz}, 2 \mathrm{H}), 7.15-7.05(\mathrm{~m}, 2 \mathrm{H}), 7.04-6.95(\mathrm{~m}, 1 \mathrm{H}), 6.65-$ $6.43(\mathrm{~m}, 2 \mathrm{H}), 6.18(\mathrm{~s}, 2 \mathrm{H}), 4.66(\mathrm{td}, J=8.6,4.9 \mathrm{~Hz}, 1 \mathrm{H}), 3.81(\mathrm{~s}, 3 \mathrm{H})$, 3.17 (s, 3H), 3.05-2.82 (m, 2H). ${ }^{13} \mathrm{C}$ NMR (100 MHz, DMSO) $\delta 171.28,166.51,163.62\left(\mathrm{dd},{ }^{1} J_{\mathrm{CF}}=246.4 \mathrm{~Hz},{ }^{3} J_{\mathrm{CF}}=13.1 \mathrm{~Hz}, 2 \mathrm{C}\right)$, 159.21, 146.47, $143.14\left(\mathrm{t},{ }^{2} J_{\mathrm{CF}}=9.1 \mathrm{~Hz}, 1 \mathrm{C}\right), 135.99,134.73,133.86$, $131.77,131.12$, 129.60, 129.33, 129.17, 128.49, 127.88, 127.32, $126.67,126.09,124.68,123.68,122.45,115.27,112.37\left(\mathrm{dd},{ }^{2} J_{\mathrm{CF}}=\right.$ $\left.19.2 \mathrm{~Hz},{ }^{4} J_{\mathrm{CF}}=6.1 \mathrm{~Hz}, 2 \mathrm{C}\right), 112.12,102.47\left(\mathrm{t},{ }^{3} J_{\mathrm{CF}}=25.3 \mathrm{~Hz}, 1 \mathrm{C}\right)$, 55.96, 52.64, 51.61, 37.84, 36.31. ESI-MS: $m / z 632.4(\mathrm{M}+\mathrm{H})^{+}$, $\mathrm{C}_{37} \mathrm{H}_{31} \mathrm{~F}_{2} \mathrm{~N}_{5} \mathrm{O}_{3}$ (631.24).

Methyl (S)-2-(4-(3-((3-(3,5-difluorophenyl)-1-((4-methoxyphenyl)(methyl)amino)-1-oxopropan-2-yl)carbamoyl)phenyl)1H-1,2,3-triazol-1-yl)acetate (II-10l). White solid, yield: 74\%, mp: $125-127{ }^{\circ} \mathrm{C} .{ }^{1} \mathrm{H}$ NMR $\left(400 \mathrm{MHz}, \mathrm{DMSO}-d_{6}\right) \delta 8.88(\mathrm{~d}, J=$ $7.9 \mathrm{~Hz}, 1 \mathrm{H}), 8.63(\mathrm{~s}, 1 \mathrm{H}), 8.34(\mathrm{t}, J=1.7 \mathrm{~Hz}, 1 \mathrm{H}), 8.01(\mathrm{~d}, J=$ $7.4 \mathrm{~Hz}, 1 \mathrm{H}), 7.78(\mathrm{~d}, J=7.8 \mathrm{~Hz}, 1 \mathrm{H}), 7.56(\mathrm{t}, J=7.8 \mathrm{~Hz}, 1 \mathrm{H})$, $7.40(\mathrm{~d}, J=8.3 \mathrm{~Hz}, 2 \mathrm{H}), 7.09(\mathrm{~d}, J=8.5 \mathrm{~Hz}, 2 \mathrm{H}), 7.01(\mathrm{ddd}, J=$ 9.4, 7.0, 2.4 Hz, 1H), 6.67-6.47 (m, 2H), $5.52(\mathrm{~s}, 2 \mathrm{H}), 4.68(\mathrm{td}$, $J=8.5,4.6 \mathrm{~Hz}, 1 \mathrm{H}), 3.82(\mathrm{~s}, 3 \mathrm{H}), 3.75(\mathrm{~s}, 3 \mathrm{H}), 3.18(\mathrm{~s}, 3 \mathrm{H})$, 3.04-2.90 (m, 2H). ${ }^{13} \mathrm{C}$ NMR (100 MHz, DMSO) $\delta$ 171.29, $168.17,166.47,163.63\left(\mathrm{dd},{ }^{1} J_{\mathrm{CF}}=246.4 \mathrm{~Hz},{ }^{3} J_{\mathrm{CF}}=13.1 \mathrm{~Hz}\right.$, 2C), $159.22,146.34,143.16\left(\mathrm{t},{ }^{2} J_{\mathrm{CF}}=9.1 \mathrm{~Hz}, 1 \mathrm{C}\right), 135.99$, $134.77,132.00,131.04,129.48,129.36,128.52,127.42$, $124.65,123.61,115.29,112.38\left(\mathrm{dd},{ }^{2} J_{\mathrm{CF}}=19.2 \mathrm{~Hz},{ }^{4} J_{\mathrm{CF}}=\right.$ $6.1 \mathrm{~Hz}, 2 \mathrm{C}), 112.13,102.49\left(\mathrm{t},{ }^{3} J_{\mathrm{CF}}=25.3 \mathrm{~Hz}, 1 \mathrm{C}\right), 65.50$, $55.97,53.10,52.65,51.00,37.86,36.33$. ESI-MS: $m / z 564.3(\mathrm{M}$ $+\mathrm{H})^{+}, \mathrm{C}_{29} \mathrm{H}_{27} \mathrm{~F}_{2} \mathrm{~N}_{5} \mathrm{O}_{5}$ (563.20).

Ethyl (S)-2-(4-(3-((3-(3,5-difluorophenyl)-1-((4-methoxyphenyl) (methyl)amino)-1-oxopropan-2-yl)carbamoyl)phenyl)-1H-1,2,3triazol-1-yl)acetate (II-10m). White solid, yield: 75\%, mp: 83$85{ }^{\circ} \mathrm{C} .{ }^{1} \mathrm{H}$ NMR (400 MHz, DMSO- $\left.d_{6}\right) \delta 8.89(\mathrm{~d}, J=7.9 \mathrm{~Hz}, 1 \mathrm{H})$, $8.63(\mathrm{~s}, 1 \mathrm{H}), 8.34(\mathrm{~d}, J=1.9 \mathrm{~Hz}, 1 \mathrm{H}), 8.01(\mathrm{~d}, J=7.7 \mathrm{~Hz}, 1 \mathrm{H}), 7.78$ (d, $J=7.8 \mathrm{~Hz}, 1 \mathrm{H}), 7.56(\mathrm{t}, J=7.7 \mathrm{~Hz}, 1 \mathrm{H}), 7.40(\mathrm{~d}, J=8.3 \mathrm{~Hz}$, $2 \mathrm{H}), 7.09$ (d, $J=8.4 \mathrm{~Hz}, 2 \mathrm{H}), 7.02(\mathrm{tt}, J=9.4,2.4 \mathrm{~Hz}, 1 \mathrm{H}), 6.65-$ $6.43(\mathrm{~m}, 2 \mathrm{H}), 5.50(\mathrm{~s}, 2 \mathrm{H}), 4.69(\mathrm{td}, J=8.6,4.6 \mathrm{~Hz}, 1 \mathrm{H}), 4.22(\mathrm{q}, J$ $=7.1 \mathrm{~Hz}, 2 \mathrm{H}), 3.82(\mathrm{~s}, 3 \mathrm{H}), 3.18(\mathrm{~s}, 3 \mathrm{H}), 3.05-2.93(\mathrm{~m}, 2 \mathrm{H}), 1.25$ $(\mathrm{t}, J=7.1 \mathrm{~Hz}, 3 \mathrm{H}) .{ }^{13} \mathrm{C}$ NMR (100 MHz, DMSO) $\delta 171.29,167.69$, $166.47,163.76\left(\mathrm{dd},{ }^{1} J_{\mathrm{CF}}=246.4 \mathrm{~Hz},{ }^{3} J_{\mathrm{CF}}=13.1 \mathrm{~Hz}, 2 \mathrm{C}\right), 159.22$, 146.32, $143.16\left(\mathrm{t},{ }^{2} J_{\mathrm{CF}}=9.1 \mathrm{~Hz}, 1 \mathrm{C}\right), 135.99,134.77,131.06$, 129.47, 129.36, 128.51, 127.40, 124.64, 123.60, 115.29, 112.38 $\left(\mathrm{dd},{ }^{2} J_{\mathrm{CF}}=19.2 \mathrm{~Hz},{ }^{4} J_{\mathrm{CF}}=6.1 \mathrm{~Hz}, 2 \mathrm{C}\right), 112.13,102.49\left(\mathrm{t},{ }^{3} J_{\mathrm{CF}}=\right.$ $25.3 \mathrm{~Hz}, 1 \mathrm{C}), 62.08,55.97,52.65,51.09,37.86,36.34,14.47$. ESIMS: $m / z 578.3(\mathrm{M}+\mathrm{H})^{+}, \mathrm{C}_{30} \mathrm{H}_{29} \mathrm{~F}_{2} \mathrm{~N}_{5} \mathrm{O}_{5}$ (577.21).

Methyl (S)-4-(4-(3-((3-(3,5-difluorophenyl)-1-((4-methoxyphenyl) (methyl)amino)-1-oxopropan-2-yl)carbamoyl)phenyl)-1H-1,2,3triazol-1-yl)butanoate (I-10n). White solid, yield: 67\%, mp: 63$65{ }^{\circ} \mathrm{C} .{ }^{1} \mathrm{H}$ NMR $\left(400 \mathrm{MHz}, \mathrm{DMSO}-d_{6}\right) \delta 8.86(\mathrm{~d}, J=7.8 \mathrm{~Hz}, 1 \mathrm{H})$, $8.66(\mathrm{~s}, 1 \mathrm{H}), 8.32(\mathrm{t}, J=1.7 \mathrm{~Hz}, 1 \mathrm{H}), 7.99(\mathrm{dt}, J=7.7,1.4 \mathrm{~Hz}, 1 \mathrm{H})$, $7.77(\mathrm{dt}, J=7.8,1.4 \mathrm{~Hz}, 1 \mathrm{H}), 7.55(\mathrm{t}, J=7.8 \mathrm{~Hz}, 1 \mathrm{H}), 7.41(\mathrm{~d}, J=$
8.4 Hz, 2H), 7.26-7.06 (m, 2H), 7.08-6.95 (m, 1H), 6.61-6.46 (m, $2 \mathrm{H}), 4.78-4.60(\mathrm{~m}, 1 \mathrm{H}), 4.47(\mathrm{t}, J=7.0 \mathrm{~Hz}, 2 \mathrm{H}), 3.82(\mathrm{~s}, 3 \mathrm{H}), 3.59$ $(\mathrm{s}, 3 \mathrm{H}), 3.18(\mathrm{~s}, 3 \mathrm{H}), 2.99(\mathrm{td}, J=14.1,9.6 \mathrm{~Hz}, 2 \mathrm{H}), 2.39(\mathrm{t}, J=$ $7.3 \mathrm{~Hz}, 2 \mathrm{H}), 2.24-2.07$ (m, 2H). ${ }^{13} \mathrm{C} \mathrm{NMR}$ (100 MHz, DMSO) $\delta 172.98,171.31,166.55,163.76\left(\mathrm{dd},{ }^{1} J_{\mathrm{CF}}=246.4 \mathrm{~Hz},{ }^{3} J_{\mathrm{CF}}=\right.$ $13.1 \mathrm{~Hz}, 2 \mathrm{C}), 159.23,146.31,143.17\left(\mathrm{t},{ }^{2} J_{\mathrm{CF}}=9.1 \mathrm{~Hz}, 1 \mathrm{C}\right), 136.00$, $134.74,131.35,129.36,128.45,127.17,124.70,122.24,115.29$, $112.38\left(\mathrm{dd},{ }^{2} J_{\mathrm{CF}}=19.2 \mathrm{~Hz},{ }^{4} J_{\mathrm{CF}}=6.1 \mathrm{~Hz}, 2 \mathrm{C}\right), 112.13,102.49(\mathrm{t}$, $\left.{ }^{3} J_{\mathrm{CF}}=25.3 \mathrm{~Hz}, 1 \mathrm{C}\right), 55.97,52.68,51.90,49.26,37.85,36.28$, 30.60, 25.52. ESI-MS: $m / z 592.4(\mathrm{M}+\mathrm{H})^{+}, \mathrm{C}_{31} \mathrm{H}_{31} \mathrm{~F}_{2} \mathrm{~N}_{5} \mathrm{O}_{5}$ (591.23).

$\mathrm{N}-((\mathrm{S})-3-(3,5-D i f l u o r o p h e n y l)-1-((4-m e t h o x y p h e n y l)($ methyl)amino)1-oxopropan-2-yl)-3-(1-(2-(hydroxymethyl)-5-(5-methyl-2,6-dioxo1,2,3, 6-tetrahydropyridin-3-yl)tetrahydrofuran-3-yl)-1H-1,2,3triazol-4-yl)benzamide (II-10o). White solid, yield: 79\%, mp: 142-144 ${ }^{\circ} \mathrm{C} .{ }^{1} \mathrm{H}$ NMR (400 MHz, DMSO- $\left.d_{6}\right) \delta 11.40(\mathrm{~s}, 1 \mathrm{H}), 8.88$ $(\mathrm{d}, J=6.5 \mathrm{~Hz}, 2 \mathrm{H}), 8.34(\mathrm{t}, J=1.8 \mathrm{~Hz}, 1 \mathrm{H}), 8.01(\mathrm{~d}, J=7.7 \mathrm{~Hz}$, $1 \mathrm{H}), 7.91-7.82(\mathrm{~m}, 1 \mathrm{H}), 7.79(\mathrm{~d}, J=7.8 \mathrm{~Hz}, 1 \mathrm{H}), 7.57(\mathrm{t}, J=$ $7.8 \mathrm{~Hz}, 1 \mathrm{H}), 7.41(\mathrm{~d}, J=8.4 \mathrm{~Hz}, 2 \mathrm{H}), 7.09(\mathrm{~d}, J=8.4 \mathrm{~Hz}, 2 \mathrm{H})$, $7.02(\mathrm{td}, J=9.4,4.7 \mathrm{~Hz}, 1 \mathrm{H}), 6.58-6.51(\mathrm{~m}, 2 \mathrm{H}), 6.47(\mathrm{t}, J=$ $6.6 \mathrm{~Hz}, 1 \mathrm{H}), 5.45(\mathrm{dd}, J=9.1,5.0 \mathrm{~Hz}, 1 \mathrm{H}), 5.34(\mathrm{t}, J=5.3 \mathrm{~Hz}$, $1 \mathrm{H}), 4.78-4.51(\mathrm{~m}, 1 \mathrm{H}), 4.30(\mathrm{q}, J=3.9 \mathrm{~Hz}, 1 \mathrm{H}), 3.83(\mathrm{~s}, 3 \mathrm{H})$, 3.79-3.62 (m, 2H), 3.19 (s, 3H), 2.98 (t, $J=7.8 \mathrm{~Hz}, 2 \mathrm{H}), 2.78$ $(\mathrm{dq}, J=38.9,7.0,6.5 \mathrm{~Hz}, 2 \mathrm{H}), 1.83(\mathrm{~s}, 3 \mathrm{H}) .{ }^{13} \mathrm{C} \mathrm{NMR}(100 \mathrm{MHz}$, DMSO) $\delta 171.32,166.54,164.21\left(\mathrm{dd},{ }^{1} J_{\mathrm{CF}}=246.4 \mathrm{~Hz},{ }^{3} J_{\mathrm{CF}}=\right.$ $13.1 \mathrm{~Hz}, 2 \mathrm{C}), 159.24,150.92,146.52,142.61\left(\mathrm{t},{ }^{2} J_{\mathrm{CF}}=9.1 \mathrm{~Hz}\right.$, 1C), 136.75, 136.00, 134.79, 131.15, 129.37, 128.47, 127.29, $124.82,121.89,115.29,112.37\left(\mathrm{dd},{ }^{2} J_{\mathrm{CF}}=19.2 \mathrm{~Hz},{ }^{4} J_{\mathrm{CF}}=\right.$ $6.1 \mathrm{~Hz}, 2 \mathrm{C}), 112.13,110.13,102.50\left(\mathrm{t},{ }^{3} J_{\mathrm{CF}}=25.3 \mathrm{~Hz}, 1 \mathrm{C}\right)$, 84.90, 84.33, 61.22, 59.92, 55.98, 52.71, 37.85, 37.59, 36.27, 12.76. ESI-MS: $m / z 716.3(\mathrm{M}+\mathrm{H})^{+}, \mathrm{C}_{36} \mathrm{H}_{35} \mathrm{~F}_{2} \mathrm{~N}_{7} \mathrm{O}_{7}$ (715.26).

4.1.7. tert-Butyl $(S)$-(1-((4-methoxyphenyl)(methyl)amino)1-oxo-3-phenylpropan-2-yl)carbamate (12). A solution of (tertbutoxycarbonyl)-L-phenylalanine (11, $8.75 \mathrm{mmol}, 2.3 \mathrm{~g})$ in $15 \mathrm{~mL}$ dichloromethane was added PyBop (10.9 mmol, $5.7 \mathrm{~g}$ ) at $0{ }^{\circ} \mathrm{C}$, and the mixture stirred for $0.5 \mathrm{~h}$. Subsequently, DIEA $(21.87 \mathrm{mmol}, 3.61 \mathrm{~mL})$ and 4-methoxy- $N$-methylaniline (7.29 mmol, $1.0 \mathrm{~g}$ ) were added to the mixture and then stirred at room temperature for another 8-9 h (monitored by TLC). The resulting mixture was evaporated under reduced pressure and the residue was initially washed by $1 \mathrm{~N} \mathrm{HCl}$ and extracted with ethyl acetate $(3 \times 20 \mathrm{~mL})$. Then, the combined organic layer was washed with saturated sodium bicarbonate $(3 \times 50 \mathrm{~mL})$, dried over anhydrous $\mathrm{Na}_{2} \mathrm{SO}_{4}$, filtered, and concentrated under reduced pressure to afford corresponding crude intermediate 12 as yellow oil with a yield of 95\%. ${ }^{1} \mathrm{H}$ NMR (400 MHz, DMSO$\left.d_{6}\right) \delta 7.21(\mathrm{~d}, J=8.4 \mathrm{~Hz}, 3 \mathrm{H}), 7.15(\mathrm{~d}, J=7.1 \mathrm{~Hz}, 2 \mathrm{H}), 7.02(\mathrm{~d}, J=$ $8.4 \mathrm{~Hz}, 2 \mathrm{H}), 6.85-6.75(\mathrm{~m}, 2 \mathrm{H}), 4.15(\mathrm{q}, J=5.4 \mathrm{~Hz}, 1 \mathrm{H}), 3.80$ (s, $3 \mathrm{H}), 3.12(\mathrm{~s}, 3 \mathrm{H}), 2.81-2.54(\mathrm{~m}, 2 \mathrm{H}), 1.30(\mathrm{~s}, 9 \mathrm{H}) ;{ }^{13} \mathrm{C}$ NMR (100 MHz, DMSO) $\delta 172.21,158.98,155.74,138.53,136.13,129.28$, 128.47, 126.70, 115.21, 78.33, 55.94, 53.53, 37.86, 37.10, 28.65. ESI-MS: $m / z 385.4(\mathrm{M}+1)^{+}, \mathrm{C}_{22} \mathrm{H}_{28} \mathrm{~N}_{2} \mathrm{O}_{4}$ (384.2).

4.1.8. (S)-2-Amino- $\mathrm{N}$-(4-methoxyphenyl)- $\mathrm{N}$-methyl-3-phenylpropanamide (13). Trifluoroacetic acid (34.2 mmol, 5.0 eq.) was added dropwise to intermediate 12 (2.6 g, $6.84 \mathrm{mmol}, 1.0$ eq.) in $30 \mathrm{~mL}$ dichloromethane and stirred at room temperature for 6$7 \mathrm{~h}$. Then, the resulting mixture solution was alkalized to $\mathrm{pH}=9$ with saturated sodium bicarbonate solution, and then extracted 
with dichloromethane $(3 \times 20 \mathrm{~mL})$. The combined organic layer was dried over anhydrous $\mathrm{Na}_{2} \mathrm{SO}_{4}$, filtered, and concentrated under reduced pressure to yield the crude product $\mathbf{1 3}$ as yellow oil, which was directly injected the next step. ${ }^{1} \mathrm{H}$ NMR $(400 \mathrm{MHz}$, DMSO- $\left.d_{6}\right) \delta 7.34-7.15(\mathrm{~m}, 3 \mathrm{H}), 6.90(\mathrm{~s}, 6 \mathrm{H}), 3.77(\mathrm{~s}, 3 \mathrm{H}), 3.35(\mathrm{t}, J$ $=6.9 \mathrm{~Hz}, 1 \mathrm{H}), 3.06(\mathrm{~s}, 3 \mathrm{H}), 2.76(\mathrm{dd}, J=12.9,6.8 \mathrm{~Hz}, 1 \mathrm{H}), 2.46$ $(\mathrm{dd}, J=12.9,7.1 \mathrm{~Hz}, 1 \mathrm{H}) ;{ }^{13} \mathrm{C} \mathrm{NMR}(100 \mathrm{MHz}, \mathrm{DMSO}) \delta 174.96$, 158.76, 139.02, 136.36, 129.51, 128.93, 128.46, 126.54, 115.03, $55.83,53.38,42.25,37.45$. ESI-MS: $m / z 285.3(\mathrm{M}+1)^{+}$, $\mathrm{C}_{17} \mathrm{H}_{20} \mathrm{~N}_{2} \mathrm{O}_{2}$ (284.1).

4.1.9. (S)-3-Ethynyl- $N$-(1-((4-methoxyphenyl)(methyl)amino)-1oxo-3-phenylpropan-2-yl)benzamide (14). 3-ethynylbenzoic acid (4.22 mmol, $0.62 \mathrm{~g}$ ) and HATU (5.28 mmol, $2.0 \mathrm{~g}$ ) were mixed in dichloromethane and stirred in an ice bath for $1 \mathrm{~h}$. Then, the intermediate 13 (6.33 mmol, $1.80 \mathrm{~g}$ ) and DIEA (7.03 mmol, $1.16 \mathrm{~mL}$ ) were added to the above solution slowly at $0{ }^{\circ} \mathrm{C}$. The reaction system was then stirred at room temperature for additional $12 \mathrm{~h}$. The solvent was removed under reduced pressure and then $1 \mathrm{~N} \mathrm{HCl}(30$ $\mathrm{mL}$ ) was added, extracted with ethyl acetate $(3 \times 30 \mathrm{~mL})$. The combined organic layer was washed with saturated sodium bicarbonate $(3 \times 50 \mathrm{~mL})$. The resulting organic layer was washed with saturated salt water, dried over anhydrous $\mathrm{Na}_{2} \mathrm{SO}_{4}$, filtered, and concentrated under reduced pressure to afford corresponding crude product, which was purified by flash column chromatography to yield compound 14. Pale yellow solid, mp: $55-57{ }^{\circ} \mathrm{C}$, yield: $87 \%$. ${ }^{1} \mathrm{H}$ NMR (400 MHz, DMSO- $\left.d_{6}\right) \delta 8.83(\mathrm{~d}, J=7.8 \mathrm{~Hz}, 1 \mathrm{H}), 7.97(\mathrm{t}, J=$ $1.8 \mathrm{~Hz}, 1 \mathrm{H}), 7.83(\mathrm{dt}, J=7.8,1.4 \mathrm{~Hz}, 1 \mathrm{H}), 7.70-7.59(\mathrm{~m}, 1 \mathrm{H}), 7.47(\mathrm{t}, J$ $=7.8 \mathrm{~Hz}, 1 \mathrm{H}), 7.32(\mathrm{~d}, J=8.3 \mathrm{~Hz}, 2 \mathrm{H}), 7.16(\mathrm{qd}, J=7.4,3.5 \mathrm{~Hz}, 3 \mathrm{H})$, $7.05(\mathrm{~d}, J=8.5 \mathrm{~Hz}, 2 \mathrm{H}), 6.96-6.77(\mathrm{~m}, 2 \mathrm{H}), 4.66(\mathrm{q}, J=7.3 \mathrm{~Hz}, 1 \mathrm{H})$, $4.30(\mathrm{~s}, 1 \mathrm{H}), 3.82(\mathrm{~s}, 3 \mathrm{H}), 3.16(\mathrm{~s}, 3 \mathrm{H}), 2.93(\mathrm{~d}, J=7.2 \mathrm{~Hz}, 2 \mathrm{H}) .{ }^{13} \mathrm{C}$ NMR (100 MHz, DMSO) $\delta$ 171.75, 165.75, 159.10, 138.56, 136.10, 134.79, 131.01, 129.21, 128.58, 126.82, 122.14, 115.21, 83.31, 81.87, 55.96, 53.11, 37.90, 36.77. ESI-MS: $m / z 413.00(\mathrm{M}+\mathrm{H})^{+}, \mathrm{C}_{26} \mathrm{H}_{24} \mathrm{~N}_{2} \mathrm{O}_{3}$ (412.18).

4.1.10. General procedure for the synthesis of target compounds III-15(a-o). The key intermediate 14 (1.0 eq.), azide substituents (1.1 eq.), ascorbic acid sodium (0.6 eq.) and $\mathrm{CuSO}_{4} \cdot 5 \mathrm{H}_{2} \mathrm{O}$ (0.3 eq.) were dissolved in the solution of tetrahydrofuran/water $(\mathrm{v}: \mathrm{v}=1: 1)$. The resulting mixture was stirred at $30-60{ }^{\circ} \mathrm{C}$ for $4-6 \mathrm{~h}$. Then the reaction mixture was extracted with ethyl acetate $(3 \times 10 \mathrm{~mL})$, and the combined organic phase was washed with saturated salt water $(3 \times 10$ $\mathrm{mL}$ ), dried over anhydrous $\mathrm{MgSO}_{4}$, filtered, and concentrated under reduced pressure to give the corresponding crude target product, which was purified by flash column chromatography to afford product III-15(a-o). Yield: $65-80 \%$.

(S)-N-(1-((4-Methoxyphenyl)(methyl)amino)-1-oxo-3-phenylpropan-2-yl) -3-(1-(2-nitrobenzyl)-1H-1,2,3-triazol-4-yl)benzamide (III-15a). Yellow solid, yield: $65 \%$, mp: $163-165{ }^{\circ} \mathrm{C} .{ }^{1} \mathrm{H}$ NMR (400 MHz, DMSO- $d_{6}$ ) $\delta 8.82(\mathrm{~d}, J=7.8 \mathrm{~Hz}, 1 \mathrm{H}), 8.66(\mathrm{~s}, 1 \mathrm{H}), 8.31(\mathrm{t}, J=1.7 \mathrm{~Hz}, 1 \mathrm{H}), 8.18$ (dd, $J=8.1,1.3 \mathrm{~Hz}, 1 \mathrm{H}), 8.01(\mathrm{dt}, J=7.7,1.4 \mathrm{~Hz}, 1 \mathrm{H}), 7.87-7.73(\mathrm{~m}, 2 \mathrm{H})$, $7.67(\mathrm{td}, J=7.8,1.4 \mathrm{~Hz}, 1 \mathrm{H}), 7.53(\mathrm{t}, J=7.7 \mathrm{~Hz}, 1 \mathrm{H}), 7.31(\mathrm{~d}, J=8.3 \mathrm{~Hz}$, 2H), 7.24-7.09 (m, 4H), 7.08-7.01 (m, 2H), 6.98-6.82 (m, 2H), 6.06 (s, $2 \mathrm{H}), 4.67$ (q, $J=7.3 \mathrm{~Hz}, 1 \mathrm{H}), 3.82(\mathrm{~s}, 3 \mathrm{H}), 3.16(\mathrm{~s}, 3 \mathrm{H}), 2.94(\mathrm{~d}, J=$ $7.2 \mathrm{~Hz}, 2 \mathrm{H}) .{ }^{13} \mathrm{C}$ NMR (100 MHz, DMSO) $\delta 171.85,166.44,159.09$, 148.09, 146.55, 138.58, 136.14, 134.95, 131.11, 130.99, 130.80, 130.22, 129.34, 129.32, 129.27, 128.58, 128.40, 127.48, 126.82, 125.62, 124.88,
123.10, 115.18, 55.95, 53.05, 50.73, 37.90, 36.90. ESI-MS: $\mathrm{m} / z$ 591.4 (M $+\mathrm{H})^{+}, \mathrm{C}_{33} \mathrm{H}_{30} \mathrm{~N}_{6} \mathrm{O}_{5}$ (590.23).

(S)-N-(1-((4-Methoxypheryl)(methyl)amino)-1-oxo-3-phenylpropan-2-yl) -3-(1-(3-nitrobenzyl)-1H-1,2,3-triazol-4-yl)benzamide (II-15b). Yellow solid, yield: $65 \%$, mp: $96-98{ }^{\circ} \mathrm{C} .{ }^{1} \mathrm{H}$ NMR $\left(400 \mathrm{MHz}\right.$, DMSO- $\left.d_{6}\right) \delta 8.83$ $(\mathrm{d}, J=7.8 \mathrm{~Hz}, 1 \mathrm{H}), 8.75$ (s, $1 \mathrm{H}), 8.31$ (dt, $J=3.9,1.7 \mathrm{~Hz}, 2 \mathrm{H}), 8.23$ (ddd, $J=8.3,2.4,1.1 \mathrm{~Hz}, 1 \mathrm{H}), 7.99(\mathrm{dt}, J=7.7,1.4 \mathrm{~Hz}, 1 \mathrm{H}), 7.83$ (d, $J=$ $7.7 \mathrm{~Hz}, 1 \mathrm{H}), 7.80-7.76(\mathrm{~m}, 1 \mathrm{H}), 7.72(\mathrm{t}, J=7.9 \mathrm{~Hz}, 1 \mathrm{H}), 7.52(\mathrm{t}, J=$ $7.7 \mathrm{~Hz}, 1 \mathrm{H}), 7.31$ (d, $J=8.3 \mathrm{~Hz}, 2 \mathrm{H}), 7.21-7.09(\mathrm{~m}, 3 \mathrm{H}), 7.05$ (d, $J=$ 8.7 Hz, 2H), 6.98-6.85 (m, 2H), 5.87 (s, 2H), 4.67 (q, $J=7.3 \mathrm{~Hz}, 1 \mathrm{H})$, 3.82 (s, 3H), 3.16 (s, 3H), 2.94 (d, $J=7.2 \mathrm{~Hz}, 2 \mathrm{H}) .{ }^{13} \mathrm{C}$ NMR $(100 \mathrm{MHz}$, DMSO) $\delta$ 171.85, 166.44, 159.08, 148.39, 146.74, 138.58, 138.43, 136.12, 135.25, 134.93, 130.98, 129.34, 129.27, 128.59, 128.37, 127.45, 126.82, 124.85, 123.69, 123.39, 122.65, 115.17, 55.95, 53.06, 52.51, 37.90, 36.86. ESI-MS: $m / z 591.4(\mathrm{M}+\mathrm{H})^{+}, \mathrm{C}_{33} \mathrm{H}_{30} \mathrm{~N}_{6} \mathrm{O}_{5}$ (590.23).

(S)-N-(1-((4-Methoxyphenyl)(methyl)amino)-1-oxo-3-phenylpropan-2yl)-3-(1-(4-nitrobenzyl)-1H-1,2,3-triazol-4-yl)benzamide (III-15c). Pale yellow solid, yield: 78\%, mp: 87-89 ${ }^{\circ} \mathrm{C}$. ${ }^{1} \mathrm{H}$ NMR (400 MHz, DMSO$\left.d_{6}\right) \delta 8.84(\mathrm{~d}, J=7.8 \mathrm{~Hz}, 1 \mathrm{H}), 8.75(\mathrm{~s}, 1 \mathrm{H}), 8.33(\mathrm{~d}, J=1.7 \mathrm{~Hz}, 1 \mathrm{H})$, 8.31-8.24 (m, 2H), $8.00(\mathrm{dt}, J=7.7,1.4 \mathrm{~Hz}, 1 \mathrm{H}), 7.78(\mathrm{dt}, J=7.7$, $1.4 \mathrm{~Hz}, 1 \mathrm{H}), 7.74-7.56(\mathrm{~m}, 2 \mathrm{H}), 7.53(\mathrm{t}, J=7.8 \mathrm{~Hz}, 1 \mathrm{H}), 7.32(\mathrm{~d}, J=$ $8.3 \mathrm{~Hz}, 2 \mathrm{H}), 7.24-7.10(\mathrm{~m}, 3 \mathrm{H}), 7.05(\mathrm{~d}, J=8.8 \mathrm{~Hz}, 2 \mathrm{H}), 6.98-6.87(\mathrm{~m}$, $2 \mathrm{H}), 5.89$ (s, 2H), 4.67 (q, $J=7.3 \mathrm{~Hz}, 1 \mathrm{H}), 3.82$ (s, 3H), $3.16(\mathrm{~s}, 3 \mathrm{H})$, 2.94 (d, $J=7.2 \mathrm{~Hz}, 2 \mathrm{H}) .{ }^{13} \mathrm{C}$ NMR (100 MHz, DMSO) $\delta 171.86$, $166.44,159.08,147.74,146.77,143.81,138.59$, 136.12, 134.93, 130.99 , 129.52, 129.34, 129.26, 128.59, 128.38, 127.46, 126.82, 124.86, 124.46, 122.82, 115.17, 55.95, 53.06, 52.65, 37.90, 36.85. ESIMS: $m / z 591.4(\mathrm{M}+\mathrm{H})^{+}, \mathrm{C}_{33} \mathrm{H}_{30} \mathrm{~N}_{6} \mathrm{O}_{5}(590.23)$.

(S)-3-(1-(4-Carbamoylbenzyl)-1H-1,2,3-triazol-4-yl)-N-(1-((4methoxyphenyl)(methyl)amino)-1-oxo-3-phenylpropan-2-yl)benzamide (III-15d). White solid, yield: 66\%, mp: 96-98 ${ }^{\circ} \mathrm{C}$. ${ }^{1} \mathrm{H}$ NMR $(400 \mathrm{MHz}$, DMSO- $\left.d_{6}\right) \delta 8.81(\mathrm{~d}, J=7.8 \mathrm{~Hz}, 1 \mathrm{H}), 8.70(\mathrm{~s}, 1 \mathrm{H}), 8.32(\mathrm{t}, J=1.7 \mathrm{~Hz}$, $1 \mathrm{H}), 8.00(\mathrm{~d}, J=7.9 \mathrm{~Hz}, 2 \mathrm{H}), 7.91(\mathrm{~d}, J=8.0 \mathrm{~Hz}, 2 \mathrm{H}), 7.78(\mathrm{dt}, J=7.8$, $1.4 \mathrm{~Hz}, 1 \mathrm{H}), 7.53(\mathrm{t}, J=7.8 \mathrm{~Hz}, 1 \mathrm{H}), 7.43(\mathrm{t}, J=6.6 \mathrm{~Hz}, 3 \mathrm{H}), 7.31(\mathrm{~d}, J$ $=8.3 \mathrm{~Hz}, 2 \mathrm{H}), 7.26-7.10(\mathrm{~m}, 3 \mathrm{H}), 7.05(\mathrm{~d}, J=8.5 \mathrm{~Hz}, 2 \mathrm{H}), 6.99-6.82$ $(\mathrm{m}, 2 \mathrm{H}), 5.76(\mathrm{~s}, 2 \mathrm{H}), 4.70(\mathrm{q}, J=7.3 \mathrm{~Hz}, 1 \mathrm{H}), 3.82(\mathrm{~s}, 3 \mathrm{H}), 3.17(\mathrm{~s}$, $3 \mathrm{H}), 2.95$ (d, $J=7.2 \mathrm{~Hz}, 2 \mathrm{H}) .{ }^{13} \mathrm{C}$ NMR (100 MHz, DMSO) $\delta 171.87$, 167.93 , 166.49, 159.09, 146.71, 139.40, 138.55, 136.13, 134.95, $134.60,131.09,129.33,129.28,128.59$, 128.47, 128.20, 127.41,

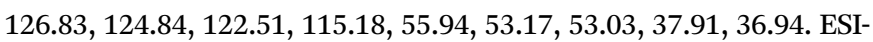
MS: $m / z 589.4(\mathrm{M}+\mathrm{H})^{+}, \mathrm{C}_{34} \mathrm{H}_{32} \mathrm{~N}_{6} \mathrm{O}_{4}(588.25)$.

(S)-N-(1-((4-Methoxyphenyl)(methyl)amino)-1-oxo-3-phenylpropan-2yl)-3-(1-(2-oxo-2-(phenylamino)ethyl)-1H-1,2,3-triazol-4-yl)benzamide (III-15e). Pale yellow solid, yield: 76\%, mp: $105-107^{\circ} \mathrm{C} .{ }^{1} \mathrm{H}$ NMR (400 MHz, DMSO- $\left.d_{6}\right) \delta 10.56(\mathrm{~s}, 1 \mathrm{H}), 8.85(\mathrm{~d}, J=7.8 \mathrm{~Hz}, 1 \mathrm{H}), 8.66(\mathrm{~s}, 1 \mathrm{H})$, $8.36(\mathrm{t}, J=1.8 \mathrm{~Hz}, 1 \mathrm{H}), 8.02(\mathrm{dt}, J=7.7,1.4 \mathrm{~Hz}, 1 \mathrm{H}), 7.78(\mathrm{dt}, J=7.7$, $1.4 \mathrm{~Hz}, 1 \mathrm{H}), 7.65-7.59(\mathrm{~m}, 2 \mathrm{H}), 7.54(\mathrm{t}, J=7.7 \mathrm{~Hz}, 1 \mathrm{H}), 7.34(\mathrm{q}, J=$ 9.5, 8.6 Hz, 4H), 7.21-7.08 (m, 4H), 7.07-7.00 (m, 2H), 6.97-6.88 (m, $2 \mathrm{H}), 5.44$ (s, 2H), 4.69 (q, $J=7.3 \mathrm{~Hz}, 1 \mathrm{H}), 3.82$ (s, 3H), 3.16 (s, 3H), 2.95 (d, $J=7.2 \mathrm{~Hz}, 2 \mathrm{H}) .{ }^{13} \mathrm{C}$ NMR (100 MHz, DMSO) $\delta 171.87$, $166.43,164.62,159.08,146.20,138.88,138.60,136.13,134.92$, $131.18,129.41,129.28,128.60,128.32,127.40,126.83,124.70$,

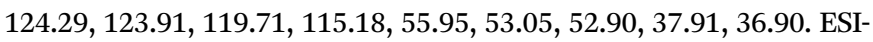
MS: $m / z 589.4(\mathrm{M}+\mathrm{H})^{+}, \mathrm{C}_{34} \mathrm{H}_{32} \mathrm{~N}_{6} \mathrm{O}_{3}(588.25)$.

(S)-N-(1-((4-Methoxyphenyl)(methyl)amino)-1-oxo-3-phenylpropan-2yl)-3-(1-(4-sulfamoylbenzyl)-1H-1,2,3-triazol-4-yl)benzamide (II-15f). Pale yellow solid, yield: 61\%, mp: $240-242{ }^{\circ} \mathrm{C} .{ }^{1} \mathrm{H}$ NMR $(400 \mathrm{MHz}$, 
DMSO- $\left.d_{6}\right) \delta 8.82(\mathrm{~d}, J=7.8 \mathrm{~Hz}, 1 \mathrm{H}), 8.73(\mathrm{~s}, 1 \mathrm{H}), 8.32(\mathrm{~s}, 1 \mathrm{H}), 8.00(\mathrm{~d}$, $J=7.8 \mathrm{~Hz}, 1 \mathrm{H}), 7.86(\mathrm{~d}, J=8.0 \mathrm{~Hz}, 2 \mathrm{H}), 7.78(\mathrm{~d}, J=7.9 \mathrm{~Hz}, 1 \mathrm{H}), 7.54$ $(\mathrm{d}, J=8.0 \mathrm{~Hz}, 3 \mathrm{H}), 7.40(\mathrm{~s}, 2 \mathrm{H}), 7.31(\mathrm{~d}, J=8.2 \mathrm{~Hz}, 2 \mathrm{H}), 7.16(\mathrm{dt}, J=$ 11.9, $6.7 \mathrm{~Hz}, 3 \mathrm{H}), 7.05$ (d, $J=8.4 \mathrm{~Hz}, 2 \mathrm{H}), 6.98-6.84(\mathrm{~m}, 2 \mathrm{H}), 5.79$ (s, $2 \mathrm{H}), 4.68$ (q, $J=7.3 \mathrm{~Hz}, 1 \mathrm{H}), 3.82(\mathrm{~s}, 3 \mathrm{H}), 3.16(\mathrm{~s}, 3 \mathrm{H}), 2.95$ (d, $J=$ $7.2 \mathrm{~Hz}, 2 \mathrm{H}) .{ }^{13} \mathrm{C}$ NMR (100 MHz, DMSO) $\delta$ 171.85, 166.44, 159.08, $146.73,144.34,140.16,138.57,136.13,134.93,129.34,129.27$, 128.85, 128.38, 127.42, 126.83, 126.65, 124.84, 122.61, 115.18, 55.95, 53.04, 52.94, 37.90, 36.89. ESI-MS: $m / z 625.4(\mathrm{M}+\mathrm{H})^{+}, \mathrm{C}_{33} \mathrm{H}_{32} \mathrm{~N}_{6} \mathrm{O}_{5} \mathrm{~S}$ (624.22).

(S)-N-(1-((4-Methoxyphenyl)(methyl)amino)-1-oxo-3-phenylpropan-2-yl) -3-(1-(3-phenylpropyl)-1H-1,2,3-triazol-4-yl)benzamide (III-15g). White solid, yield: $82 \%$, mp: $141-143{ }^{\circ} \mathrm{C} .{ }^{1} \mathrm{H}$ NMR (400 MHz, DMSO- $d_{6}$ ) $\delta 8.83(\mathrm{~d}, J=7.7 \mathrm{~Hz}, 1 \mathrm{H}), 8.68(\mathrm{~s}, 1 \mathrm{H}), 8.33(\mathrm{t}, J=1.7 \mathrm{~Hz}, 1 \mathrm{H})$, $7.99(\mathrm{dd}, J=7.7,1.6 \mathrm{~Hz}, 1 \mathrm{H}), 7.78(\mathrm{~d}, J=7.7 \mathrm{~Hz}, 1 \mathrm{H}), 7.53(\mathrm{t}, J=$ $7.8 \mathrm{~Hz}, 1 \mathrm{H}), 7.31$ (t, $J=7.6 \mathrm{~Hz}, 4 \mathrm{H}), 7.26-7.22(\mathrm{~m}, 2 \mathrm{H}), 7.19(\mathrm{~d}, J$ $=10.5 \mathrm{~Hz}, 2 \mathrm{H}), 7.13(\mathrm{dd}, J=13.6,6.7 \mathrm{~Hz}, 2 \mathrm{H}), 7.05(\mathrm{~d}, J=8.6 \mathrm{~Hz}$, $2 \mathrm{H}), 6.95-6.88(\mathrm{~m}, 2 \mathrm{H}), 4.68(\mathrm{q}, J=7.4 \mathrm{~Hz}, 1 \mathrm{H}), 4.44(\mathrm{t}, J=$ $7.0 \mathrm{~Hz}, 2 \mathrm{H}), 3.82(\mathrm{~s}, 3 \mathrm{H}), 3.16(\mathrm{~s}, 3 \mathrm{H}), 2.95(\mathrm{~d}, J=7.2 \mathrm{~Hz}, 2 \mathrm{H})$, $2.62(\mathrm{dd}, J=8.8,6.6 \mathrm{~Hz}, 2 \mathrm{H}), 2.29-2.07$ (m, 2H). ${ }^{13} \mathrm{C}$ NMR $(100$ MHz, DMSO) $\delta 171.88,166.50,159.09,146.34,141.21,138.61$, $136.14,134.92,131.36,129.35,129.27,128.87,128.83,128.59$, 128.31, 127.24, 126.82, 126.49, 124.79, 122.13, 115.18, 55.95, 53.07, 49.61, 37.91, 36.86, 32.37, 31.73. ESI-MS: $m / z 574.5(\mathrm{M}+$ $\mathrm{H})^{+}, \mathrm{C}_{35} \mathrm{H}_{35} \mathrm{~N}_{5} \mathrm{O}_{3}$ (573.27).

(S)-N-(1-((4-Methoxyphenyl)(methyl)amino)-1-oxo-3-phenylpropan-2yl)-3-(1-(3-(thiophen-3-yl)propyl)-1H-1,2,3-triazol-4-yl)benzamide (III15h). White solid, yield: 76\%, mp: 69-71 ${ }^{\circ} \mathrm{C} .{ }^{1} \mathrm{H}$ NMR $(400 \mathrm{MHz}$, DMSO- $\left.d_{6}\right) \delta 8.81(\mathrm{~d}, J=7.8 \mathrm{~Hz}, 1 \mathrm{H}), 8.57(\mathrm{~s}, 1 \mathrm{H}), 8.29(\mathrm{~s}, 1 \mathrm{H}), 7.95(\mathrm{~d}$, $J=7.8 \mathrm{~Hz}), 7.77$ (d, $J=7.8 \mathrm{~Hz}, 1 \mathrm{H}), 7.61-7.43(\mathrm{~m}, 2 \mathrm{H}), 7.31$ (d, $J=$ $8.3 \mathrm{~Hz}, 2 \mathrm{H}), 7.24$ (d, $J=2.8 \mathrm{~Hz}, 1 \mathrm{H}), 7.17$ (dt, $J=11.9,6.7 \mathrm{~Hz}, 3 \mathrm{H})$, $7.05(\mathrm{~d}, J=8.5 \mathrm{~Hz}, 2 \mathrm{H}), 7.01(\mathrm{~d}, J=4.9 \mathrm{~Hz}, 1 \mathrm{H}), 6.97-6.86(\mathrm{~m}, 2 \mathrm{H})$, $4.69(\mathrm{t}, J=7.2 \mathrm{~Hz}, 3 \mathrm{H}), 3.83(\mathrm{~s}, 3 \mathrm{H}), 3.27(\mathrm{t}, J=7.2 \mathrm{~Hz}, 2 \mathrm{H}), 3.17(\mathrm{~s}$, $3 \mathrm{H}), 2.95$ (d, $J=7.2 \mathrm{~Hz}, 2 \mathrm{H}) .{ }^{13} \mathrm{C}$ NMR (100 MHz, DMSO) $\delta 171.87$, 166.50 , 159.09, 146.13, 138.58, 138.26, 136.14, 134.94, 131.30, $129.34,129.28,128.69,128.59,128.26,127.24,126.83,126.69$, 124.73, 122.58, 122.13, 115.18, 55.96, 53.05, 50.55, 37.91, 36.90, 30.69. ESI-MS: $m / z 566.4(\mathrm{M}+\mathrm{H})^{+}, \mathrm{C}_{32} \mathrm{H}_{31} \mathrm{~N}_{5} \mathrm{O}_{3} \mathrm{~S}(565.21)$.

(S)-N-(1-((4-Methoxyphenyl)(methyl)amino)-1-oxo-3-phenylpropan-2yl)-3-(1-(quinolin-2-yl)-1H-1,2,3-triazol-4-yl)benzamide (III-15i). Pale yellow solid, yield: $81 \%$, mp: $148-150{ }^{\circ} \mathrm{C} .{ }^{1} \mathrm{H}$ NMR $(400 \mathrm{MHz}$, DMSO- $\left._{6}\right) \delta 9.60(\mathrm{~s}, 1 \mathrm{H}), 9.55(\mathrm{~d}, J=2.6 \mathrm{~Hz}, 1 \mathrm{H}), 9.00(\mathrm{~d}, J=2.5 \mathrm{~Hz}$, $1 \mathrm{H}), 8.89(\mathrm{~d}, J=7.7 \mathrm{~Hz}, 1 \mathrm{H}), 8.48(\mathrm{t}, J=1.7 \mathrm{~Hz}, 1 \mathrm{H}), 8.23-8.15(\mathrm{~m}$, $2 \mathrm{H}), 8.14-8.08(\mathrm{~m}, 1 \mathrm{H}), 7.95-7.85(\mathrm{~m}, 2 \mathrm{H}), 7.76(\mathrm{dd}, J=8.5,7.0 \mathrm{~Hz}$, $1 \mathrm{H}), 7.62(\mathrm{t}, J=7.7 \mathrm{~Hz}, 1 \mathrm{H}), 7.33(\mathrm{~d}, J=8.1 \mathrm{~Hz}, 2 \mathrm{H}), 7.18(\mathrm{dt}, J=$ 13.8, $6.8 \mathrm{~Hz}, 3 \mathrm{H}), 7.06$ (d, $J=8.6 \mathrm{~Hz}, 2 \mathrm{H}), 6.99-6.87$ (m, 2H), 4.904.60 (m, 1H, CHCO), 3.83 (s, 3H, $\mathrm{OCH}_{3}$ ), 3.18 (s, 3H, $\mathrm{NCH}_{3}$ ), 3.09$2.85\left(\mathrm{~m}, 2 \mathrm{H}, \mathrm{Ph}^{\prime \prime}-\mathrm{CH}_{2}\right) .{ }^{13} \mathrm{C} \mathrm{NMR}(100 \mathrm{MHz}, \mathrm{DMSO}) \delta 171.90,166.48$, $159.11,147.44,143.55,138.58,136.16$, 135.14, 130.98, 130.63, 129.42 , 129.35, 129.30, 129.10, 128.61, 127.72, 127.56, 126.84, 126.31, 125.19, 121.02, 115.19, 55.96, 53.13, 37.92, 36.91. ESI-MS: $m /$ $z 583.3(\mathrm{M}+\mathrm{H})^{+}, \mathrm{C}_{35} \mathrm{H}_{30} \mathrm{~N}_{6} \mathrm{O}_{3}(582.24)$.

(S)-N-(1-((4-Methoxyphenyl)(methyl)amino)-1-oxo-3-phenylpropan-2yl)-3-(1-(naphthalen-2-ylmethyl)-1H-1,2,3-triazol-4-yl)benzamide (III15j). White solid, yield: $71 \%$, mp: $86-88{ }^{\circ} \mathrm{C} .{ }^{1} \mathrm{H}$ NMR $(400 \mathrm{MHz}$, DMSO- $\left.d_{6}\right) \delta 8.80(\mathrm{~d}, J=7.8 \mathrm{~Hz}, 1 \mathrm{H}, \mathrm{NH}), 8.72(\mathrm{~s}, 1 \mathrm{H}), 8.31(\mathrm{~d}, J=$ $1.7 \mathrm{~Hz}, 1 \mathrm{H}), 8.08-7.85$ (m, 5H), 7.83-7.69 (m, 1H), 7.60-7.45 (m, 4H), $7.30(\mathrm{~d}, J=8.2 \mathrm{~Hz}, 2 \mathrm{H}), 7.14(\mathrm{dt}, J=12.1,6.7 \mathrm{~Hz}, 3 \mathrm{H}), 7.04(\mathrm{~d}, J=$ $8.6 \mathrm{~Hz}, 2 \mathrm{H}), 6.97-6.83(\mathrm{~m}, 2 \mathrm{H}), 5.86(\mathrm{~s}, 2 \mathrm{H}), 4.67(\mathrm{~d}, J=7.4 \mathrm{~Hz}, 1 \mathrm{H})$, $3.82(\mathrm{~s}, 3 \mathrm{H}), 3.16(\mathrm{~s}, 3 \mathrm{H}), 2.94(\mathrm{~d}, J=7.2 \mathrm{~Hz}, 2 \mathrm{H}) .{ }^{13} \mathrm{C} \mathrm{NMR}(100 \mathrm{MHz}$, DMSO) $\delta 171.84,166.46,159.08,146.68,138.56,136.13,134.93$, $133.86,133.26,133.03,131.14,129.33,129.27,129.07,128.57$, 128.32 , 128.10, 127.45, 127.37, 127.06, 126.94, 126.80, 126.19, 124.81, 122.44, 115.17, 55.95, 53.77, 53.02, 37.90, 36.90. ESI-MS: $\mathrm{m} / \mathrm{z}$ $596.4(\mathrm{M}+\mathrm{H})^{+}, \mathrm{C}_{37} \mathrm{H}_{33} \mathrm{~N}_{5} \mathrm{O}_{3}$ (595.26).

(S)-N-(1-((4-Methoxyphenyl)(methyl)amino)-1-oxo-3-phenylpropan-2yl)-3-(1-(naphthalen-1-ylmethyl)-1H-1,2,3-triazol-4-yl)benzamide (III15k). White solid, yield: $76 \%$, mp: $109-111^{\circ} \mathrm{C} .{ }^{1} \mathrm{H}$ NMR $(400 \mathrm{MHz}$, DMSO- $\left.d_{6}\right) \delta 8.79(\mathrm{~d}, J=7.8 \mathrm{~Hz}, 1 \mathrm{H}), 8.62(\mathrm{~s}, 1 \mathrm{H}), 8.33-8.17(\mathrm{~m}, 2 \mathrm{H})$, 8.10-7.94 (m, 3H), $7.74(\mathrm{dt}, J=7.7,1.4 \mathrm{~Hz}, 1 \mathrm{H}), 7.66-7.41(\mathrm{~m}, 5 \mathrm{H})$, $7.30(\mathrm{~d}, J=8.3 \mathrm{~Hz}, 2 \mathrm{H}), 7.21-7.07(\mathrm{~m}, 3 \mathrm{H}), 7.04(\mathrm{~d}, J=8.8 \mathrm{~Hz}, 2 \mathrm{H})$, 6.97-6.85 (m, 2H), $6.18(\mathrm{~s}, 2 \mathrm{H}), 4.66(\mathrm{~d}, J=7.3 \mathrm{~Hz}, 1 \mathrm{H}), 3.82(\mathrm{~s}, 3 \mathrm{H})$, 3.15 (s, 3H), 2.93 (d, $J=7.3 \mathrm{~Hz}, 2 \mathrm{H}) .{ }^{13} \mathrm{C}$ NMR (100 MHz, DMSO) $\delta 171.83,166.46,159.07,146.53,138.56,136.13,134.92,133.88$, $131.78,131.14,131.04,129.61,129.33,129.26,129.18,128.57$, 128.33 , 127.90, 127.33, 126.80, 126.68, 126.10, 124.79, 123.69, 122.40, 115.17, 55.94, 53.02, 51.61, 37.89, 36.89. ESI-MS: $\mathrm{m} / z$ 596.4 $(\mathrm{M}+\mathrm{H})^{+}, \mathrm{C}_{37} \mathrm{H}_{33} \mathrm{~N}_{5} \mathrm{O}_{3}$ (595.26).

(S)-N-(1-((4-Methoxyphenyl)(methyl)amino)-1-oxo-3-phenylpropan-2yl)-3-(1-(naphthalen-1-ylmethyl)-1H-1,2,3-triazol-4-yl)benzamide (III15l). White solid, yield: 63\%, mp: $71-73{ }^{\circ} \mathrm{C} .{ }^{1} \mathrm{H}$ NMR $(400 \mathrm{MHz}$, DMSO- $\left.d_{6}\right) \delta 8.84(\mathrm{~d}, J=7.8 \mathrm{~Hz}, 1 \mathrm{H}), 8.62(\mathrm{~s}, 1 \mathrm{H}), 8.33(\mathrm{t}, J=1.8 \mathrm{~Hz}$, $1 \mathrm{H}), 8.00(\mathrm{~d}, J=7.7 \mathrm{~Hz}, 1 \mathrm{H}), 7.78(\mathrm{~d}, J=7.8 \mathrm{~Hz}, 1 \mathrm{H}), 7.54(\mathrm{t}, J=$ $7.7 \mathrm{~Hz}, 1 \mathrm{H}), 7.31$ (d, $J=8.2 \mathrm{~Hz}, 2 \mathrm{H}), 7.16(\mathrm{dt}, J=13.5,6.8 \mathrm{~Hz}, 3 \mathrm{H})$, $7.05(\mathrm{~d}, J=8.5 \mathrm{~Hz}, 2 \mathrm{H}), 6.98-6.78(\mathrm{~m}, 2 \mathrm{H}), 5.52(\mathrm{~s}, 2 \mathrm{H}), 4.68(\mathrm{~d}, J=$ $7.4 \mathrm{~Hz}, 1 \mathrm{H}), 3.82(\mathrm{~s}, 3 \mathrm{H}), 3.75$ (s, 3H), 3.16 (s, 3H), 2.95 (d, J=7.2 Hz, $2 \mathrm{H}) .{ }^{13} \mathrm{C}$ NMR (100 MHz, DMSO) $\delta$ 171.85, 168.17, 166.41, 159.09, 146.39 , 138.59, 136.14, 134.96, 130.97, 129.35, 129.28, 128.60, 128.36, 127.51, 126.83, 124.76, 123.59, 115.19, 55.95, 53.10, 53.04, 51.00, 37.91, 36.92. ESI-MS: $m / z 528.3(\mathrm{M}+\mathrm{H})^{+}, \mathrm{C}_{29} \mathrm{H}_{29} \mathrm{~N}_{5} \mathrm{O}_{5}(527.22)$.

Methyl (S)-2-(4-(3-((1-((4-methoxyphenyl)(methyl)amino)-1-oxo-3phenylpropan-2-yl)carbamoyl)phenyl)-1H-1,2,3-triazol-1-yl)acetate (III15m). Pale yellow solid, yield: $73 \%$, mp: $87-89{ }^{\circ} \mathrm{C}$. ${ }^{1} \mathrm{H}$ NMR (400 MHz, DMSO- $\left.d_{6}\right) \delta 8.85(\mathrm{~d}, J=7.8 \mathrm{~Hz}, 1 \mathrm{H}), 8.62(\mathrm{~s}, 1 \mathrm{H}), 8.33(\mathrm{~d}, J=$ $1.8 \mathrm{~Hz}, 1 \mathrm{H}), 8.00(\mathrm{~d}, J=7.7 \mathrm{~Hz}, 1 \mathrm{H}), 7.78(\mathrm{~d}, J=7.8 \mathrm{~Hz}, 1 \mathrm{H}), 7.54(\mathrm{t}, J$ $=7.7 \mathrm{~Hz}, 1 \mathrm{H}), 7.31(\mathrm{~d}, J=8.2 \mathrm{~Hz}, 2 \mathrm{H}), 7.16(\mathrm{dt}, J=13.6,6.8 \mathrm{~Hz}, 3 \mathrm{H})$, $7.08-7.00(\mathrm{~m}, 2 \mathrm{H}), 6.98-6.79(\mathrm{~m}, 2 \mathrm{H}), 5.50(\mathrm{~s}, 2 \mathrm{H}), 4.68(\mathrm{q}, J=7.3 \mathrm{~Hz}$, $1 \mathrm{H}), 4.22(\mathrm{q}, J=7.1 \mathrm{~Hz}, 2 \mathrm{H}), 3.82(\mathrm{~s}, 3 \mathrm{H}), 3.16(\mathrm{~s}, 3 \mathrm{H}), 2.95$ (d, $J=$ $7.2 \mathrm{~Hz}, 2 \mathrm{H}), 1.25$ (t, $J=7.1 \mathrm{~Hz}, 3 \mathrm{H}) .{ }^{13} \mathrm{C}$ NMR (100 MHz, DMSO) $\delta 171.85,167.70,166.41,159.09,146.37,138.59,136.14,134.96$, 130.99 , 129.35, 128.60, 128.36, 127.50, 126.82, 124.75, 123.59, 115.18, 62.08, 55.95, 53.04, 51.09, 37.91, 36.91, 14.47. ESI-MS: $m / z$ $542.4(\mathrm{M}+\mathrm{H})^{+}, \mathrm{C}_{30} \mathrm{H}_{31} \mathrm{~N}_{5} \mathrm{O}_{5}$ (541.23).

Ethyl (S)-2-(4-(3-((1-((4-methoxyphenyl)(methyl)amino)-1-oxo-3phenylpropan-2-yl)carbamoyl)phenyl)-1H-1,2,3-triazol-1-yl)acetate (III-15n). Pale yellow solid, yield: $68 \%$, mp: $116-118{ }^{\circ} \mathrm{C} .{ }^{1} \mathrm{H}$ NMR $\left(400 \mathrm{MHz}, \mathrm{DMSO}-d_{6}\right) \delta 8.83(\mathrm{~d}, J=7.8 \mathrm{~Hz}, 1 \mathrm{H}), 8.65(\mathrm{~s}, 1 \mathrm{H}), 8.32$ (t, $J=1.7 \mathrm{~Hz}, 1 \mathrm{H}), 7.98(\mathrm{~d}, J=7.7 \mathrm{~Hz}, 1 \mathrm{H}), 7.78(\mathrm{~d}, J=7.7 \mathrm{~Hz}$, $1 \mathrm{H}), 7.53(\mathrm{t}, J=7.7 \mathrm{~Hz}, 1 \mathrm{H}), 7.32(\mathrm{~d}, J=8.2 \mathrm{~Hz}, 2 \mathrm{H}), 7.16(\mathrm{dt}, J=$ 13.1, $6.8 \mathrm{~Hz}, 3 \mathrm{H}), 7.09-7.01(\mathrm{~m}, 2 \mathrm{H}), 6.98-6.85$ (m, 2H), 4.68 (q, $=7.4 \mathrm{~Hz}, 1 \mathrm{H}), 4.47(\mathrm{t}, J=6.9 \mathrm{~Hz}, 2 \mathrm{H}), 3.82\left(\mathrm{~s}, 3 \mathrm{H}, \mathrm{OCH}_{3}\right), 3.59(\mathrm{~s}$, $3 \mathrm{H}), 3.17(\mathrm{~s}, 3 \mathrm{H}), 2.95(\mathrm{~d}, J=7.2 \mathrm{~Hz}, 2 \mathrm{H}), 2.39(\mathrm{t}, J=7.3 \mathrm{~Hz}, 2 \mathrm{H})$, 2.15 (p, $J=7.2 \mathrm{~Hz}, 2 \mathrm{H}) .{ }^{13} \mathrm{C}$ NMR (100 MHz, DMSO) $\delta 172.99$, 171.88 , 166.50, 159.08, 146.35, 138.60, 136.13, 131.29, 129.35, 
129.27, 128.59, 128.31, 127.27, 126.83, 124.78, 122.23, 115.17, 55.95, 53.07, 51.90, 49.26, 37.90, 36.86, 30.61, 25.53. ESI-MS: $\mathrm{m} / \mathrm{z}$ $556.3(\mathrm{M}+\mathrm{H})^{+}, \mathrm{C}_{31} \mathrm{H}_{33} \mathrm{~N}_{5} \mathrm{O}_{5}(555.25)$.

3-(1-(2-(Hydroxymethyl)-5-(5-methyl-2, 6-dioxo-1,2,3, 6-tetrahyd ropyridin-3-yl)tetrahydrofuran-3-yl)-1H-1,2,3-triazol-4-yl)-N-((S)-1((4-methoxyphenyl)(methyl)amino)-1-oxo-3-phenylpropan-2-yl) benzamide (III-15o). White solid, yield: 74\%, mp: $132-134{ }^{\circ} \mathrm{C} .{ }^{1} \mathrm{H}$ NMR (400 MHz, DMSO- $\left.d_{6}\right) \delta 11.39(\mathrm{~s}, 1 \mathrm{H}), 8.99-8.71(\mathrm{~m}, 2 \mathrm{H})$, $8.33(\mathrm{t}, J=1.7 \mathrm{~Hz}, 1 \mathrm{H}), 8.00(\mathrm{~d}, J=7.7 \mathrm{~Hz}, 1 \mathrm{H}), 7.85(\mathrm{~d}, J=$ $1.4 \mathrm{~Hz}, 1 \mathrm{H}), 7.79$ (d, J=7.8 Hz, 1H), 7.54 (t, $J=7.8 \mathrm{~Hz}, 1 \mathrm{H}), 7.32$ $(\mathrm{d}, J=8.3 \mathrm{~Hz}, 2 \mathrm{H}), 7.16(\mathrm{dt}, J=12.9,6.7 \mathrm{~Hz}, 3 \mathrm{H}), 7.05(\mathrm{~d}, J=$ $8.8 \mathrm{~Hz}, 2 \mathrm{H}), 6.99-6.87(\mathrm{~m}, 2 \mathrm{H}), 6.47(\mathrm{t}, J=6.6 \mathrm{~Hz}, 1 \mathrm{H}), 5.44(\mathrm{dt}, J$ $=8.8,5.4 \mathrm{~Hz}, 1 \mathrm{H}), 5.33(\mathrm{t}, J=5.3 \mathrm{~Hz}, 1 \mathrm{H}), 4.67(\mathrm{q}, J=7.4 \mathrm{~Hz}$, $1 \mathrm{H}), 4.30(\mathrm{q}, J=3.9 \mathrm{~Hz}, 1 \mathrm{H}), 3.82(\mathrm{~s}, 3 \mathrm{H}), 3.76-3.55(\mathrm{~m}, 2 \mathrm{H}), 3.16$ $(\mathrm{s}, 3 \mathrm{H}), 2.95(\mathrm{~d}, J=7.3 \mathrm{~Hz}, 2 \mathrm{H}), 2.88-2.61(\mathrm{~m}, 2 \mathrm{H}), 1.83(\mathrm{~d}, J=$ $1.1 \mathrm{~Hz}, 3 \mathrm{H}) .{ }^{13} \mathrm{C}$ NMR (100 MHz, DMSO) $\delta 171.87,166.47$, 164.21, 159.09, 150.92, 146.56, 138.60, 136.74, 136.14, 134.97, 131.08, 129.35, 128.60, 127.39, 126.83, 124.89, 121.89, 115.18, 110.13, 84.90, 84.35, 61.23, 59.93, 55.96, 53.09, 37.91, 37.59, 36.84, 12.75. ESI-MS: $m / z 680.3(\mathrm{M}+\mathrm{H})^{+}, \mathrm{C}_{36} \mathrm{H}_{37} \mathrm{~N}_{7} \mathrm{O}_{7}$ (679.28).

\subsection{In vitro anti-HIV assay}

4.2.1. Assessment of inhibitory activity on HIV-1 replication in TZM-bl cells. Inhibitory activity of compounds against HIV-1 infection in TZM-bl cells was measured as the reduction in luciferase gene expression after multiple rounds of virus infection of the cells similar to that described previously. ${ }^{37}$ Briefly, 200 TCID50 of virus $\left(\mathrm{NL}_{4-3}\right)$ was used to infect TZM-bl cells in the presence of various concentrations of compounds. Two days after infection, the culture medium was removed from each well and $100 \mu \mathrm{L}$ of Bright Glo reagent (Promega, Luis Obispo, CA) was added to the cells for measurement of luminescence using a Victor 2 luminometer. The effective concentration $\left(\mathrm{EC}_{50}\right)$ against $\mathrm{HIV}-1$ strains was defined as the concentration that caused a $50 \%$ reduction of luciferase activity (Relative Light Units) compared to virus control wells.

4.2.2. Cytotoxicity assay. A CytoTox-Glo cytotoxicity assay (Promega) was used to determine the cytotoxicity of the synthesized compounds. Parallel to the antiviral assays, TZM-bl cells were cultured in the presence of various concentrations of the compounds for 1 day. The percent of viable cells was determined by following the protocol provided by the manufacturer. The $50 \%$ cytotoxic concentration $\left(\mathrm{CC}_{50}\right)$ was defined as the concentration that caused a $50 \%$ reduction in cell viability.

\subsection{Binding to CA proteins analysis via surface plasmon resonance (SPR)}

All binding assays were performed on a ProteOn XPR36 SPR Protein Interaction Array System (Bio-Rad Laboratories, Hercules, CA). The instrument temperature was set at $25{ }^{\circ} \mathrm{C}$ for all kinetic analyses. ProteOn GLH sensor chips were preconditioned with two short pulses each $(10 \mathrm{~s})$ of $50 \mathrm{mM}$ $\mathrm{NaOH}, 100 \mathrm{mM} \mathrm{HCl}$, and $0.5 \%$ sodium dodecyl sulfide. Then the system was equilibrated with PBS-T buffer $(20 \mathrm{mM}$ sodium phosphate, $150 \mathrm{mM} \mathrm{NaCl}$, and $0.005 \%$ polysorbate $20, \mathrm{pH} 7.4$ ). The surface of a GLH sensor chip was activated with a $1: 100$ dilution of a $1: 1$ mixture of 1-ethyl-3-(3dimethylaminopropyl)carbodiimide hydrochloride $\left(\begin{array}{ll}0.2 \mathrm{M}\end{array}\right)$ and sulfo- $N$-hydroxysuccinimide $(0.05 \mathrm{M})$. Immediately after chip activation, the HIV-1 NL4-3 capsid protein constructs, purified as in Xu et al. ${ }^{\mathbf{2 6}}$ were immobilized on the sensor chip surface. The capsid monomer was prepared at a concentration of $0.1 \mathrm{mg} \mathrm{L}^{-1}$ in $10 \mathrm{mM}$ sodium acetate, $\mathrm{pH} 5.0$ and injected across ligand flow channels for $13 \mathrm{~min}$ at a flow rate of $25 \mu \mathrm{L} \mathrm{min}{ }^{-1}$. The capsid disulfide stabilized hexamer was prepared at a concentration of $0.05 \mathrm{mg} \mathrm{mL}^{-1}$ in $10 \mathrm{mM}$ sodium acetate, $\mathrm{pH} 5.0$ and injected across ligand flow channels for $50 \mathrm{~s}$ at a flow rate of $30 \mu \mathrm{L} \mathrm{min}{ }^{-1}$. Then, after unreacted protein had been washed out, excess active ester groups on the sensor surface were capped by a 5 min injection of $1 \mathrm{M}$ ethanolamine $\mathrm{HCl}(\mathrm{pH} \mathrm{8.0})$ at a flow rate of 30 $\mu \mathrm{L} \min ^{-1}$. A reference surface was similarly created by immobilizing a non-specific protein (IgG b12 anti HIV-1 gp120; was obtained through the NIH AIDS Reagent Program, Division of AIDS, NIAID, NIH: Anti-HIV-1 gp120 Monoclonal (IgG1 b12) from Dr Dennis Burton and Carlos Barbas) and was used as a background to correct non-specific binding.

To prepare a compound for direct binding analysis, compound stock solutions, along with 100\% DMSO, and totaling $30 \mu \mathrm{L}$ was made to a final volume of $1 \mathrm{~mL}$ by addition of sample preparation buffer (PBST, $\mathrm{pH}$ 7.4). Preparation of analyte in this manner ensured that the concentration of DMSO was matched with that of running buffer with 3\% DMSO. Serial dilutions were then prepared in the running buffer (PBS, 3\% DMSO, $0.005 \%$ polysorbate $20, \mathrm{pH} 7.4$ ) and injected at a flow rate of $100 \mathrm{~mL} \mathrm{~min}^{-1}$, for a $1 \mathrm{~min}$ association phase, followed by up to a 5 min dissociation phase using the "one-shot kinetics" capability of the Proteon instrument. ${ }^{38}$ Data were analyzed using the ProteOn Manager Software version 3.0 (Bio-Rad). The responses from the reference flow cell were subtracted to account for the nonspecific binding and injection artifacts. The equilibrium dissociation constant $\left(K_{\mathrm{D}}\right)$ for the interactions, and derived from a minimum of three experiments, were calculated in ProteOn Manager Version 3.1.0.6 (Bio-Rad, Hercules, CA), using the equilibrium analysis function.

\subsection{Molecular dynamics simulation}

4.4.1. Initial structure preparation. The initial X-ray structure of hexameric HIV-1 CA was downloaded from the protein databank (PDB code 5HGL with a resolution of $3.1 \AA$ ). ${ }^{39}$ Only one monomer of the hexameric structure was used for the entire MD study. This structure, which is used in the binding assay, has four mutated amino acids (M185A, E45C, A14C and W184A). 5HGL structure misses amino acids Ala-88, Gly-89, Pro90, Ile-91, Ala-92, Pro-93, Gly-94, Gln-95, Lys-182, Asn-183, Ala184, and Ala-185. Accordingly, we used HIV-1 CA X-ray structure $3 \mathrm{GV} 2$ to extract the missed amino acids with their corresponding tertiary structure and add them to 5HGL structure after their alignment using discovery studio software. ${ }^{40}$ Then, the whole system was energy minimized to remove any strains 
due to the added amino acid residues, which is then used for further study.

4.4.2. Molecular dynamics simulation production. Atomic point charges for II-10c were derived from AM1-BCC charge model with ANTECHAMBER module of AMBER14. Coordinate and topology parameters were prepared using ff14sb force field for HIV-1 CA monomer and GAFF force field for II-10c. The whole system was solvated in explicit water TIP3PBOX octahedral solvent box model with $9 \AA$ cut, and the system was neutralized by Nat ions. Water was minimized for 10000 cycles using steepest descent and then conjugate gradient algorithms. The whole system was then minimized for 5000 cycles using steepest descent followed by conjugate gradient algorithms. Then, water was equilibrated for 20 ps at constant volume and periodic boundaries with weak strength restraints on the whole system through the equilibrium stage, a force constant of $10 \AA$ as position restraint. The whole system was then equilibrated for 40 ps using constant pressure periodic boundaries with no restraints. The minimized and equilibrated structure was used in the molecular dynamics simulation for $1 \mathrm{~ms}$ at constant temperature $(300 \mathrm{~K})$ and constant pressure ( $1 \mathrm{~atm})$. Non-bonded forces were calculated at a cutoff distance of $10 \AA$. H Mass Repartition was used to shift the mass of all hydrogen atoms of solute to 3.024 Da. ${ }^{41}$ This allowed us to use an integration time step of 4 fs during MD. ${ }^{41}$ SHAKE bond length constraint involving hydrogen atoms was turned on.

4.4.3. Clustering. All frames were imaged and then water molecules and Nat ions were stripped off. All frames were aligned against the first frame of the MD production using protein residues only. They were then clustered by DBSCAN algorithm $^{\mathbf{4 2}}$ implemented in CPPTRAJ of AMBER14 on II-10c using minimum points of 3 and epsilon of 2.5 with no frame orientation (no fit), which clustered all frames according to II$10 \mathrm{c}$ to explore the binding site of 5HGL.

\subsection{Cell permeability assay}

Caco-2 cells purchased from ATCC were seeded onto polyethylene membranes (PET) in 96-well BD Insert plates at $1 \times$ 105 cells per $\mathrm{cm}^{2}$, and refreshed medium every 4-5 days until to the 21st to 28th day for confluent cell monolayer formation. The transport buffer in the study was HBSS with $10 \mathrm{mM}$ HEPES at pH $7.40 \pm 0.05$. Test compound were tested at $2 \mu \mathrm{M}$ in $\mathrm{A}$ to $\mathrm{B}$ direction in duplicate, control compounds nadolol, metoprolol were tested at $2 \mu \mathrm{M}$ in A to B direction in duplicate. Final DMSO concentration was adjusted to less than $1 \%$. The plate was incubated for 2 hours in $\mathrm{CO}_{2}$ incubator at $37 \pm 1{ }^{\circ} \mathrm{C}$, with $5 \%$ $\mathrm{CO}_{2}$ at saturated humidity without shaking. And all samples after mixed with acetonitrile containing internal standard were centrifuged at $4000 \mathrm{rpm}$ for $10 \mathrm{~min}$. Subsequently, $100 \mu \mathrm{L}$ supernatant solution was diluted with $100 \mu \mathrm{L}$ distilled water for LC/MS/MS analysis. Concentrations of test and control compounds in starting solution, donor solution, and receiver solution were quantified by LC/MS/MS methodologies, using peak area ratio of analyte/internal standard. After transport assay, lucifer yellow rejection assay was applied to determine the Caco-2 cell monolayer integrity.
The apparent permeability coefficient $P_{\text {app }}\left(\mathrm{cm} \mathrm{s}^{-1}\right)$ was calculated using the equation:

$$
P_{\mathrm{app}}=\left(\mathrm{d} C_{\mathrm{r}} / \mathrm{d} t\right) \times V_{\mathrm{r}} /\left(A \times C_{0}\right)
$$

where $\mathrm{d} C_{\mathrm{r}} / \mathrm{d} t$ is the cumulative concentration of compound in the receiver chamber as a function of time $\left(\mu \mathrm{M} \mathrm{s}^{-1}\right) ; V_{\mathrm{r}}$ is the solution volume in the receiver chamber $(0.075 \mathrm{~mL}$ on the apical side, $0.25 \mathrm{~mL}$ on the basolateral side); $A$ is the surface area for the transport, i.e. $0.0804 \mathrm{~cm}^{2}$ for the area of the monolayer; $C_{0}$ is the initial concentration in the donor chamber $(\mu \mathrm{M})$.

Percent recovery was calculated using the equation:

$\%$ Solution recovery $=100 \times\left[\left(V_{\mathrm{r}} \times C_{\mathrm{r}}\right)+\left(V_{\mathrm{d}} \times C_{\mathrm{d}}\right)\right] /\left(V_{\mathrm{d}} \times \mathrm{C}_{0}\right)$

where $V_{\mathrm{d}}$ is the volume in the donor chambers $(0.075 \mathrm{~mL}$ on the apical side, $0.25 \mathrm{~mL}$ on the basolateral side); $C_{\mathrm{d}}$ and $C_{\mathrm{r}}$ are the final concentrations of transport compound in donor and receiver chambers, respectively. $C_{\mathrm{c}}$ is the compound concentration in the cell lysate solution $(\mu \mathrm{M}) . V_{\mathrm{c}}$ is the volume of insert well (0.075 $\mathrm{mL}$ in this assay).

\subsection{Measurements of water solubility and $\log P$}

Water solubility was measured in water at $\mathrm{pH} 7.0$ and phosphate buffer at pH 7.4 and 2.0 using an HPLC-UV method. Compounds were initially dissolved in DMSO at $10 \mathrm{mg} \mathrm{mL}^{-1} 10$ $\mu \mathrm{L}$ of this stock solution was spiked into purified water $(1 \mathrm{~mL})$ with the final DMSO concentration being $1 \%$. The mixture was ultrasonic for $2 \mathrm{~h}$ at room temperature and restored at room temperature overnight. The saturated solution was filtrated through a filter membrane (pore size $=0.22 \mu \mathrm{m}$ ) and transferred to other Eppendorf tubes for analysis by HPLC-UV. The sample was performed in duplicate. For quantification, a model LC-20AT HPLC-UV (SHIMADZU) system was used with an Inertsil® OD-SP-C18 column $(150 \mathrm{~mm} \times 4.6 \mathrm{~mm}, 5 \mu \mathrm{m})$ and $\mathrm{MeOH} /$ water as eluant. The flow rate was $1.0 \mathrm{~mL} \mathrm{~min}^{-1}$, and the injection volume was $20 \mu \mathrm{L}$. Aqueous concentration was determined by comparison of the peak area of the saturated solution with a standard curve plotted peak area versus known concentrations, which were prepared by solutions in $\mathrm{MeOH}$ at 80, 40, $20,10,5$, and $2.5 \mu \mathrm{g} \mathrm{mL}{ }^{-1}$.

DMSO stock solution $1 \mathrm{mg} \mathrm{mL}^{-1}$ was prepared, and then, 20 $\mu \mathrm{L}$ of this solution was added into $n$-octanol $(1 \mathrm{~mL})$ and $\mathrm{H}_{2} \mathrm{O}(1$ $\mathrm{mL}$ ). The mixture was ultrasonic for $2 \mathrm{~h}$ at room temperature and left to sit overnight. Each solution $(\sim 0.4 \mathrm{~mL})$ was transferred from two phases, respectively, into other Eppendorf tubes for HPLC analysis. The instrument and conditions were the same as those for solubility determination. The $P$ (partition coefficient) value was calculated by the peak area ratios in $n$ octanol and in $\mathrm{H}_{2} \mathrm{O}$.

\section{Conflicts of interest}

The authors declare no competing financial interest. 


\section{Acknowledgements}

Financial support from the National Natural Science Foundation of China (NSFC No. 81273354, 81573347), Key Project of NSFC for International Cooperation (No. 81420108027), Young Scholars Program of Shandong University (YSPSDU, No. 2016WLJH32), the Fundamental Research Funds of Shandong University (No. 2017JC006), Key Research and Development Project of Shandong Province (No. 2017CXGC1401), Major Project of Science and Technology of Shandong Province (No. 2015ZDJS04001), NIH R01GM125396 (Cocklin, PI) and NIH T32MH079785 are gratefully acknowledged.

\section{References}

1 E. L. Asahchop, M. A. Wainberg, R. D. Sloan and C. L. Tremblay, Antimicrob. Agents Chemother., 2012, 56, 5000-5008.

2 P. Zhan, C. Pannecouque, E. De Clercq and X. Liu, J. Med. Chem., 2016, 59, 2849-2878.

3 L. Menendez-Arias, Antiviral Res., 2013, 98, 93-120.

4 X. F. Zuo, Z. P. Huo, D. W. Kang, G. C. Wu, Z. X. Zhou, X. Y. Liu and P. Zhan, Expert Opin. Ther. Pat., 2018, 28, 299-316.

5 Y. N. Song, P. Zhan, X. Li, D. Rai, E. De Clercq and X. Y. Liu, Curr. Med. Chem., 2013, 20, 815-832.

6 S. Thenin-Houssier and S. T. Valente, Curr. HIV Res., 2016, 14, 270-282.

7 G. C. Wu, W. A. Zalloum, M. E. Meuser, L. L. Jing, D. W. Kang, C. H. Chen, Y. Tian, F. F. Zhang, S. Cocklin, K. H. Lee, X. Y. Liu and P. Zhan, Eur. J. Med. Chem., 2018, 158, 478-492.

8 M. Yamashita and A. N. Engelman, Trends Microbiol., 2017, 25, 741-755.

9 T. Schaller, K. E. Ocwieja, J. Rasaiyaah, A. J. Price, T. L. Brady, S. L. Roth, S. Hue, A. J. Fletcher, K. Lee, V. N. KewalRamani, M. Noursadeghi, R. G. Jenner, L. C. James, F. D. Bushman and G. J. Towers, PLoS Pathog., 2011, 7, e1002439.

10 E. M. Campbell and T. J. Hope, Nat. Rev. Microbiol., 2015, 13, 471-483.

11 V. Le Sage, A. J. Mouland and F. Valiente-Echeverria, Virus Res., 2014, 193, 116-129.

12 A. N. Engelman and P. K. Singh, Cell. Mol. Life Sci., 2018, 75, 2491-2507.

13 C. S. Lopez, J. D. Eccles, A. Still, R. E. Sloan, R. L. Barklis, S. M. Tsagli and E. Barklis, Virology, 2011, 417, 137-146.

14 W. S. Blair, C. Pickford, S. L. Irving, D. G. Brown, M. Anderson, R. Bazin, J. A. Cao, G. Ciaramella, J. Isaacson, L. Jackson, R. Hunt, A. Kjerrstrom, J. A. Nieman, A. K. Patick, M. Perros, A. D. Scott, K. Whitby, H. Wu and S. L. Butler, PLoS Pathog., 2010, 6, e1001220.

15 S. K. Carnes, J. H. Sheehan and C. Aiken, Curr. Opin. HIV AIDS, 2018, 13, 359-365.

16 A. Saito, D. Ferhadian, G. A. Sowd, E. Serrao, J. Shi, U. D. Halambage, S. Teng, J. Soto, M. A. Siddiqui,
A. N. Engelman, C. Aiken and M. Yamashita, J. Virol., 2016, 90, 5808-5823.

17 J. Zhou, A. J. Price, U. D. Halambage, L. C. James and C. Aiken, J. Virol., 2015, 89, 9068-9079.

18 A. J. Price, D. A. Jacques, W. A. McEwan, A. J. Fletcher, S. Essig, J. W. Chin, U. D. Halambage, C. Aiken and L. C. James, PLoS Pathog., 2014, 10, e1004459.

19 B. K. Ganser-Pornillos, A. Cheng and M. Yeager, Cell, 2007, 131, 70-79.

20 A. Bhattacharya, S. L. Alam, T. Fricke, K. Zadrozny, J. Sedzicki, A. B. Taylor, B. Demeler, O. Pornillos, B. K. Ganser-Pornillos, F. Diaz-Griffero, D. N. Ivanov and M. Yeager, Proc. Natl. Acad. Sci. U. S. A., 2014, 111, 1862518630.

21 A. T. Gres, K. A. Kirby, V. N. KewalRamani, J. J. Tanner, O. Pornillos and S. G. Sarafianos, Science, 2015, 349, 99-103.

22 J. Shi, J. Zhou, V. B. Shah, C. Aiken and K. Whitby, J. Virol., 2011, 85, 542-549.

23 H. Z. Xu, T. Franks, G. Gibson, K. Huber, N. Rahm, C. S. De Castillia, J. Luban, C. Aiken, S. Watkins, N. Sluis-Cremer and Z. Ambrose, Retrovirology, 2013, 10, 70.

24 A. L. Brass, D. M. Dykxhoorn, Y. Benita, N. Yan, A. Engelman, R. J. Xavier, J. Lieberman and S. J. Elledge, Science, 2008, 319, 921-926.

25 R. Konig, Y. Y. Zhou, D. Elleder, T. L. Diamond, G. M. C. Bonamy, J. T. Irelan, C. Y. Chiang, B. P. Tu, P. D. De Jesus, C. E. Lilley, S. Seidel, A. M. Opaluch, J. S. Caldwell, M. D. Weitzman, K. L. Kuhen, S. Bandyopadhyay, T. Ideker, A. P. Orth, L. J. Miraglia, F. D. Bushman, J. A. Young and S. K. Chanda, Cell, 2008, 135, 49-60.

26 J. P. Xu, A. C. Francis, M. E. Meuser, M. Mankowski, R. G. Ptak, A. A. Rashad, G. B. Melikyan and S. Cocklin, J. Drug Des. Res., 2018, 5, 1070.

27 J. P. Xu, J. D. Branson, R. Lawrence and S. Cocklin, Bioorg. Med. Chem. Lett., 2016, 26, 824-828.

28 P. Gao, L. Sun, J. S. Zhou, X. Li, P. Zhan and X. Y. Liu, Expert Opin. Drug Discovery, 2016, 11, 857-871.

29 G. C. Wu, Y. Gao, D. W. Kang, B. S. Huang, Z. P. Huo, H. Q. Liu, V. Poongavanam, P. Zhan and X. Y. Liu, MedChemComm, 2018, 9, 149-159.

30 X. Jiang, X. Hao, L. Jing, G. Wu, D. Kang, X. Liu and P. Zhan, Expert Opin. Drug Discovery, 2019, 1-11.

31 Z. X. Zhou, T. Liu, G. C. Wu, D. W. Kang, Z. P. Fu, Z. Wang, E. De Clercq, C. Pannecouque, P. Zhan and X. Y. Liu, Org. Biomol. Chem., 2019, 17, 3202-3217.

32 Y. Tian, Z. Q. Liu, J. H. Liu, B. S. Huang, D. W. Kang, H. Zhang, E. De Clercq, D. Daelemans, C. Pannecouque, K. H. Lee, C. H. Chen, P. Zhan and X. Y. Liu, Eur. J. Med. Chem., 2018, 151, 339-350.

33 X. S. Wang, B. S. Huang, X. Y. Liu and P. Zhan, Drug Discovery Today, 2016, 21, 118-132.

34 G. M. Morris, R. Huey, W. Lindstrom, M. F. Sanner, R. K. Belew, D. S. Goodsell and A. J. Olson, J. Comput. Chem., 2009, 30, 2785-2791.

35 X. Jiang, J. Yu, Z. Zhou, J. Kongsted, Y. Song, C. Pannecouque, E. Clercq, D. Kang, V. Poongavanam, 
X. Liu and P. Zhan, Med. Res. Rev., 2019, DOI: 10.1002/ med.21581.

36 G. Wu, T. Zhao, D. Kang, J. Zhang, Y. Song, V. Namasivayam, J. Kongsted, C. Pannecouque, E. De Clercq, V. Poongavanam, X. Liu and P. Zhan, J. Med. Chem., 2019, DOI: 10.1021/ acs.jmedchem.9b00359.

37 Z. Dang, W. H. Lai, K. D. Qian, P. Ho, K. H. Lee, C. H. Chen and L. Huang, J. Med. Chem., 2009, 52, 7887-7891.

38 T. Bravman, V. Bronner, K. Lavie, A. Notcovich, G. A. Papalia and D. G. Myszka, Anal. Biochem., 2006, 358, 281-288.
39 D. A. Jacques, W. A. McEwan, L. Hilditch, A. J. Price, G. J. Towers and L. C. James, Nature, 2016, 536, 349-353.

40 P. C. D. Hawkins, A. G. Skillman, G. L. Warren, B. A. Ellingson and M. T. Stahl, J. Chem. Inf. Model., 2010, 50, 572-584.

41 C. W. Hopkins, S. Le Grand, R. C. Walker and A. E. Roitberg, J. Chem. Theory Comput., 2015, 11, 1864-1874.

42 J. Y. Shao, S. W. Tanner, N. Thompson and T. E. Cheatham, J. Chem. Theory Comput., 2007, 3, 2312-2334. 